\title{
Validation of RELAP5-3D Using HE-FUS3 Data
}

Cliff B. Davis

August 2018

The INL is a

U.S. Department of Energy

National Laboratory

operated by

Battelle Energy Alliance

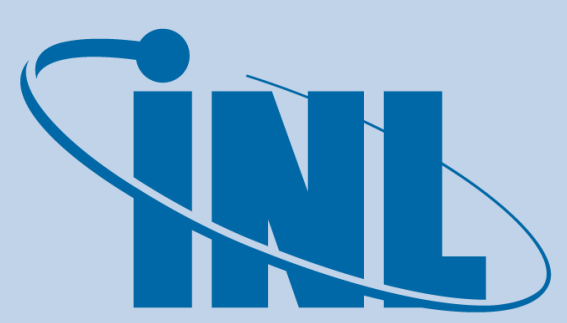

Idaho National Laboratory

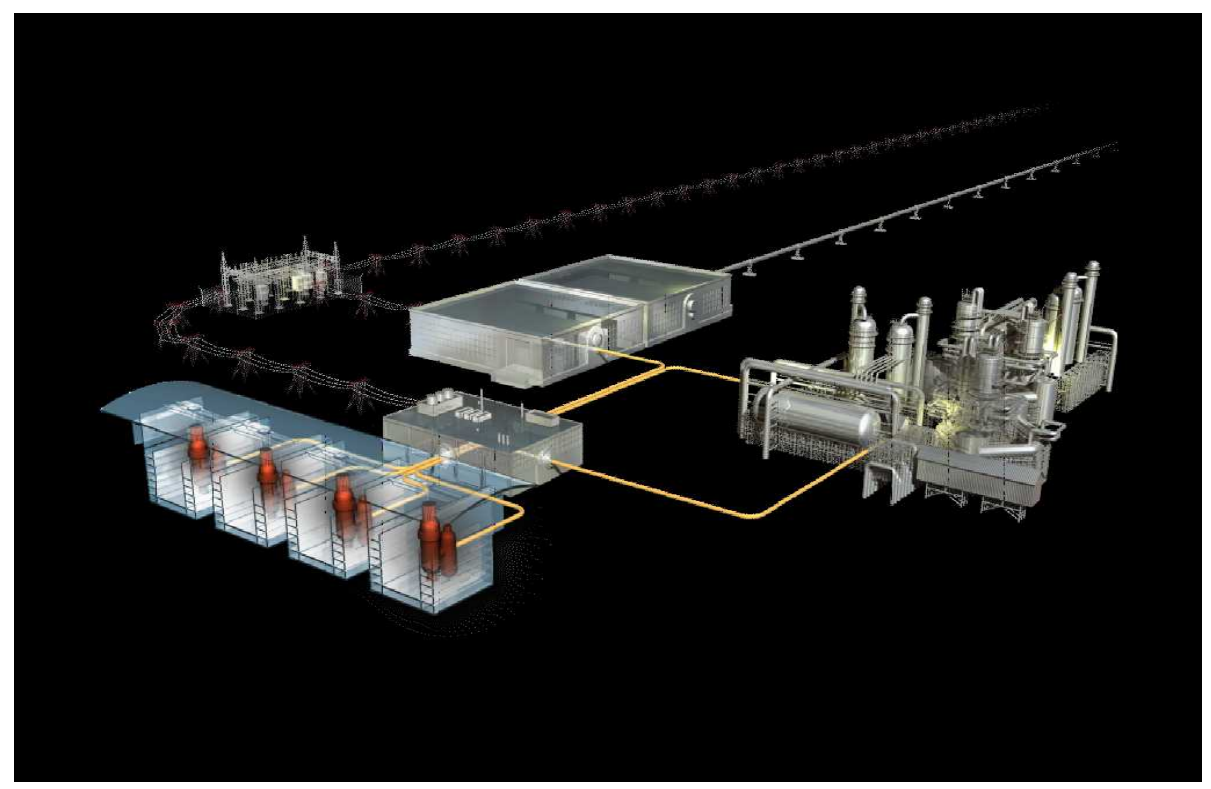




\section{DISCLAIMER}

This information was prepared as an account of work sponsored by an agency of the U.S. Government. Neither the U.S. Government nor any agency thereof, nor any of their employees, makes any warranty, expressed or implied, or assumes any legal liability or responsibility for the accuracy, completeness, or usefulness, of any information, apparatus, product, or process disclosed, or represents that its use would not infringe privately owned rights. References herein to any specific commercial product, process, or service by trade name, trade mark, manufacturer, or otherwise, does not necessarily constitute or imply its endorsement, recommendation, or favoring by the U.S. Government or any agency thereof. The views and opinions of authors expressed herein do not necessarily state or reflect those of the U.S. Government or any agency theof. 


\title{
Validation of RELAP5-3D Using HE-FUS3 Data
}

\author{
Cliff B. Davis
}

August 2018

\begin{abstract}
Idaho National Laboratory
INL ART Program

Idaho Falls, Idaho 83415
\end{abstract}

http://www.inl.gov

Prepared for the

U.S. Department of Energy

Office of Nuclear Energy

Under DOE Idaho Operations Office

Contract DE-AC07-05ID14517 

INL ART Program

\section{Validation of RELAP5-3D Using HE-FUS3 Data}

INL/EXT-18-46153

August 2018

Author:

Cliff B. Davis

INL Engineer

Date

Technical Reviewer:

Carlo Parisi

Date

INL Engineer

Approved by:

Diane V. Croson

Date

INL ART Deputy Director

Michelle T. Sharp

Date

INL Quality Engineer 



\begin{abstract}
The RELAP5-3D computer code was validated using data from the HE-FUS3 experimental facility. HE-FUS3 is a helium-cooled, electrically-heated experimental facility that was used to generate experimental data for a benchmark exercise aimed at the validation of system transient analysis codes for very-high-temperature gas reactor applications. RELAP5-3D was validated using results from seven steady-state tests and one transient that simulated a loss-offlow accident.
\end{abstract}




\section{CONTENTS}

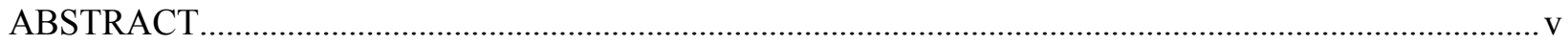

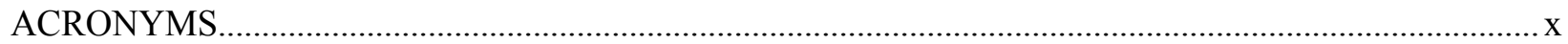

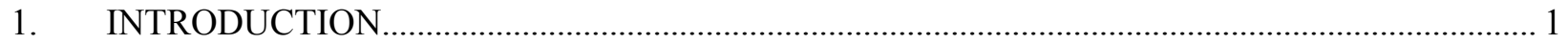

2. EXPERIMENT FACILITY AND TEST DESCRIPTION …...................................................... 1

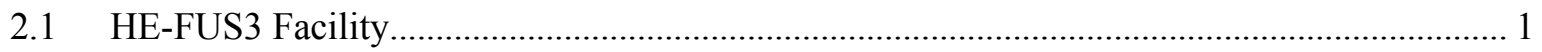

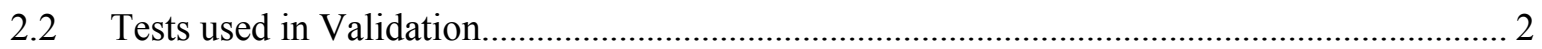

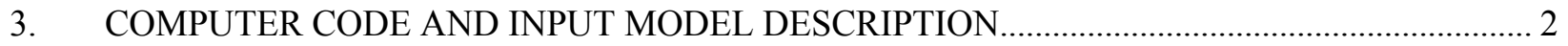

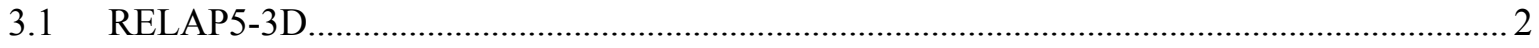

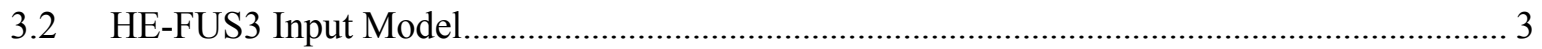

4. RESULTS

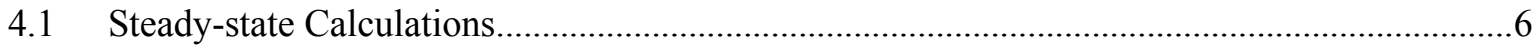

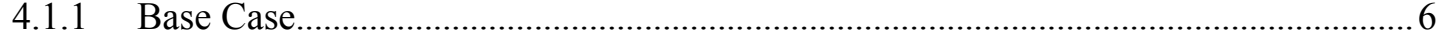

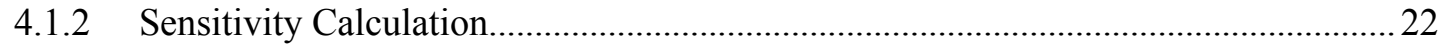

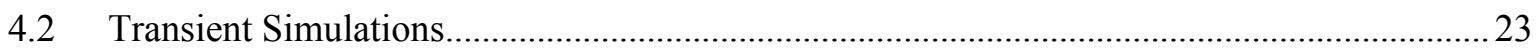

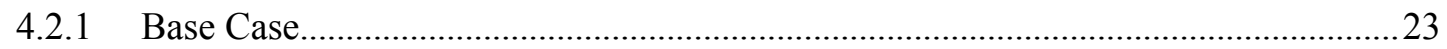

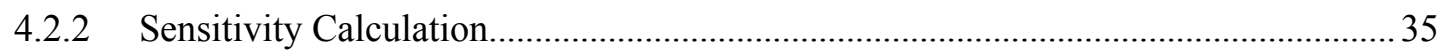

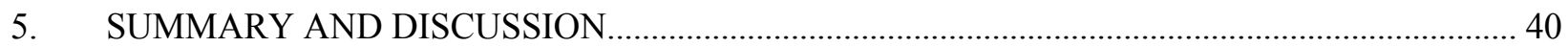

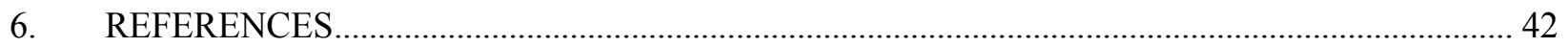

\section{FIGURES}

Figure 1. HE-FUS3 schematic (from Meloni and Polidori 2009) ................................................................. 2

Figure 2. RELAP5-3D model of the HE-FUS3 facility......................................................................... 4

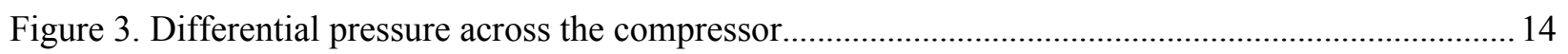

Figure 4. Differential pressure across the test section................................................................................ 14

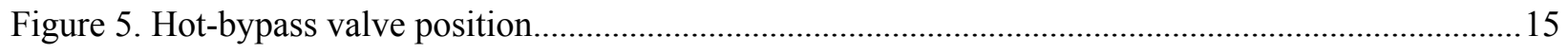

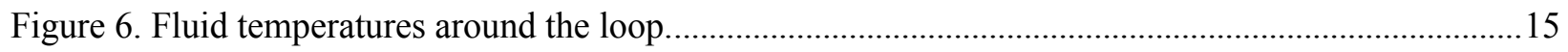

Figure 7. Temperatures in the heater rods in Step 1............................................................................. 16

Figure 8. Temperatures in the heater rods in Step 2 .............................................................................. 17

Figure 9. Temperatures in the heater rods in Step 3 …........................................................................... 17

Figure 10. Temperatures in the heater rods in Step 4............................................................................ 18

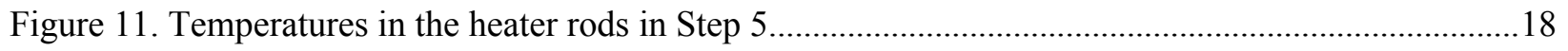

Figure 12. Temperatures in the heater rods in Step 6............................................................................. 19

Figure 13. Temperatures in the heater rods in Step 7 ........................................................................ 19 
Figure 14. Temperatures in the average heater rods............................................................................. 20

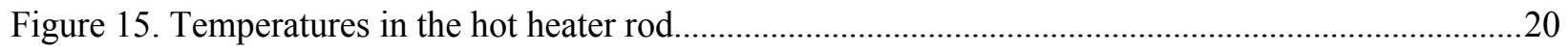

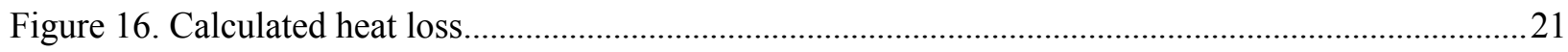

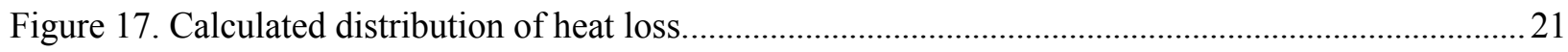

Figure 18. The effect of heat-transfer correlation on temperatures in the average heater rods....................23

Figure 19. The effect of heat-transfer correlation on temperatures in the hot heater rod............................ 23

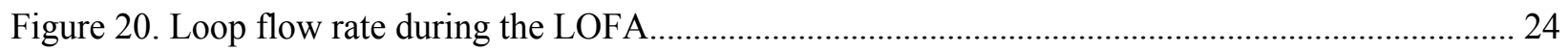

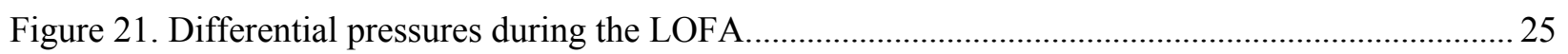

Figure 22. Hot-bypass valve area during the LOFA............................................................................... 25

Figure 23. Economizer cold-side fluid temperatures during the LOFA..................................................... 26

Figure 24. Economizer hot-side fluid temperatures during the LOFA........................................................ 27

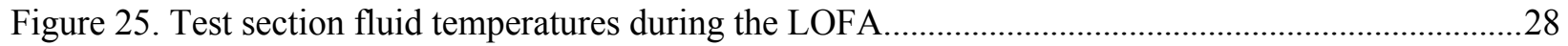

Figure 26. Average-rod temperatures at $0.25 \mathrm{~m}$ during the LOFA........................................................... 29

Figure 27. Average-rod temperatures at $0.75 \mathrm{~m}$ during the LOFA............................................................ 30

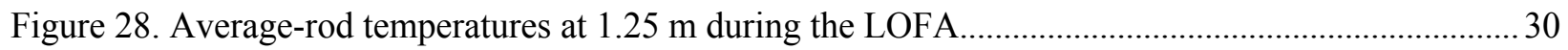

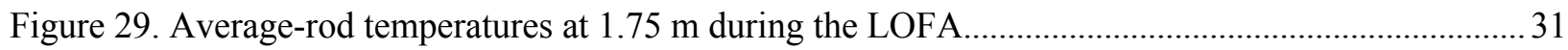

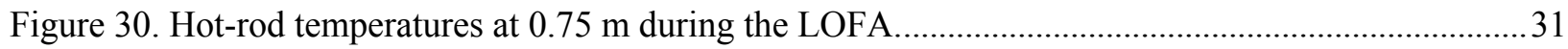

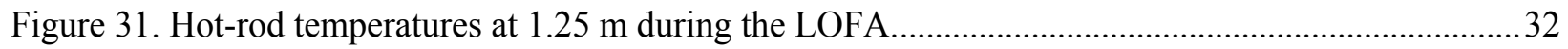

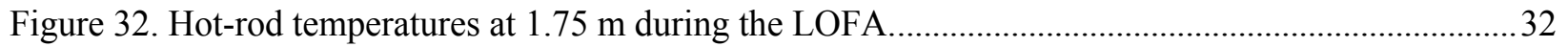

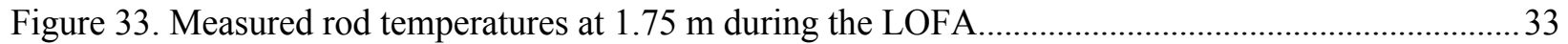

Figure 34. Quasi-steady axial temperature profile in the heater rods at $2000 \mathrm{~s}$ during the LOFA.............. 34

Figure 35. Temperatures in the average heater rods, including data from the LOFA................................. 34

Figure 36. Temperatures in the hot heater rod, including data from the LOFA...........................................35

Figure 37. Test section inlet and lower-plenum temperatures during the LOFA.........................................36

Figure 38. The effect of preheating on average-rod temperature at $0.25 \mathrm{~m}$ in the LOFA...........................36

Figure 39. The effect of preheating on average-rod temperature at $0.75 \mathrm{~m}$ in the LOFA........................... 37

Figure 40. The effect of preheating on average-rod temperature at $1.25 \mathrm{~m}$ in the LOFA........................... 37

Figure 41. The effect of preheating on average-rod temperature at $1.75 \mathrm{~m}$ in the LOFA...........................38

Figure 42. The effect of preheating on hot-rod temperature at $0.75 \mathrm{~m}$ in the LOFA...................................38

Figure 43. The effect of preheating on hot-rod temperature at $1.25 \mathrm{~m}$ in the LOFA...................................39

Figure 44. The effect of preheating on hot-rod temperature at $1.75 \mathrm{~m}$ in the LOFA..................................39 


\section{TABLES}

Table 1. Calculated and measured results for Step 1........................................................................ 7

Table 2. Calculated and measured results for Step 2 .................................................................... 8

Table 3. Calculated and measured results for Step 3 ........................................................................... 9

Table 4. Calculated and measured results for Step 4 .................................................................................. 10

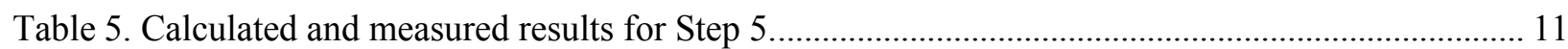

Table 6. Calculated and measured results for Step 6................................................................................. 12

Table 7. Calculated and measured results for Step 7 ............................................................................ 13

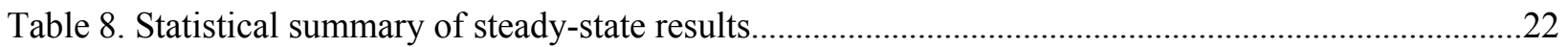




\section{ACRONYMS}

ENEA Ente per le Nuove tecnologie, l'Energia e l'Ambiente

INL Idaho National Laboratory

LOCA loss-of-coolant accident

LOFA loss-of-flow accident

$\mathrm{PF} \quad$ peaking factor

TDV time-dependent volume 


\section{Validation of RELAP5-3D Using HE-FUS3 Data \\ 1. INTRODUCTION}

A validation of Version 4.4.2ie of the RELAP5-3D computer code (INL 2018) was performed using data from the HE-FUS3 experimental facility. HE-FUS3 is a helium-cooled, electrically-heated experimental facility that was used to generate experimental data for a benchmark exercise aimed at the validation of system transient analysis codes for very-high-temperature gas reactor applications.

Section 2 provides a description of the HE-FUS3 facility and experimental data. A brief description of the RELAP5-3D code and a more detailed description of the HE-FUS3 input model are provided in Section 3. Detailed validation results are presented in Section 4. Section 5 summarizes the results. References are listed in Section 6.

\section{EXPERIMENT FACILITY AND TEST DESCRIPTION}

An overview of the HE-FUS3 facility is provided in the next section, followed by a description of the experiments used for the validation of RELAP5-3D.

\subsection{HE-FUS3 Facility}

HE-FUS3 is a helium-cooled, electrically-heated experimental facility that was designed and constructed at Ente per le Nuove tecnologie, l'Energia e l'Ambiente (ENEA) in Italy in the mid-1990s. The facility was used to perform experiments to support the validation of thermal-hydraulic system codes for gas-reactor applications (Meloni 2009, Meloni and Polidori 2009, and Meloni and Nitti 2010).

A schematic of the facility is shown in Figure 1. The flow circuit will be described to illustrate operation of the system. The lowest fluid pressure and temperature in the system occur at the suction of the compressor. The compressor pressurizes the gas, which then flows into a large expansion tank. The flow can split downstream of the expansion tank. The major flow path is through the cold side of the economizer, which is a tube-in-shell heat exchanger. The cold fluid flows outside the tubes. A series of diaphragms are used to promote crossflow and improve the heat transfer from the hot helium, which flows downwards through the tubes. After leaving the cold side of the economizer, flow passes through three vessels containing electrical heaters. A hot-bypass path allows flow from the expansion tank to bypass the economizer and the heaters to control the fluid temperature at the exit of the heaters. The flow through economizer and the hot bypass combine in a mixer between the outlet of the heaters and the test section. Valve FV234 in the hot bypass opens as necessary to maintain the mixed temperature at $300^{\circ} \mathrm{C}$. The test section contains an annular downcomer, lower plenum, and core simulator than contains seven simulated fuel rods that are electrically heated. The simulator contains six average-powered heater rods and one high-powered rod, which are hereafter referred to as the average rods and hot rod, respectively. The downcomer and core simulator are thermally coupled through pipe walls and a stagnant helium gap. The fluid from the exit of the test section is directed to the hot side of the economizer. After exiting the hot side of the economizer, the fluid is directed to an air cooler, which is a counterflow helium-air heat exchanger. After exiting the air cooler, the helium flows through a filter and back to the inlet of the compressor, which completes the flow circuit.

The facility has the capability to simulate loss-of-flow and loss-of-coolant accidents. A loss-of-flow accident (LOFA) can be simulated by reducing the speed of the compressor or opening valve FV235, which is located in the LOFA bypass line. A loss-of-coolant accident (LOCA) can be simulated by opening valves connected to the expansion tank.

The facility has 36 instruments that measure temperature, pressure, differential pressure, mass-flow 
rate, valve position, or compressor speed. The facility also has 27 embedded thermocouples that measure temperature near the surface of the simulated fuel rods.

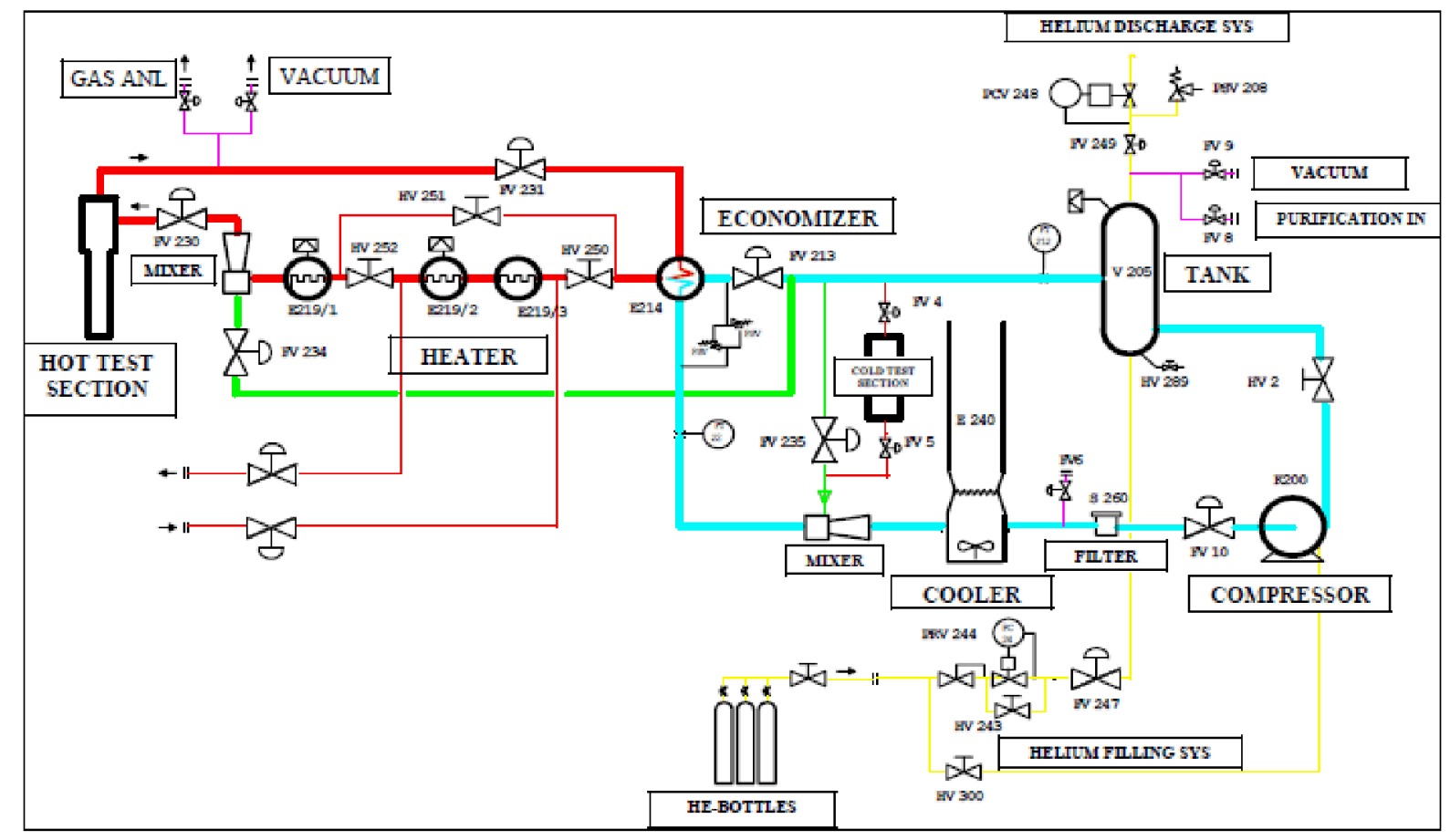

Figure 1. HE-FUS3 schematic (from Meloni and Polidori 2009).

\subsection{Tests used in Validation}

Meloni and Polidori (2009) report results from seven steady-state tests, two LOFAs, and two LOCAs.

All seven of the steady-state tests were used in the validation of RELAP5-3D. These tests covered a range of operating conditions that included approximately a factor of two variations in pressure, loop mass-flow rate, and test-section power. The maximum helium temperature varied between 269 and $469^{\circ} \mathrm{C}$. The hot-bypass system was active in four of the steady-state tests.

RELAP5-3D was also validated using the first transient described by Meloni and Polidori (2009), which was a LOFA initiated by a reduction in compressor speed.

\section{COMPUTER CODE AND INPUT MODEL DESCRIPTION}

The general characteristics of the RELAP5-3D computer code are provided, followed by a description of the HE-FUS3 input model.

\subsection{RELAP5-3D}

The RELAP5 series of codes has been developed at Idaho National Laboratory (INL); RELAP5-3D is the latest code version in the series. While RELAP5 was originally developed to model accidents and operational transients in light water reactor systems, the general nature of the code allows it to be used to simulate a wide variety of hydraulic and thermal transients in both nuclear and non-nuclear systems that can be stationary or moving. More than 25 working fluids are available in the code, including water, gases, liquid metals, refrigerants, and molten salts; 11 noncondensable gases are also available.

RELAP5-3D uses a two-fluid, nonequilibrium, six-equation hydrodynamic model. This model provides continuity, momentum, and energy equations for both the liquid and the vapor phases within a 
control volume. Noncondensable gases and boron in solution in the liquid are also modeled. The energy equation contains source terms that couple the hydrodynamic model to the heat structure conduction model by a convective heat transfer formulation.

RELAP5-3D has a fully integrated, multi-dimensional thermal-hydraulic and neutron kinetics modeling capability. Several specific component models are available in the code in addition to the basic control volumes and junctions, allowing the user more flexibility in modeling fluid systems. These include models for branching, turbines, pumps, compressors, accumulators, valves, separators, and jet mixers.

The code uses special process models to treat phenomena that involve large spatial gradients or that are sufficiently complex that empirical models are required. Special process models in the code address critical flow, countercurrent flow limitation (flooding), horizontal stratification and entrainment, crossflow, reactor kinetics, cladding oxidation and deformation, and molecular diffusion. The code also contains trip and control system models that can be used to simulate automatic or operator-initiated actions during a transient. The control systems can also be used to calculate parameters of interest during the calculation (such as peak fuel temperature) to aid in the analysis of the code calculation.

System hardware is modeled using heat structures. Heat structures use a one- (radial) or twodimensional (radial and axial) conduction solution internally, and can have a variety of boundary conditions applied on the surface, depending on the needs of the user. Energy can be transferred directly between heat structures using an enclosure model that models either radiation or conduction. An energy source term allows heat to be generated within a structure; direct (gamma/neutron) heating of the adjacent fluid volumes can also be modeled. A reflood model is also available that can be applied to the heat structures where needed. Thermophysical properties for the heat structures are normally input by the user.

Version 4.4.2ie of the code was used for this analysis. This code version is the most recent externallyreleased version of the code.

\subsection{HE-FUS3 Input Model}

The RELAP5-3D input model used in this analysis was based on the RELAP5/MOD3.3 model described by Meloni and Nitti (2010). The RELAP5-3D model is shown in Figure 2. 


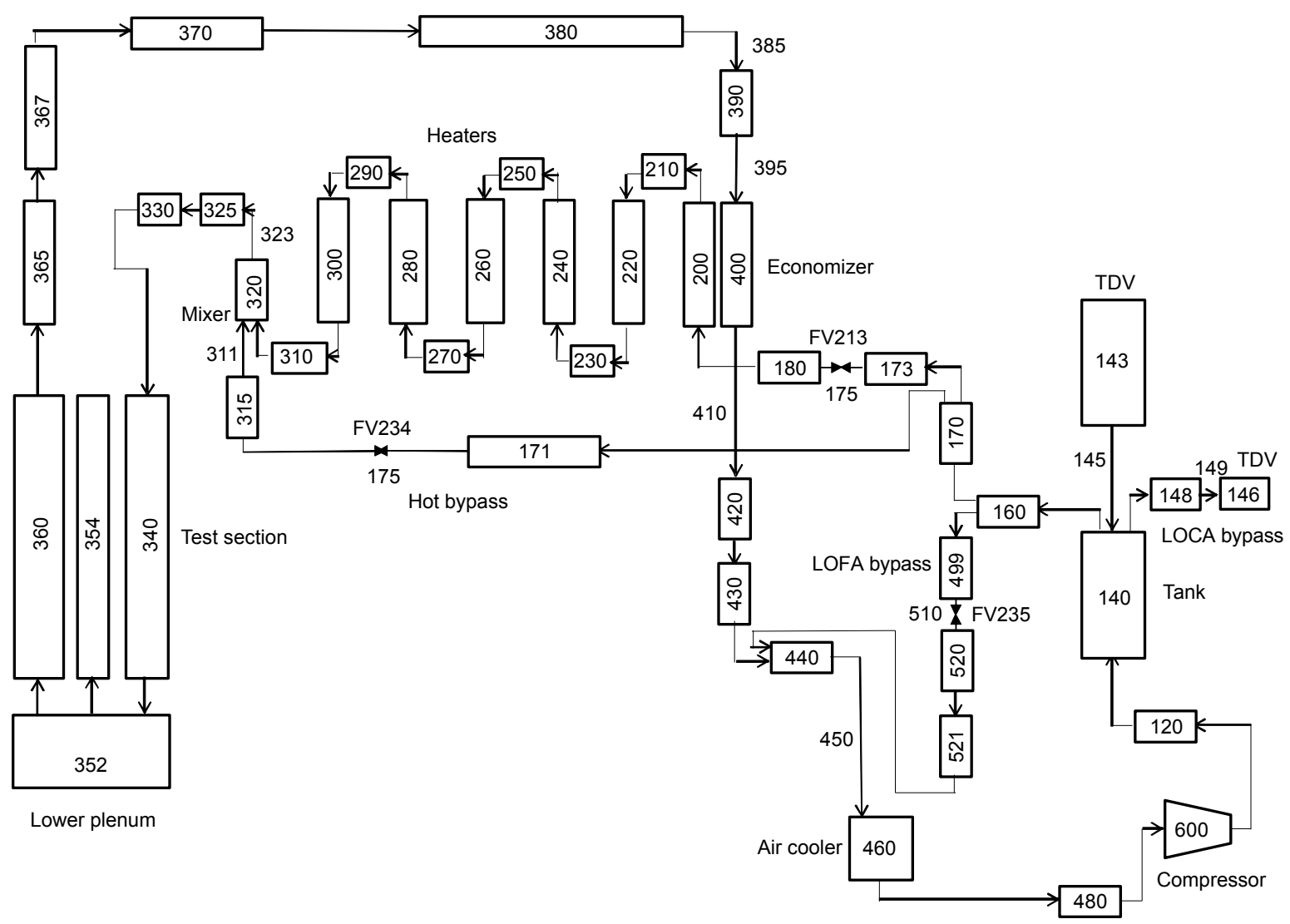

Figure 2. RELAP5-3D model of the HE-FUS3 facility. 
The nodalization of the RELAP5-3D model is identical to that shown by Meloni and Nitti (2010) except as described below. However, substantial revisions to the original model were made. The model was changed to take advantage of advanced features of RELAP5-3D, incorporate typical modeling practices used at the INL, and adjust various input parameters to match the steady-state data better. The general approach used in the adjustment of the model was to divide the model into various components (economizer, heaters, test section, etc.), apply measured boundary conditions, and then adjust heat losses, and form loss coefficients to match measured parameters, such as fluid temperatures and differential pressures. The adjustments were made so that the average error between the calculated and measured values was close to zero for the seven steady-state tests. The adjusted component models were then reassembled into a system model.

The geometry of major components in the model was compared against design information contained in Meloni (2009), Meloni and Polidori (2009), and Meloni and Nitti (2010), and minor modifications were made, where necessary. Other changes to the model are described below.

Helium was modeled as a real working fluid rather than as an ideal gas. In principle, this approach allows a more accurate representation of fluid properties as a function of pressure and temperature. However, the actual effect of this change was relatively small. For example, the difference between real and ideal helium caused differences in fluid temperature that were generally less than $1{ }^{\circ} \mathrm{C}$.

The Gnielinski (1976) heat-transfer correlation was applied on the inside surface of the economizer tubes rather than the default Dittus-Boelter correlation (INL 2018). The Gnielinski correlation accounts for wall-temperature effects on the heat-transfer coefficient and also is expected to be more accurate at low Reynolds numbers. The effect of low Reynolds number is relatively important because the Reynolds number in the tubes varied between 2100 and 5700 for the steady-state results presented in this report. The economizer contains 18 diaphragms that promote cross-flow on the shell side of the heat exchanger. The total length of the flow path on the shell side of the economizer was estimated from the number and widths of the diaphragms. The flow area was then calculated to preserve the volume. The input flow area on the cold side of the economizer was $0.0161 \mathrm{~m}^{2}$. The Dittus-Boelter correlation was applied on the outside surface of the economizer tubes, and a fouling factor of 0.96 was applied to match the measured fluid temperatures.

The test section was originally modeled with two parallel channels, a downcomer (Component 340) and a core simulator (Component 360). The stagnant helium gap that thermally insulates the core simulator from the downcomer was modeled as a material within a heat structure. In the RELAP5-3D model, the helium gap is explicitly modeled as Component 354 . The radiation-enclosure model was used to model radiation across the gap between the outer wall of the test section and the inner wall of the downcomer. The Gnielinski heat-transfer correlation was applied on the outer surface of the simulated fuel rods. Form loss coefficients at the simulated grids in the test section were increased to better match the measured differential pressure across the test section.

The compressor in the facility was changed prior to the start of the experimental campaign described by Meloni and Polidori (2009). The original RELAP5 model represented the previous compressor in the facility and does not accurately represent the performance of the new compressor. Therefore, a control system was developed that adjusts the speed of the compressor to obtain a desired mass flow rate. The desired flow rate was set equal to the measured flow rate during both the steady-state and transient calculations.

The flow coefficient for Component 175, which represents valve FV213 in the facility, was reduced by about $20 \%$. This change results in improved calculations of the normalized area of the hot-bypass valve, FV234, when it was open, and the pressure rise across the compressor.

Calculated heat losses accounted for conduction within the insulation and natural convection from the outer surface of the insulation to the ambient air. The thermal conductivity of the insulation was based on 
the nominal properties of rockwool times a multiplier that was adjusted to match measured fluidtemperature differences across components. Different multipliers were used in different regions. A multiplier of 1.0 was used for the cold region between the outlet of the hot side of the economizer (Component 400) and the inlet to the cold side of the economizer (Component 200). The cold region includes Components 420 through 180 in the main flow path, the hot bypass (Components 171 and 315), and the LOFA bypass (Components 499 through 521). A multiplier of 15.0 was applied to the insulation surrounding the economizer vessel wall, which was attached to Component 200. A multiplier of 3.5 was applied in the region of the heaters and adjacent piping (Components 210 through 320). A multiplier of 10.5 was applied to the insulation surrounding the test section (Components 325 through 352). A multiplier of 10.0 was applied to the insulation surrounding the outlet piping of the test section (Components 365 through 390). The heat-transfer coefficient for the outer surface of the insulation was based on the recommended correlation for vertical plates contained in Incropera and DeWitt (1990). The ambient temperature of the air was assumed to be $13^{\circ} \mathrm{C}$.

The volumetric heat capacities of the heat-structure materials in the model were reduced by a factor of 1000 to achieve steady state quickly. The correct values were used during the transient. The same approach was used in the original RELAP5 model described by Meloni and Nitti (2010).

\section{RESULTS}

Calculations were performed for seven steady-state tests and one LOFA. Comparisons between calculated and measured steady-state results are compared in Section 4.1. Transient results are compared in Section 4.2.

\subsection{Steady-state Calculations}

A steady-state calculation was performed for each of the seven steady-state tests, which are referred to as steps by Meloni and Polidori (2009). The base calculations were performed using the Gnielinski (1976) heat-transfer correlation for the heater rods. Sensitivity calculations were performed using the code's default forced convection correlation, which is Dittus-Boelter (INL 2018).

\subsubsection{Base Case}

A steady-state calculation was performed for each of the seven steady-state steps. Results of the steady-state calculation for Step 1 are provided in Table 1. The table shows the instrument number, when available, and the RELAP5-3D minor edit variable used for comparison. These parameters may be useful in subsequent analyses. Several of the parameters, including the loop pressure, the test section power, the loop mass flow rate, and the cooler outlet temperature, were input as boundary conditions. The loop pressure was entered into Component 143, which is a time-dependent volume (TDV). The test section power was divided between the average and hot rods and entered into Tables 150 and 151. Independent measurements of the power applied to the average and hot rods were made. Unfortunately, Meloni and Polidori (2009) reported only the total power and not the power applied to the average and hot rods. Therefore, the actual power-peaking factor applied during the tests was not known. Meloni and Polidori (2009) reported that the power-peaking factor varied from 1.4 to 2.0 during the tests, so an average value of 1.7 was used for this analysis. The variation in the power-peaking factor between the average and bounding values causes about a $14 \%$ uncertainty in the power applied to the hot rod and approximately a $4 \%$ uncertainty in the power applied to the average rods. The loop mass-flow rate was entered as a setpoint in Control Variable 99. A control system adjusted the compressor speed to obtain the desired flow rate. The cooler outlet temperature was entered into Table 500, which was the sink temperature for the heat structure representing the cooler. The area of the heat structure was large enough that the helium temperature at the outlet of the cooler was approximately equal to the input sink temperature.

The remaining parameters shown in Table 1 were calculated by the code. The table shows the calculated and measured fluid temperature distributions beginning at the outlet of the cooler and ending at 
the inlet of the cooler. The temperatures downstream of the mixing tee located near the test section inlet (TT232) and the test section inlet temperature (TE101) were not reported. The table shows the temperature of the average heater rods as a function of elevation above the bottom of the heated length. The reported temperature was the average of four of the six measurements in average rods. Two of the six measurements were excluded because of an unphysical decrease in temperature with elevation. The table also shows the temperature of the hot rod as a function of elevation above the bottom of the heated length.

The results for the other steps are shown in Table 2 through Table 7. The format is similar to that shown in Table 1 except that temperature TT232 was assumed to read $300^{\circ} \mathrm{C}$ for Steps 3 through 6 because valve FV234 in the hot-bypass line opened to control the temperature. The temperature of the mixing tee is therefore listed as a boundary condition in Steps 3 through 6.

Meloni and Polidori (2009) state that previous work estimated that the uncertainty in the thermocouples used to measure fluid temperatures was about $3{ }^{\circ} \mathrm{C}$. Uncertainties for other measurements are not given.

Table 1. Calculated and measured results for Step 1.

\begin{tabular}{|c|c|c|c|c|}
\hline Parameter & $\begin{array}{l}\text { Instrument } \\
\text { number }\end{array}$ & $\begin{array}{l}\text { RELAP5-3D minor } \\
\text { edit variable }\end{array}$ & Measured & Calculated \\
\hline Loop pressure ${ }^{\mathrm{a}}$, bar & & p-140040000 & 35 & 35.00 \\
\hline Electrical power ${ }^{\mathrm{a}}, \mathrm{kW}$ & & cntrlvar-555 & 44 & 44.00 \\
\hline Loop mass-flow rate ${ }^{\mathrm{a}}, \mathrm{kg} / \mathrm{s}$ & & mflowj-150000000 & 0.1333 & 0.1333 \\
\hline Total pressure drop, bar & PD201 & cntrlvar-40 & 1.31 & 1.389 \\
\hline Test section pressure drop, bar & PD229 & cntrlvar-41 & 0.405 & 0.4349 \\
\hline Hot-bypass valve, $\%$ open & ZT234 & vlvstem-172 & 0 & 0.00 \\
\hline \multicolumn{5}{|l|}{ Fluid temperature, ${ }^{\circ} \mathrm{C}$} \\
\hline Cooler outlet $^{\mathrm{a}}$ & TT241 & cntrlvar-241 & 65 & 65.0 \\
\hline Compressor outlet & TR204 & cntrlvar-209 & 77 & 86.4 \\
\hline Cold economizer inlet & TR215 & cntrlvar-200 & 77 & 83.3 \\
\hline Cold economizer outlet & TR216 & cntrlvar-201 & 240 & 244.9 \\
\hline Heater outlet & TR236 & cntrlvar-244 & 235 & 239.5 \\
\hline Mixing tee & TT232 & cntrlvar-205 & & 238.4 \\
\hline Test section outlet & TE102 & cntrlvar-225 & 293 & 297.2 \\
\hline Hot economizer inlet & TR217 & cntrlvar-206 & 289 & 294.5 \\
\hline Hot economizer outlet & TR218 & cntrlvar-207 & 122 & 128.5 \\
\hline Cooler inlet & TT239 & cntrlvar-239 & 124 & 127.9 \\
\hline \multicolumn{5}{|l|}{ Average rod temperature, ${ }^{\circ} \mathrm{C}$} \\
\hline at $0.25 \mathrm{~m}$ & & cntrlvar-210 & 290 & 294.3 \\
\hline at $0.75 \mathrm{~m}$ & & cntrlvar-211 & 306 & 309.6 \\
\hline at $1.25 \mathrm{~m}$ & & cntrlvar-212 & 337 & 324.6 \\
\hline at $1.75 \mathrm{~m}$ & & cntrlvar-213 & 348 & 339.7 \\
\hline \multicolumn{5}{|l|}{ Hot rod temperature, ${ }^{\circ} \mathrm{C}$} \\
\hline at $0.75 \mathrm{~m}$ & TE310 & cntrlvar-315 & 344 & 342.9 \\
\hline at $1.25 \mathrm{~m}$ & TE304 & cntrlvar-316 & 382 & 357.7 \\
\hline at $1.75 \mathrm{~m}$ & TE301 & cntrlvar-317 & 401 & 372.6 \\
\hline
\end{tabular}

a. Input as a boundary condition. 
Table 2. Calculated and measured results for Step 2.

\begin{tabular}{|c|c|c|c|c|}
\hline Parameter & $\begin{array}{l}\text { Instrument } \\
\text { number }\end{array}$ & $\begin{array}{l}\text { RELAP5-3D minor } \\
\text { edit variable }\end{array}$ & Measured & Calculated \\
\hline Loop pressure ${ }^{\mathrm{a}}$, bar & & p-140040000 & 34 & 34.00 \\
\hline Electrical power ${ }^{\mathrm{a}}, \mathrm{kW}$ & & cntrlvar-555 & 44 & 44.00 \\
\hline Loop mass-flow rate ${ }^{\mathrm{a}}, \mathrm{kg} / \mathrm{s}$ & & mflowj-150000000 & 0.1625 & 0.1625 \\
\hline Total pressure drop, bar & PD201 & cntrlvar-40 & 1.91 & 2.140 \\
\hline Test section pressure drop, bar & PD229 & cntrlvar-41 & 0.662 & 0.6398 \\
\hline Hot-bypass valve, $\%$ open & ZT234 & vlvstem-172 & 0 & 0.00 \\
\hline \multicolumn{5}{|l|}{ Fluid temperature, ${ }^{\circ} \mathrm{C}$} \\
\hline Cooler outlet $^{\mathrm{a}}$ & TT241 & cntrlvar-241 & 65 & 65.0 \\
\hline Compressor outlet & TR204 & cntrlvar-209 & 92 & 100.0 \\
\hline Cold economizer inlet & TR215 & cntrlvar-200 & 92 & 95.5 \\
\hline Cold economizer outlet & TR216 & cntrlvar-201 & 226 & 226.7 \\
\hline Heater outlet & TR236 & cntrlvar-244 & 223 & 222.6 \\
\hline Mixing tee & TT232 & cntrlvar-205 & & 221.8 \\
\hline Test section outlet & TE102 & cntrlvar-225 & 269 & 269.8 \\
\hline Hot economizer inlet & TR217 & cntrlvar-206 & 267 & 267.9 \\
\hline Hot economizer outlet & TR218 & cntrlvar-207 & 129 & 133.2 \\
\hline Cooler inlet & TT239 & cntrlvar-239 & 130 & 132.3 \\
\hline \multicolumn{5}{|l|}{ Average rod temperature, ${ }^{\circ} \mathrm{C}$} \\
\hline at $0.25 \mathrm{~m}$ & & cntrlvar-210 & 267 & 269.0 \\
\hline at $0.75 \mathrm{~m}$ & & cntrlvar-211 & 279 & 281.4 \\
\hline at $1.25 \mathrm{~m}$ & & cntrlvar-212 & 303 & 293.8 \\
\hline at $1.75 \mathrm{~m}$ & & cntrlvar-213 & 312 & 306.2 \\
\hline \multicolumn{5}{|l|}{ Hot rod temperature, ${ }^{\circ} \mathrm{C}$} \\
\hline at $0.75 \mathrm{~m}$ & TE310 & cntrlvar-315 & 310 & 310.1 \\
\hline at $1.25 \mathrm{~m}$ & TE304 & cntrlvar-316 & 346 & 322.3 \\
\hline at $1.75 \mathrm{~m}$ & TE301 & cntrlvar-317 & 358 & 334.6 \\
\hline
\end{tabular}

a. Input as a boundary condition. 
Table 3. Calculated and measured results for Step 3.

\begin{tabular}{|c|c|c|c|c|}
\hline Parameter & $\begin{array}{l}\text { Instrument } \\
\text { number }\end{array}$ & $\begin{array}{l}\text { RELAP5-3D minor } \\
\text { edit variable }\end{array}$ & Measured & Calculated \\
\hline Loop pressure ${ }^{a}$, bar & & p-140040000 & 35 & 35.00 \\
\hline Electrical power ${ }^{\mathrm{a}}, \mathrm{kW}$ & & cntrlvar-555 & 85 & 85.00 \\
\hline Loop mass-flow rate ${ }^{\mathrm{a}}, \mathrm{kg} / \mathrm{s}$ & & mflowj-150000000 & 0.1572 & 0.1572 \\
\hline Total pressure drop, bar & PD201 & cntrlvar-40 & 1.97 & 1.928 \\
\hline Test section pressure drop, bar & PD229 & cntrlvar-41 & 0.670 & 0.6987 \\
\hline Hot-bypass valve, $\%$ open & ZT234 & vlvstem-172 & 26 & 15.69 \\
\hline \multicolumn{5}{|l|}{ Fluid temperature, ${ }^{\circ} \mathrm{C}$} \\
\hline Cooler outlet $^{\mathrm{a}}$ & TT241 & cntrlvar-241 & 65 & 65.0 \\
\hline Compressor outlet & TR204 & cntrlvar-209 & 93 & 95.3 \\
\hline Cold economizer inlet & TR215 & cntrlvar-200 & 93 & 91.8 \\
\hline Cold economizer outlet & TR216 & cntrlvar-201 & 342 & 338.6 \\
\hline Heater outlet & TR236 & cntrlvar-244 & 334 & 330.1 \\
\hline Mixing tee ${ }^{\mathrm{a}}$ & TT232 & cntrlvar-205 & 300 & 300.0 \\
\hline Test section outlet & TE102 & cntrlvar-225 & 398 & 397.9 \\
\hline Hot economizer inlet & TR217 & cntrlvar-206 & 397 & 394.3 \\
\hline Hot economizer outlet & TR218 & cntrlvar-207 & 172 & 171.3 \\
\hline Cooler inlet & TT239 & cntrlvar-239 & 176 & 170.3 \\
\hline \multicolumn{5}{|l|}{ Average rod temperature, ${ }^{\circ} \mathrm{C}$} \\
\hline at $0.25 \mathrm{~m}$ & & cntrlvar-210 & 400 & 395.6 \\
\hline at $0.75 \mathrm{~m}$ & & cntrlvar-211 & 417 & 420.2 \\
\hline at $1.25 \mathrm{~m}$ & & cntrlvar-212 & 466 & 444.6 \\
\hline at $1.75 \mathrm{~m}$ & & cntrlvar-213 & 501 & 469.1 \\
\hline \multicolumn{5}{|l|}{ Hot rod temperature, ${ }^{\circ} \mathrm{C}$} \\
\hline at $0.75 \mathrm{~m}$ & TE310 & cntrlvar-315 & 458 & 478.2 \\
\hline at $1.25 \mathrm{~m}$ & TE304 & cntrlvar-316 & 514 & 501.9 \\
\hline at $1.75 \mathrm{~m}$ & TE301 & cntrlvar-317 & 525 & 525.7 \\
\hline
\end{tabular}
a. Input as a boundary condition. 
Table 4. Calculated and measured results for Step 4.

\begin{tabular}{|c|c|c|c|c|}
\hline Parameter & $\begin{array}{l}\text { Instrument } \\
\text { number }\end{array}$ & $\begin{array}{l}\text { RELAP5-3D minor } \\
\text { edit variable }\end{array}$ & Measured & Calculated \\
\hline Loop pressure ${ }^{a}$, bar & & p-140040000 & 34 & 34.00 \\
\hline Electrical power ${ }^{\mathrm{a}}, \mathrm{kW}$ & & cntrlvar-555 & 104 & 104.00 \\
\hline Loop mass-flow rate ${ }^{\mathrm{a}}, \mathrm{kg} / \mathrm{s}$ & & mflowj-150000000 & 0.1556 & 0.1556 \\
\hline Total pressure drop, bar & PD201 & cntrlvar-40 & 1.92 & 1.859 \\
\hline Test section pressure drop, bar & PD229 & cntrlvar-41 & 0.681 & 0.7191 \\
\hline Hot-bypass valve, $\%$ open & ZT234 & vlvstem-172 & 42 & 42.48 \\
\hline \multicolumn{5}{|l|}{ Fluid temperature, ${ }^{\circ} \mathrm{C}$} \\
\hline Cooler outlet $^{\mathrm{a}}$ & TT241 & cntrlvar-241 & 64 & 64.0 \\
\hline Compressor outlet & TR204 & cntrlvar-209 & 93 & 93.6 \\
\hline Cold economizer inlet & TR215 & cntrlvar-200 & 93 & 90.5 \\
\hline Cold economizer outlet & TR216 & cntrlvar-201 & 372 & 370.9 \\
\hline Heater outlet & TR236 & cntrlvar-244 & 361 & 360.0 \\
\hline Mixing tee ${ }^{\mathrm{a}}$ & TT232 & cntrlvar-205 & 300 & 300.0 \\
\hline Test section outlet & TE102 & cntrlvar-225 & 423 & 422.2 \\
\hline Hot economizer inlet & TR217 & cntrlvar-206 & 418 & 418.3 \\
\hline Hot economizer outlet & TR218 & cntrlvar-207 & 192 & 191.6 \\
\hline Cooler inlet & TT239 & cntrlvar-239 & 195 & 190.5 \\
\hline \multicolumn{5}{|l|}{ Average rod temperature, ${ }^{\circ} \mathrm{C}$} \\
\hline at $0.25 \mathrm{~m}$ & & cntrlvar-210 & 429 & 420.1 \\
\hline at $0.75 \mathrm{~m}$ & & cntrlvar-211 & 442 & 450.4 \\
\hline at $1.25 \mathrm{~m}$ & & cntrlvar-212 & 504 & 480.3 \\
\hline at $1.75 \mathrm{~m}$ & & cntrlvar-213 & 536 & 510.3 \\
\hline \multicolumn{5}{|l|}{ Hot rod temperature, ${ }^{\circ} \mathrm{C}$} \\
\hline at $0.75 \mathrm{~m}$ & TE310 & cntrlvar-315 & 489 & 523.4 \\
\hline at $1.25 \mathrm{~m}$ & TE304 & cntrlvar-316 & 560 & 552.2 \\
\hline at $1.75 \mathrm{~m}$ & TE301 & cntrlvar-317 & 554 & 581.1 \\
\hline
\end{tabular}
a. Input as a boundary condition. 
Table 5. Calculated and measured results for Step 5.

\begin{tabular}{|c|c|c|c|c|}
\hline Parameter & $\begin{array}{l}\text { Instrument } \\
\text { number }\end{array}$ & $\begin{array}{l}\text { RELAP5-3D minor } \\
\text { edit variable }\end{array}$ & Measured & Calculated \\
\hline Loop pressure ${ }^{a}$, bar & & p-140040000 & 32 & 32.00 \\
\hline Electrical power ${ }^{\mathrm{a}}, \mathrm{kW}$ & & cntrlvar-555 & 85 & 85.00 \\
\hline Loop mass-flow rate ${ }^{\mathrm{a}}, \mathrm{kg} / \mathrm{s}$ & & mflowj-150000000 & 0.1194 & 0.1194 \\
\hline Total pressure drop, bar & PD201 & cntrlvar-40 & 1.22 & 1.161 \\
\hline Test section pressure drop, bar & PD229 & cntrlvar-41 & 0.441 & 0.4556 \\
\hline Hot-bypass valve, $\%$ open & ZT234 & vlvstem-172 & 35 & 41.16 \\
\hline \multicolumn{5}{|l|}{ Fluid temperature, ${ }^{\circ} \mathrm{C}$} \\
\hline Cooler outlet $^{\mathrm{a}}$ & TT241 & cntrlvar-241 & 65 & 65.0 \\
\hline Compressor outlet & TR204 & cntrlvar-209 & 79 & 84.2 \\
\hline Cold economizer inlet & TR215 & cntrlvar-200 & 79 & 81.7 \\
\hline Cold economizer outlet & TR216 & cntrlvar-201 & 364 & 373.4 \\
\hline Heater outlet & TR236 & cntrlvar-244 & 351 & 359.4 \\
\hline Mixing tee ${ }^{\mathrm{a}}$ & TT232 & cntrlvar-205 & 300 & 300.0 \\
\hline Test section outlet & TE102 & cntrlvar-225 & 424 & 429.7 \\
\hline Hot economizer inlet & TR217 & cntrlvar-206 & 419 & 424.5 \\
\hline Hot economizer outlet & TR218 & cntrlvar-207 & 178 & 184.2 \\
\hline Cooler inlet & TT239 & cntrlvar-239 & 180 & 183.3 \\
\hline \multicolumn{5}{|l|}{ Average rod temperature, ${ }^{\circ} \mathrm{C}$} \\
\hline at $0.25 \mathrm{~m}$ & & cntrlvar-210 & 425 & 423.1 \\
\hline at $0.75 \mathrm{~m}$ & & cntrlvar-211 & 439 & 455.4 \\
\hline at $1.25 \mathrm{~m}$ & & cntrlvar-212 & 496 & 487.2 \\
\hline at $1.75 \mathrm{~m}$ & & cntrlvar-213 & 536 & 518.8 \\
\hline \multicolumn{5}{|l|}{ Hot rod temperature, ${ }^{\circ} \mathrm{C}$} \\
\hline at $0.75 \mathrm{~m}$ & TE310 & cntrlvar-315 & 502 & 528.2 \\
\hline at $1.25 \mathrm{~m}$ & TE304 & cntrlvar-316 & 566 & 558.8 \\
\hline at $1.75 \mathrm{~m}$ & TE301 & cntrlvar-317 & 563 & 589.3 \\
\hline
\end{tabular}
a. Input as a boundary condition. 
Table 6. Calculated and measured results for Step 6.

\begin{tabular}{|c|c|c|c|c|}
\hline Parameter & $\begin{array}{l}\text { Instrument } \\
\text { number }\end{array}$ & $\begin{array}{l}\text { RELAP5-3D minor } \\
\text { edit variable }\end{array}$ & Measured & Calculated \\
\hline Loop pressure ${ }^{a}$, bar & & p-140040000 & 20 & 20.00 \\
\hline Electrical power ${ }^{\mathrm{a}}, \mathrm{kW}$ & & cntrlvar-555 & 82 & 82.00 \\
\hline Loop mass-flow rate ${ }^{\mathrm{a}}, \mathrm{kg} / \mathrm{s}$ & & mflowj-150000000 & 0.0897 & 0.0897 \\
\hline Total pressure drop, bar & PD201 & cntrlvar-40 & 1.16 & 1.048 \\
\hline Test section pressure drop, bar & PD229 & cntrlvar-41 & 0.435 & 0.4364 \\
\hline Hot-bypass valve, $\%$ open & ZT234 & vlvstem-172 & 53 & 52.43 \\
\hline \multicolumn{5}{|l|}{ Fluid temperature, ${ }^{\circ} \mathrm{C}$} \\
\hline Cooler outlet $^{\mathrm{a}}$ & TT241 & cntrlvar-241 & 65 & 64.9 \\
\hline Compressor outlet & TR204 & cntrlvar-209 & 91 & 93.2 \\
\hline Cold economizer inlet & TR215 & cntrlvar-200 & 91 & 89.7 \\
\hline Cold economizer outlet & TR216 & cntrlvar-201 & 417 & 409.9 \\
\hline Heater outlet & TR236 & cntrlvar-244 & 389 & 386.4 \\
\hline Mixing tee & TT232 & cntrlvar-205 & 300 & 300.0 \\
\hline Test section outlet & TE102 & cntrlvar-225 & 470 & 465.6 \\
\hline Hot economizer inlet & TR217 & cntrlvar-206 & 461 & 458.0 \\
\hline Hot economizer outlet & TR218 & cntrlvar-207 & 222 & 214.2 \\
\hline Cooler inlet & TT239 & cntrlvar-239 & 223 & 212.8 \\
\hline \multicolumn{5}{|l|}{ Average rod temperature, ${ }^{\circ} \mathrm{C}$} \\
\hline at $0.25 \mathrm{~m}$ & & cntrlvar-210 & 472 & 454.6 \\
\hline at $0.75 \mathrm{~m}$ & & cntrlvar-211 & 475 & 495.4 \\
\hline at $1.25 \mathrm{~m}$ & & cntrlvar-212 & 554 & 535.4 \\
\hline at $1.75 \mathrm{~m}$ & & cntrlvar-213 & 599 & 575.1 \\
\hline \multicolumn{5}{|l|}{ Hot rod temperature, ${ }^{\circ} \mathrm{C}$} \\
\hline at $0.75 \mathrm{~m}$ & TE310 & cntrlvar-315 & 576 & 584.2 \\
\hline at $1.25 \mathrm{~m}$ & TE304 & cntrlvar-316 & 649 & 622.3 \\
\hline at $1.75 \mathrm{~m}$ & TE301 & cntrlvar-317 & 647 & 660.3 \\
\hline
\end{tabular}
a. Input as a boundary condition. 
Table 7. Calculated and measured results for Step 7.

\begin{tabular}{|c|c|c|c|c|}
\hline Parameter & $\begin{array}{l}\text { Instrument } \\
\text { number }\end{array}$ & $\begin{array}{l}\text { RELAP5-3D minor } \\
\text { edit variable }\end{array}$ & Measured & Calculated \\
\hline Loop pressure ${ }^{a}$, bar & & p-140040000 & 18 & 18.00 \\
\hline Electrical power ${ }^{\mathrm{a}}, \mathrm{kW}$ & & cntrlvar-555 & 41 & 41.00 \\
\hline Loop mass-flow rate ${ }^{\mathrm{a}}, \mathrm{kg} / \mathrm{s}$ & & mflowj-150000000 & 0.0822 & 0.0822 \\
\hline Total pressure drop, bar & PD201 & cntrlvar-40 & 1.13 & 1.046 \\
\hline Test section pressure drop, bar & PD229 & cntrlvar-41 & 0.364 & 0.3657 \\
\hline Hot-bypass valve, $\%$ open & ZT234 & vlvstem-172 & 0 & 0.00 \\
\hline \multicolumn{5}{|l|}{ Fluid temperature, ${ }^{\circ} \mathrm{C}$} \\
\hline Cooler outlet $^{\mathrm{a}}$ & TT241 & cntrlvar-241 & 43 & 43.0 \\
\hline Compressor outlet & TR204 & cntrlvar-209 & 77 & 73.7 \\
\hline Cold economizer inlet & TR215 & cntrlvar-200 & 77 & 69.6 \\
\hline Cold economizer outlet & TR216 & cntrlvar-201 & 300 & 285.8 \\
\hline Heater outlet & TR236 & cntrlvar-244 & 289 & 275.0 \\
\hline Mixing tee & TT232 & cntrlvar-205 & & 272.8 \\
\hline Test section outlet & TE102 & cntrlvar-225 & 377 & 359.7 \\
\hline Hot economizer inlet & TR217 & cntrlvar-206 & 371 & 354.0 \\
\hline Hot economizer outlet & TR218 & cntrlvar-207 & 141 & 129.7 \\
\hline Cooler inlet & TT239 & cntrlvar-239 & 141 & 128.8 \\
\hline \multicolumn{5}{|l|}{ Average rod temperature, ${ }^{\circ} \mathrm{C}$} \\
\hline at $0.25 \mathrm{~m}$ & & cntrlvar-210 & 371 & 351.4 \\
\hline at $0.75 \mathrm{~m}$ & & cntrlvar-211 & 387 & 374.1 \\
\hline at $1.25 \mathrm{~m}$ & & cntrlvar-212 & 424 & 396.3 \\
\hline at $1.75 \mathrm{~m}$ & & cntrlvar-213 & 449 & 418.4 \\
\hline \multicolumn{5}{|l|}{ Hot rod temperature, ${ }^{\circ} \mathrm{C}$} \\
\hline at $0.75 \mathrm{~m}$ & TE310 & cntrlvar-315 & 451 & 419.2 \\
\hline at $1.25 \mathrm{~m}$ & TE304 & cntrlvar-316 & 495 & 441.0 \\
\hline at $1.75 \mathrm{~m}$ & TE301 & cntrlvar-317 & 506 & 462.6 \\
\hline
\end{tabular}
a. Input as a boundary condition.

Selected results from the previous tables are shown graphically and discussed in more detail below.

The differential pressure across the compressor, which equals the sum of the pressure drops around the loop, is shown in Figure 3. The differential pressure across the test section is shown in Figure 4. On average, the calculated results are within about 0.01 bar of the measurements, which is judged to be in reasonable agreement. Only two differential-pressure measurements were reported for the facility. The differential pressure across the test section was about $35 \%$ of the total, which means that $65 \%$ of the losses are not specifically measured. According to the model, the losses across FV213 and the filter near the compressor inlet are significant. Differential pressure measurements across these devices would be needed to better characterize the hydraulic resistance of the loop. 


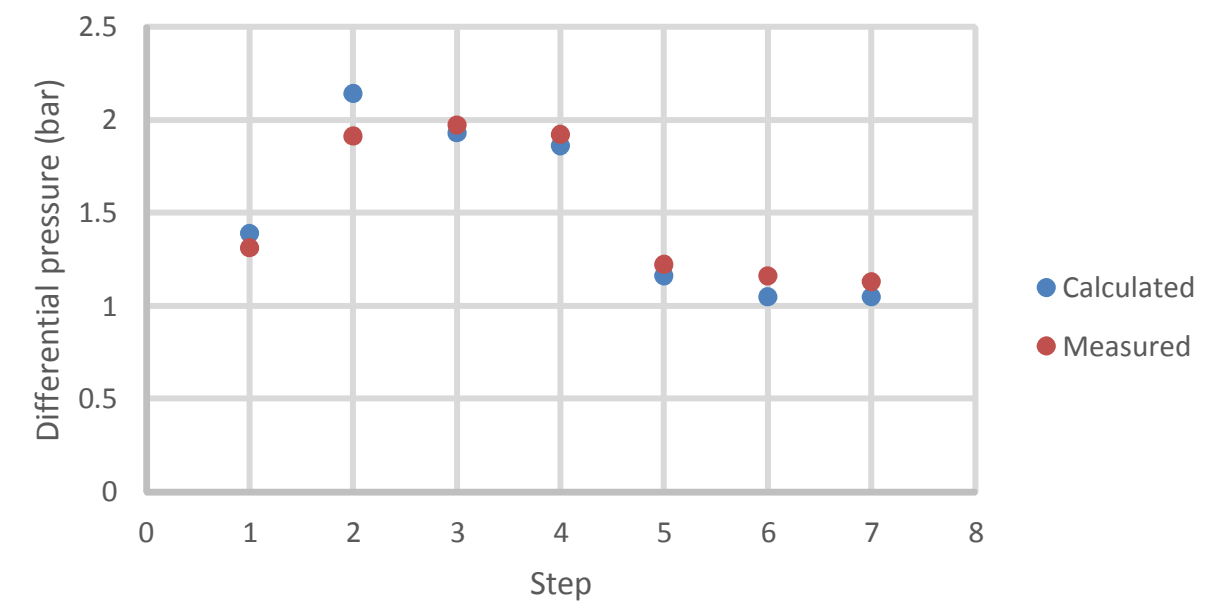

Figure 3. Differential pressure across the compressor.

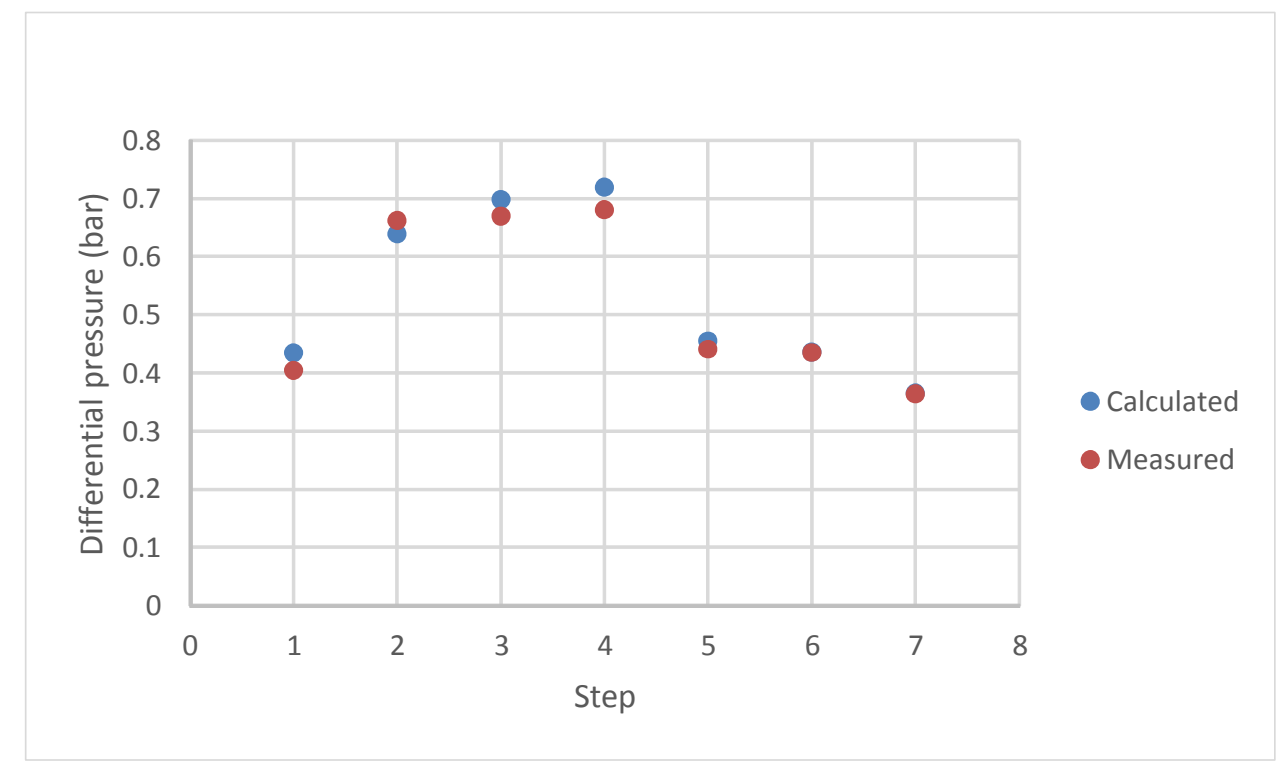

Figure 4. Differential pressure across the test section.

The calculated and measured positions of the hot-bypass valve are shown in Figure 5. The original RELAP5 model contained a control system that adjusted the bypass valve as necessary to maintain the temperature downstream of the mixer at $300^{\circ} \mathrm{C}$ or lower. The original control system was used in these calculations. The temperature at the exit of the heaters was below $300^{\circ} \mathrm{C}$ for Steps 1,2 , and 7 , so the control system caused the valve to close. For the other steps, the temperature at the exit of the heaters was greater than $300^{\circ} \mathrm{C}$, and the control system opened the valve as necessary to obtain a mixed temperature of $300^{\circ} \mathrm{C}$. On average, the calculated valve position agreed to within about $1 \%$, but the largest difference was about $10 \%$. The percentage of loop flow going through the hot-bypass valve varied between $10 \%$ and $30 \%$ in the calculations of Steps 3 through 6 . The flow split between the economizer and the bypass is governed by the energy balance resulting from the performance of the economizer and the heat loss. However, the valve position required to obtain the required flow split primarily depends on the relative resistances of the flow paths through the economizer and the hot-bypass lines. As mentioned previously, 
measurements were not available to characterize these resistances, so the flow coefficient for valve FV213 was reduced to better match the normalized area of the hot-bypass valve and the pressure rise across the compressor.

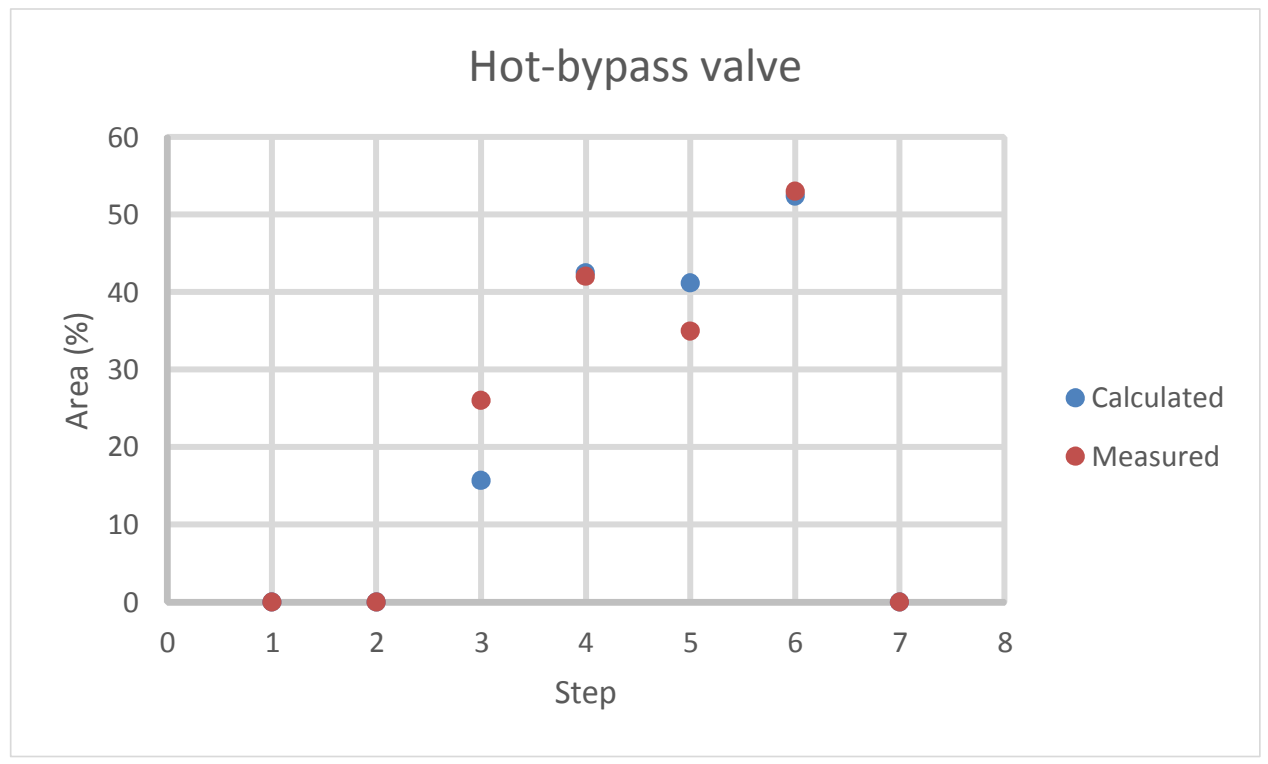

Figure 5. Hot-bypass valve position.

Figure 6 is a scatter plot that compares calculated and measured fluid temperatures around the loop for all seven steps. Overall, the calculated and measured fluid temperatures are in reasonable agreement. The average deviation between calculated and measured fluid temperatures was less than $1^{\circ} \mathrm{C}$. The largest deviation was $17.4^{\circ} \mathrm{C}$ and occurred at the outlet of the test section in Step 7. Table 7 shows that more than $40 \%$ of the temperature difference occurred between the outlet of the compressor and the inlet to the cold side of the economizer. A large part of the deviation for Step 7 is suspected to be due to the behavior of the compressor, which isn't modeled mechanistically.

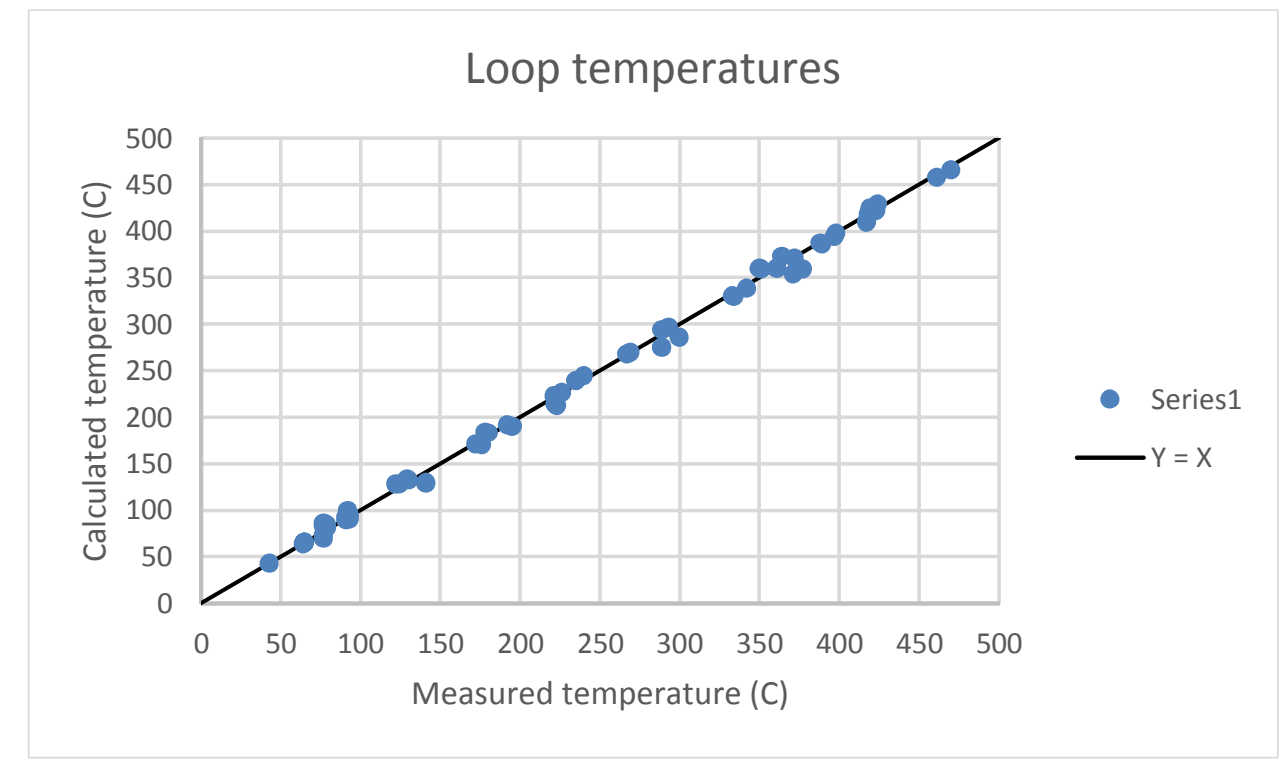

Figure 6. Fluid temperatures around the loop.

The axial temperature distributions in the heater rods are shown in Figure 7 through Figure 13 for 
Step 1 through Step 7, respectively. Each figure shows temperature as a function of elevation for both the average and hot heater rods. The solid lines correspond to the calculation. The dotted lines represent measurements. Each figure also shows the calculated fluid temperature as a function of elevation although fluid temperature measurements were not made in the core simulator. The calculated temperatures are plotted at the elevation of the outlet of each control volume, which is consistent with the steady-state solution to the energy equation and is appropriate for the upstream donoring scheme used by the code. The calculated rod temperatures correspond approximately to the radial location of the embedded thermocouples.

The trends for each step are similar to those shown in Figure 7 for Step 1. The calculated results are nearly linear. Each axial level in the model is represented by a single control volume. The fluid within each level is assumed to be well mixed, and the hot and average rods have the same sink temperature. The temperature difference between the hot rod and the fluid is, on average, 1.76 times the temperature difference between the average rod and the fluid. The ratio is a few percent higher than the assumed peaking factor of the hot rod, which is 1.70 , because the Gnielinski correlation accounts for the effects of wall temperature on the heat-transfer coefficient.

The measured temperatures are not as linear as the calculated temperatures. The slope in the temperature of the average rod between 0.75 and $1.25 \mathrm{~m}$ was generally greater than the slope below $0.75 \mathrm{~m}$ or above $1.25 \mathrm{~m}$. This trend was exaggerated in the hot rod, where the measured temperature at $1.75 \mathrm{~m}$ was actually lower than the measured temperature at $1.25 \mathrm{~m}$ for Steps 4 through 6 . These measured trends are completely unexpected in rods with a supposedly uniform axial power profile. The cause of this anomalous behavior is not known, but some of the thermocouples may be located at a different elevation than reported. Nonetheless, the overall agreement between the calculated and measured temperatures is reasonably good as shown in Figure 14 for the average rods and in Figure 15 for the hot rod. On average, the calculated temperatures were $9.6^{\circ} \mathrm{C}$ too low for the average rods and $6.1^{\circ} \mathrm{C}$ too low for the hot rod.

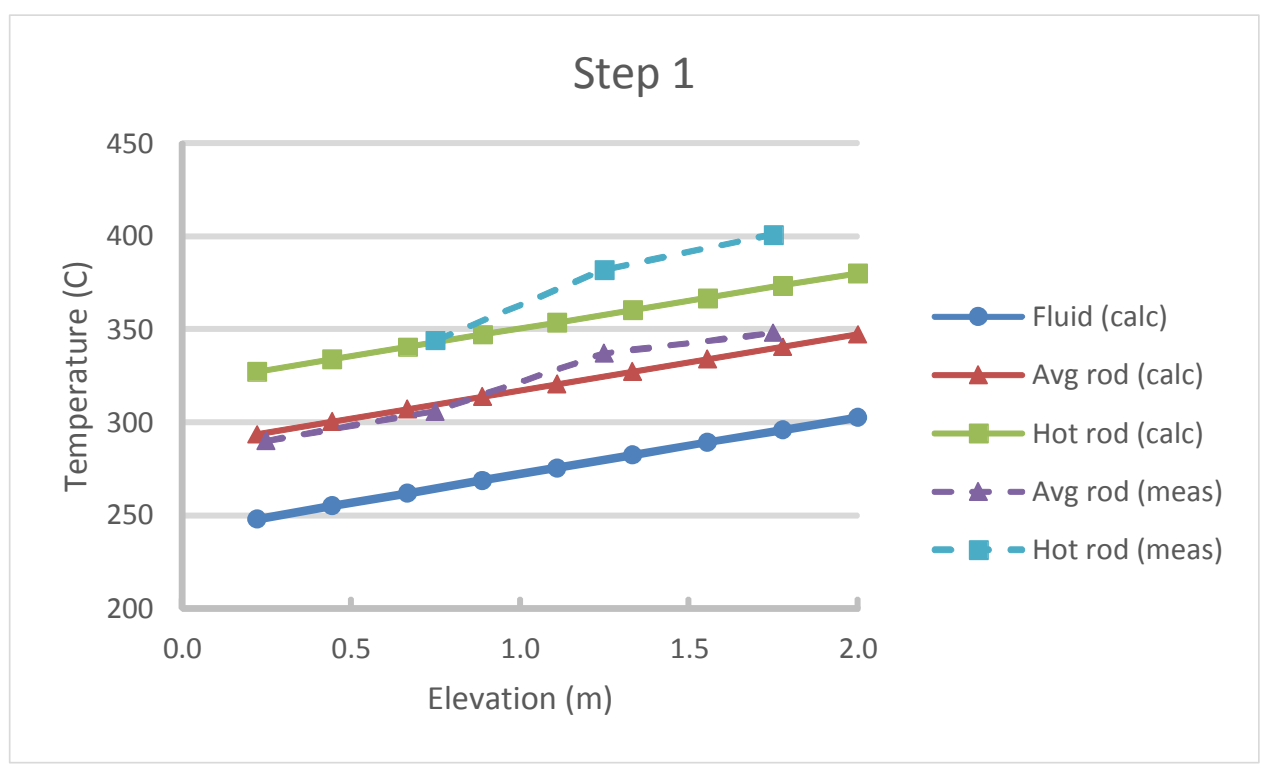

Figure 7. Temperatures in the heater rods in Step 1. 


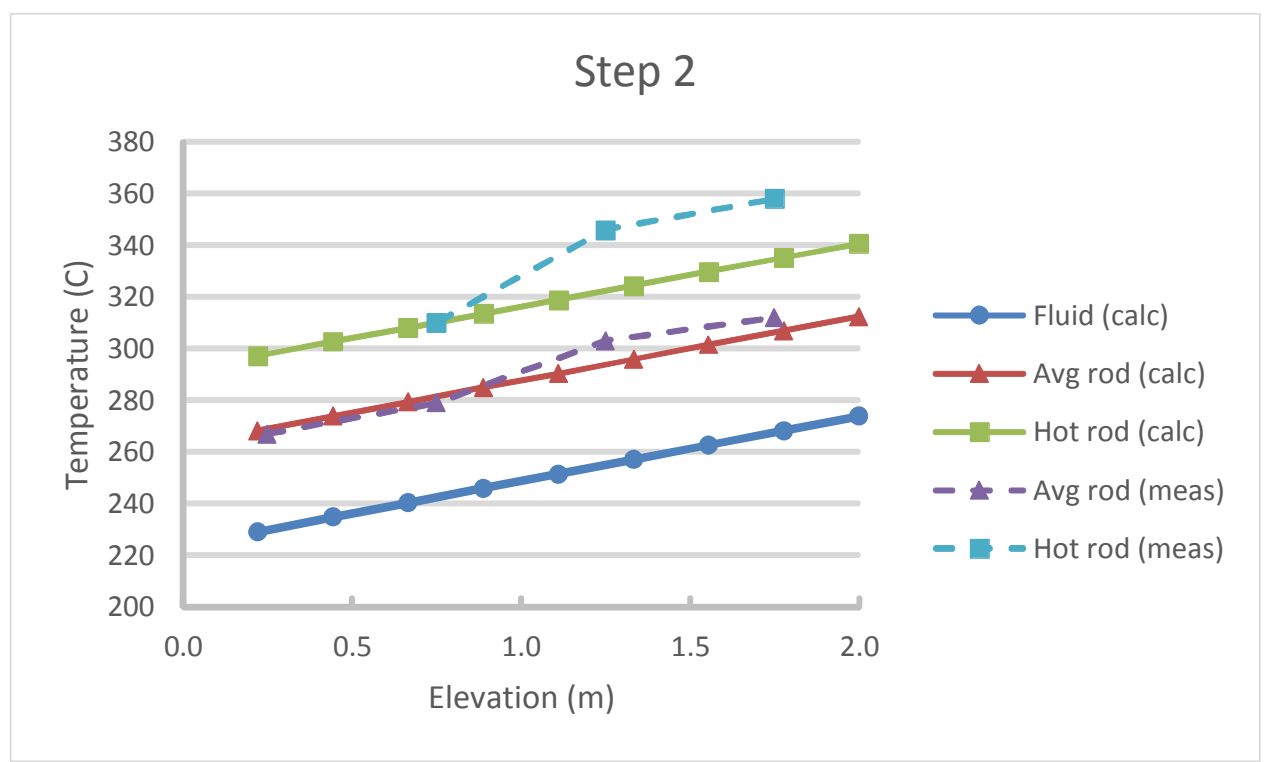

Figure 8. Temperatures in the heater rods in Step 2.

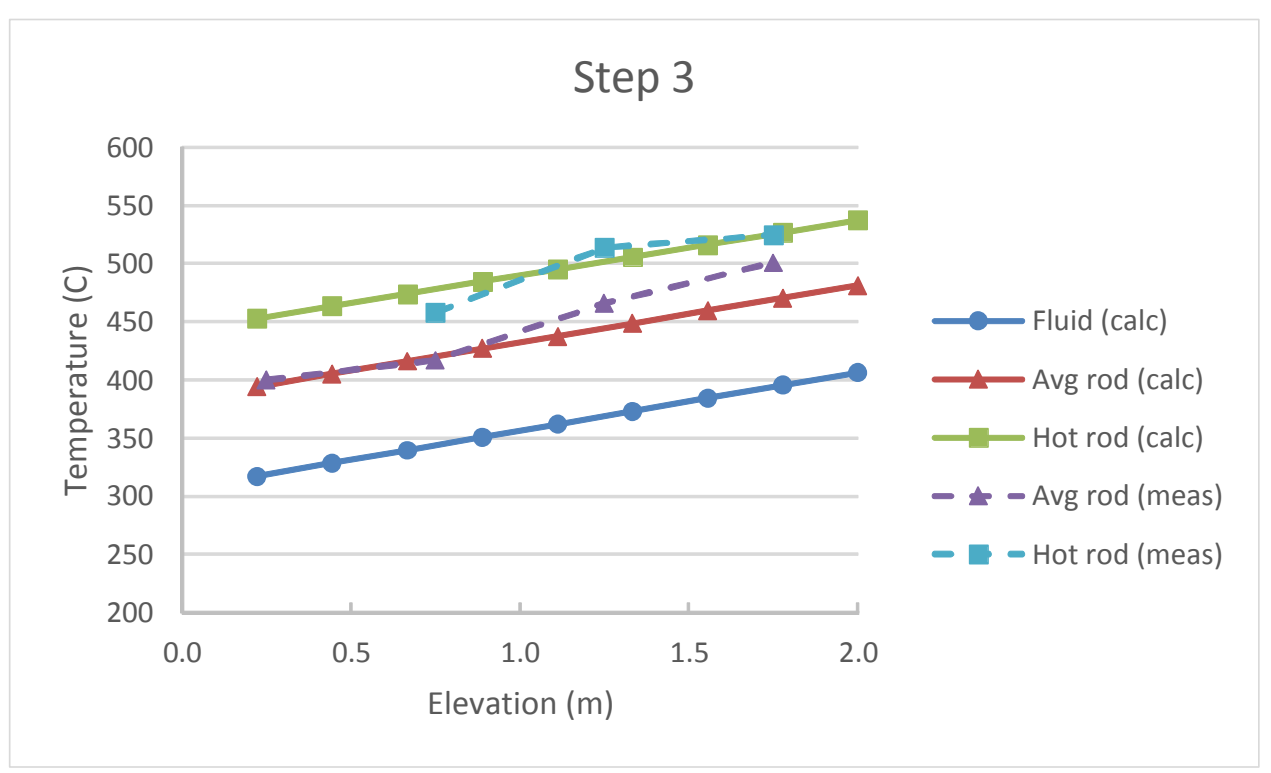

Figure 9. Temperatures in the heater rods in Step 3. 


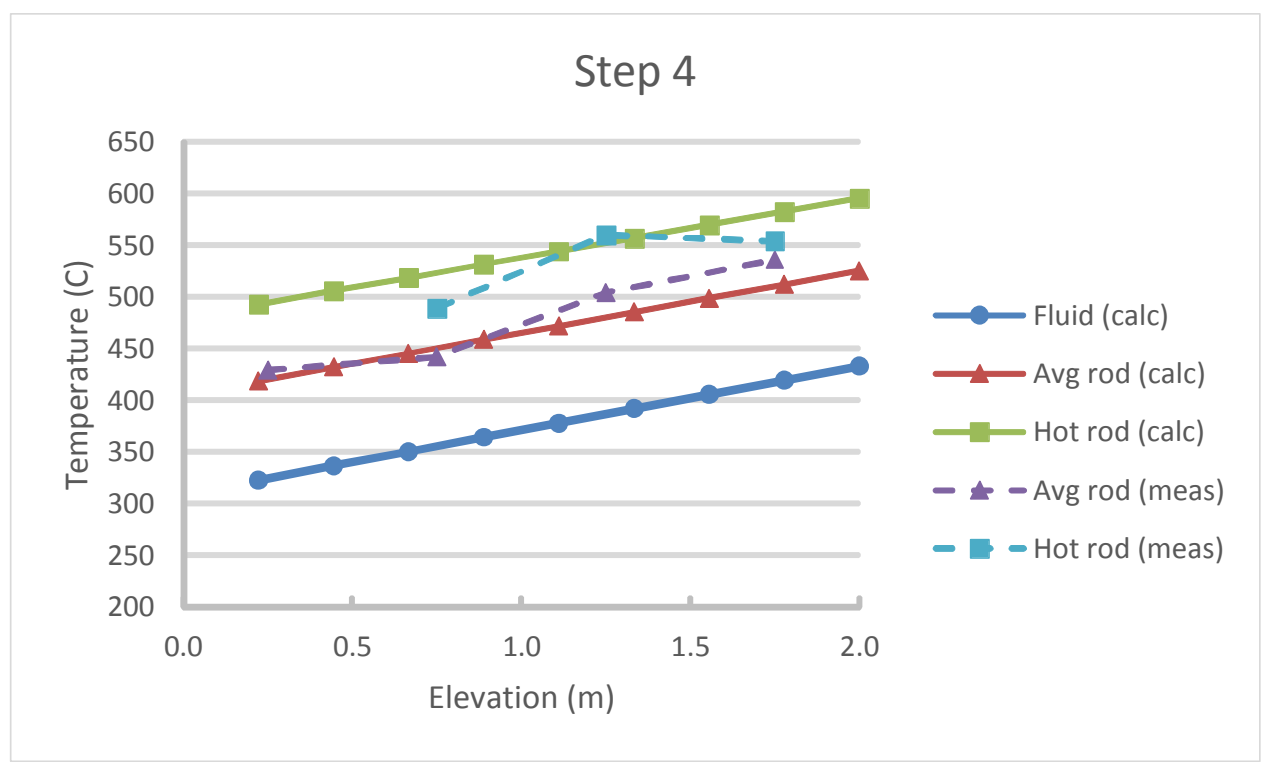

Figure 10. Temperatures in the heater rods in Step 4.

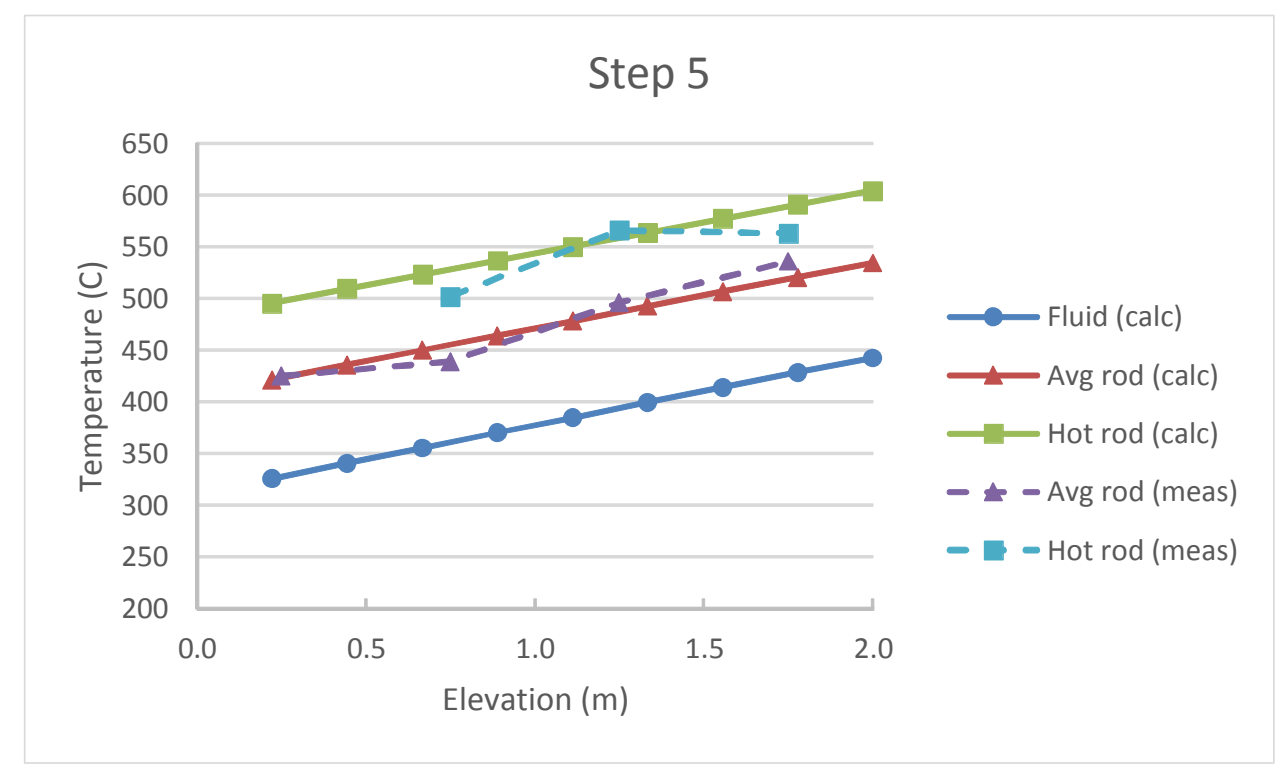

Figure 11. Temperatures in the heater rods in Step 5. 


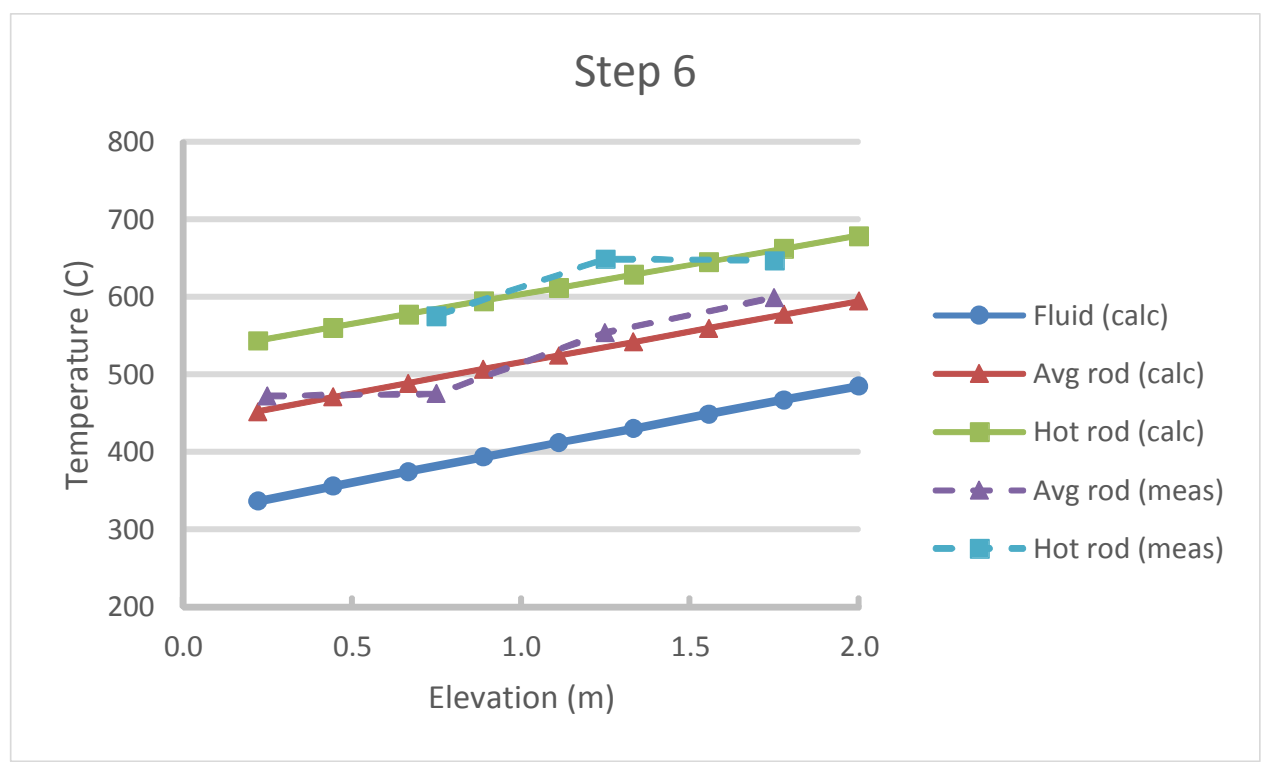

Figure 12. Temperatures in the heater rods in Step 6.

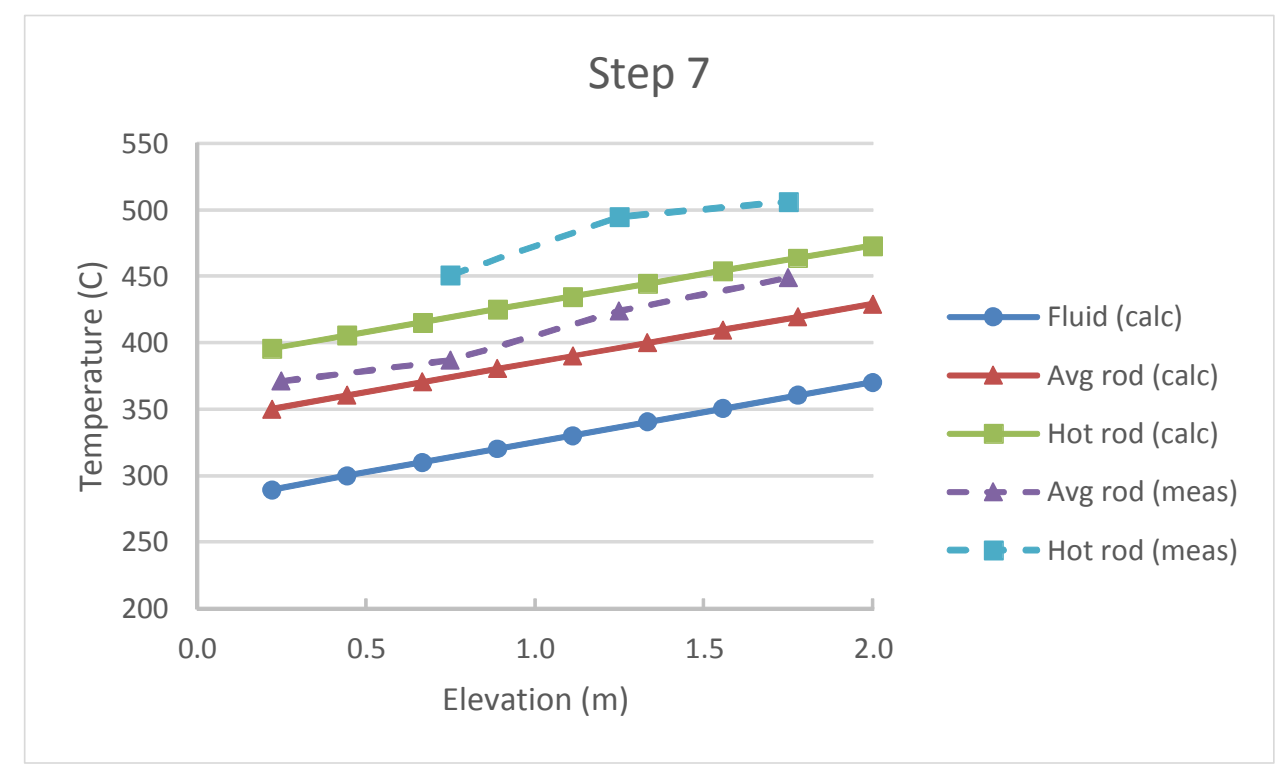

Figure 13. Temperatures in the heater rods in Step 7. 


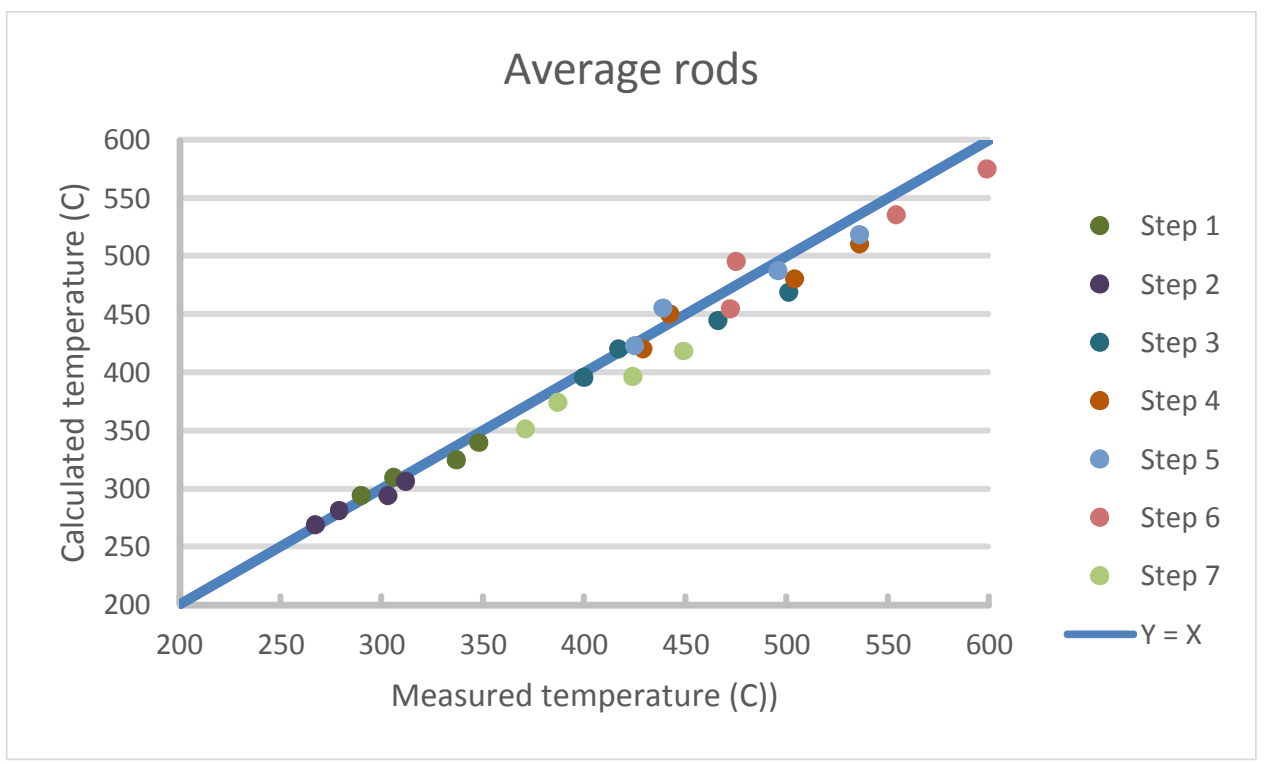

Figure 14. Temperatures in the average heater rods.

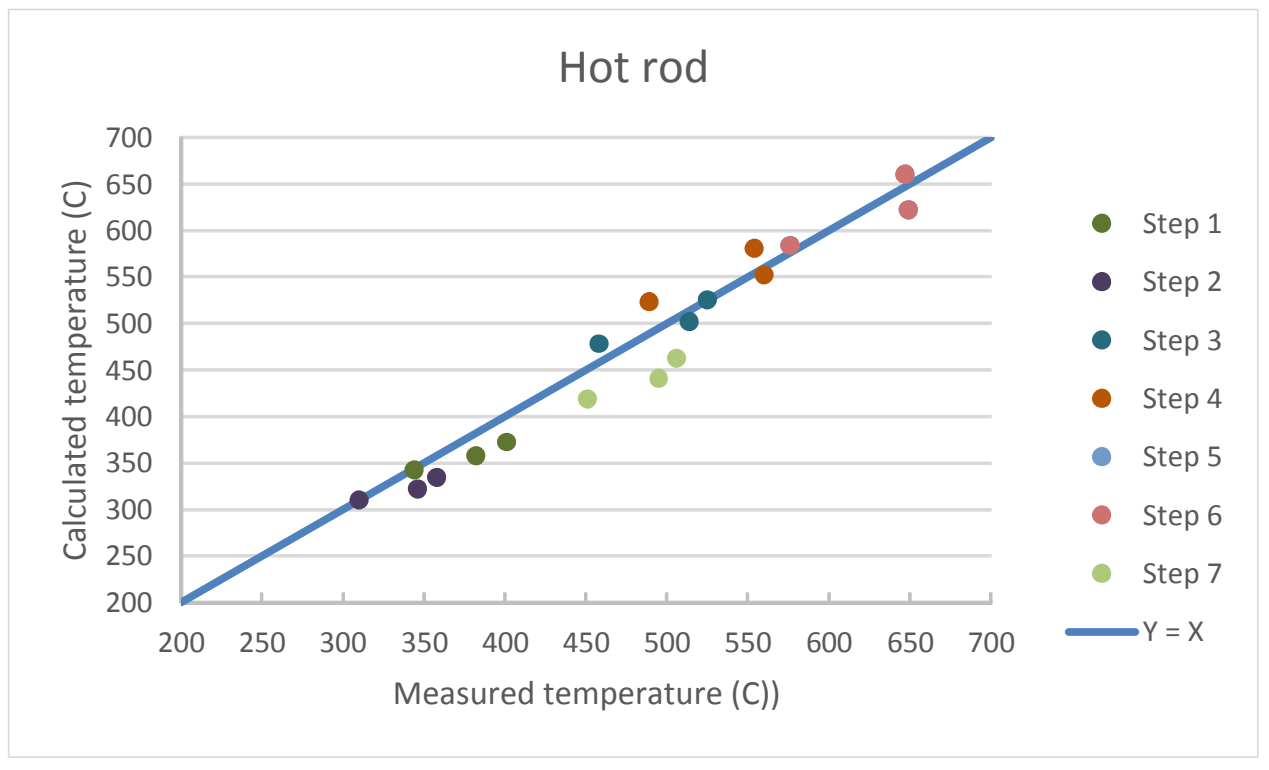

Figure 15. Temperatures in the hot heater rod.

The heat loss from the facility is a significant fraction of the power deposited in the heater rods, as shown in Figure 16. The heat loss varies from about $20 \%$ to about $40 \%$ of the test section power. The calculated distribution of the heat loss is shown in Figure 17. The heat loss from the test section includes that from Components 325 through 390. The heat loss from the economizer is from Component 200. The heat loss from the heaters is from Components 210 through 310 and 320. The heat loss from the cold zone includes that from the remainder of the system. 


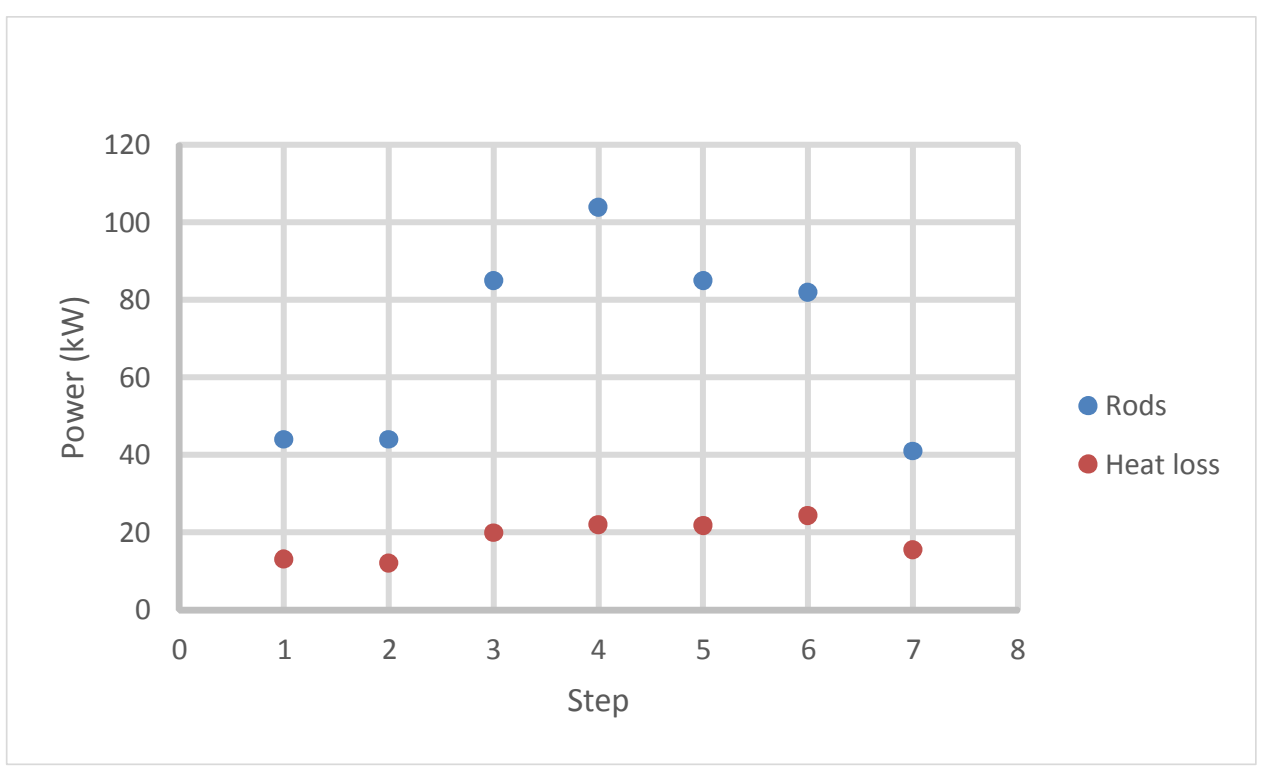

Figure 16. Calculated heat loss.

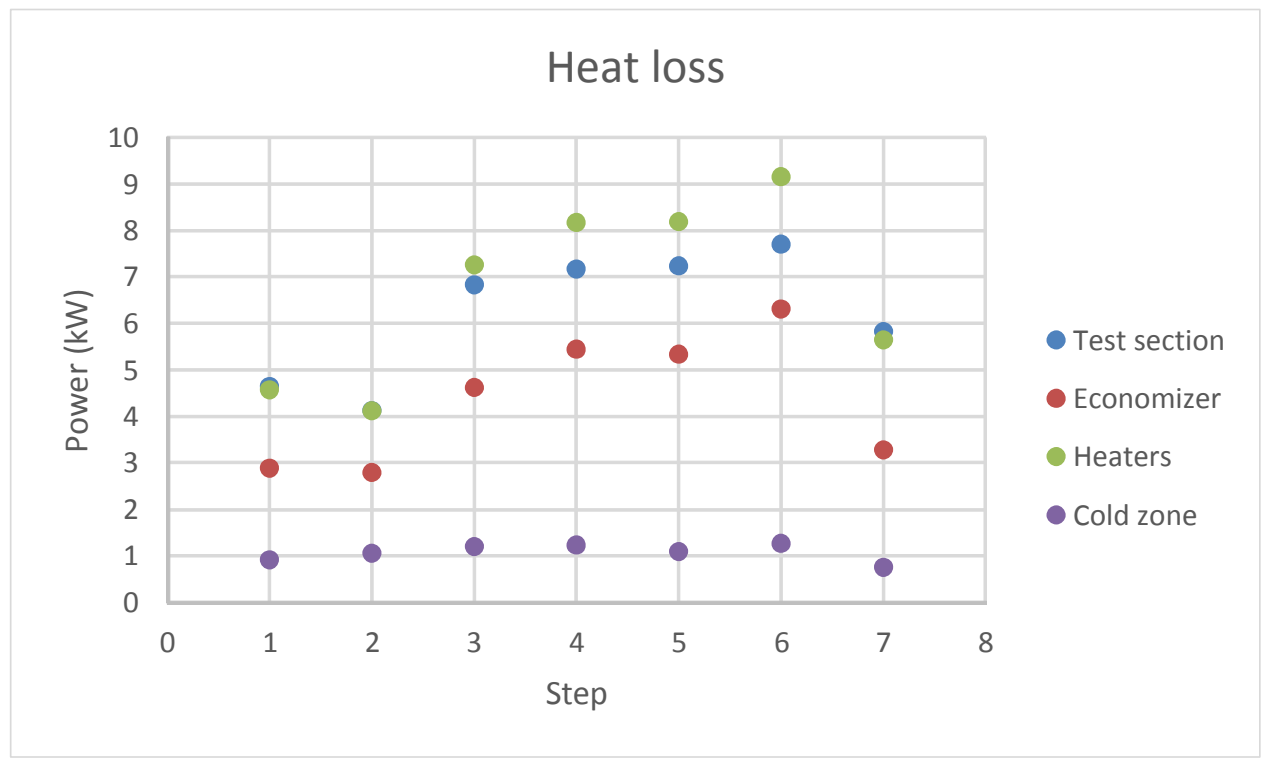

Figure 17. Calculated distribution of heat loss.

A statistical summary of steady-state results for the base case calculation is presented in Table 8 . The table presents the mean and standard deviation for the difference between the calculated and measured results presented in Table 1 through Table 7 . Statistical results were not presented for the fluid temperature at the mixing tee because Meloni and Polidori (2009) did not present measured results for all seven steps. The absolute value of the mean for the hot heater rod is a little smaller than for the average rod, but the standard deviation is significantly larger. These results suggest that the average peaking factor for the hot rod is probably near the 1.7 value assumed in the model. The scatter between the calculated and measured hot-rod temperatures would probably decrease if the actual peaking factor, which varied between 1.4 and 2.0, had been reported by Meloni and Polidori (2009) and could therefore be used in this analysis. As will be shown later, the variability in the peaking factor has a much larger effect on the calculated temperature of the hot rod than an average rod, which causes the larger standard deviation for the hot rod. 
Table 8. Statistical summary of steady-state results.

\begin{tabular}{|c|c|c|c|c|}
\hline \multirow[b]{2}{*}{ Parameter } & \multirow[b]{2}{*}{$\begin{array}{l}\text { Instrument } \\
\text { number }\end{array}$} & \multirow[b]{2}{*}{$\begin{array}{l}\text { RELAP5-3D minor } \\
\text { edit variable }\end{array}$} & \multicolumn{2}{|c|}{ Calculated - measured } \\
\hline & & & Mean & $\begin{array}{l}\text { Standard } \\
\text { deviation }\end{array}$ \\
\hline Loop pressure ${ }^{\mathrm{a}}$, bar & & p-140040000 & 0.00 & 0.00 \\
\hline Electrical power $^{\mathrm{a}}, \mathrm{kW}$ & & cntrlvar-555 & 0.00 & 0.00 \\
\hline Loop mass flow rate ${ }^{\mathrm{a}}, \mathrm{kg} / \mathrm{s}$ & & mflowj-150000000 & 0.0000 & 0.0000 \\
\hline Total pressure drop, bar & PD201 & cntrlvar-40 & -0.007 & 0.121 \\
\hline Test section pressure drop, bar & PD229 & cntrlvar-41 & 0.0132 & 0.0211 \\
\hline Hot-bypass valve, $\%$ open & ZT234 & vlvstem-172 & -0.61 & 4.87 \\
\hline \multicolumn{5}{|l|}{ Fluid temperature, ${ }^{\circ} \mathrm{C}$} \\
\hline Cooler outlet $^{\mathrm{a}}$ & TT241 & cntrlvar-241 & 0.0 & 0.0 \\
\hline Compressor outlet & TR204 & cntrlvar-209 & 3.5 & 4.4 \\
\hline Cold economizer inlet & TR215 & cntrlvar-200 & 0.0 & 4.5 \\
\hline Cold economizer outlet & TR216 & cntrlvar-201 & -1.6 & 7.8 \\
\hline Heater outlet & TR236 & cntrlvar-244 & -1.3 & 7.0 \\
\hline Mixing tee & TT232 & cntrlvar-205 & & \\
\hline Test section outlet & TE102 & cntrlvar-225 & -1.7 & 7.6 \\
\hline Hot economizer inlet & TR217 & cntrlvar-206 & -1.5 & 7.6 \\
\hline Hot economizer outlet & TR218 & cntrlvar-207 & -0.5 & 6.9 \\
\hline Cooler inlet & TT239 & cntrlvar-239 & -3.3 & 6.6 \\
\hline Average rod temperature, ${ }^{\circ} \mathrm{C}$ & & & -9.6 & 13.9 \\
\hline Hot rod temperature, ${ }^{\circ} \mathrm{C}$ & & & -6.1 & 25.0 \\
\hline
\end{tabular}

a. Input as a boundary condition.

\subsubsection{Sensitivity Calculation}

A sensitivity calculation was performed in which the Dittus-Boelter heat-transfer correlation was applied to the heater rods instead of the Gnielinski correlation that was used in the base case. The results of the base and sensitivity calculations are compared in Figure 18 for the average rods and in Figure 19 for the hot rod. The calculated temperatures were consistently higher, and in better agreement with the measurements, with the Gnielinski correlation. On average, the use of the Dittus-Boelter correlation reduced the calculated temperatures by $10.1^{\circ} \mathrm{C}$ for the average rods and by $21.5^{\circ} \mathrm{C}$ for the hot rod. 


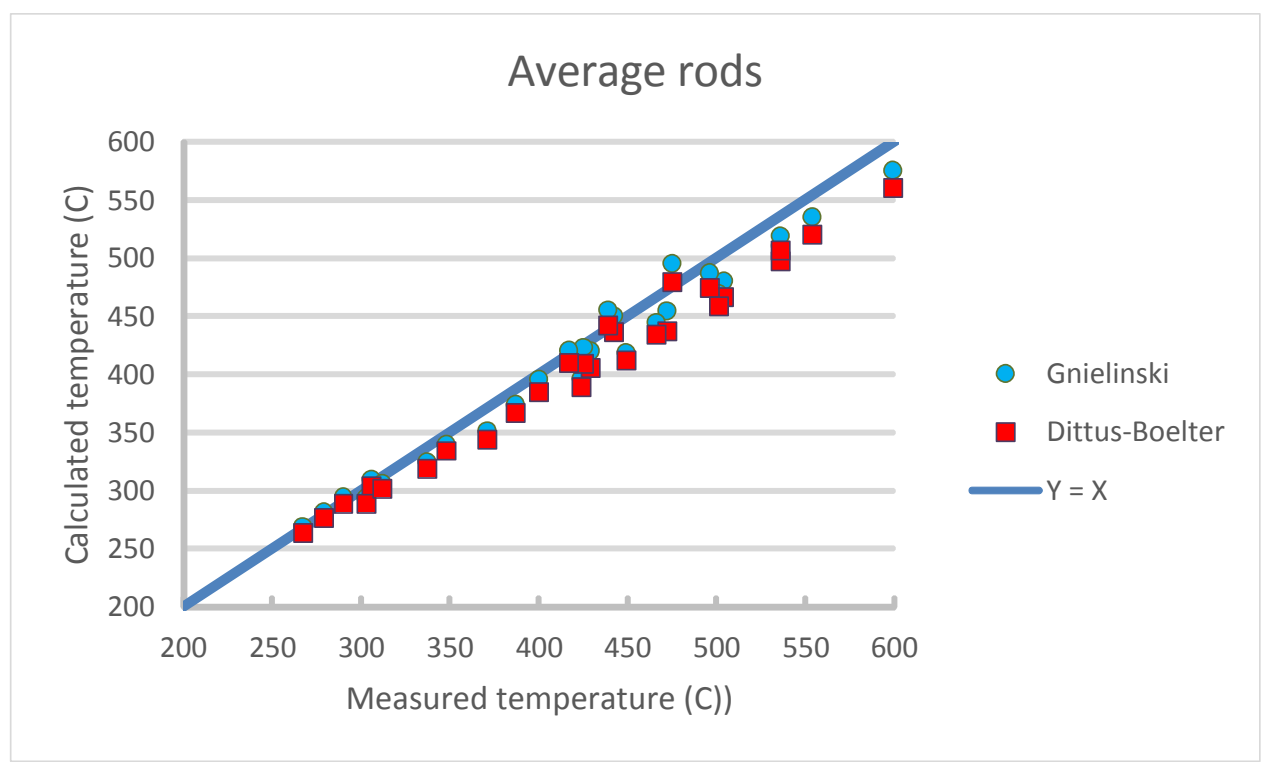

Figure 18. The effect of heat-transfer correlation on temperatures in the average heater rods.

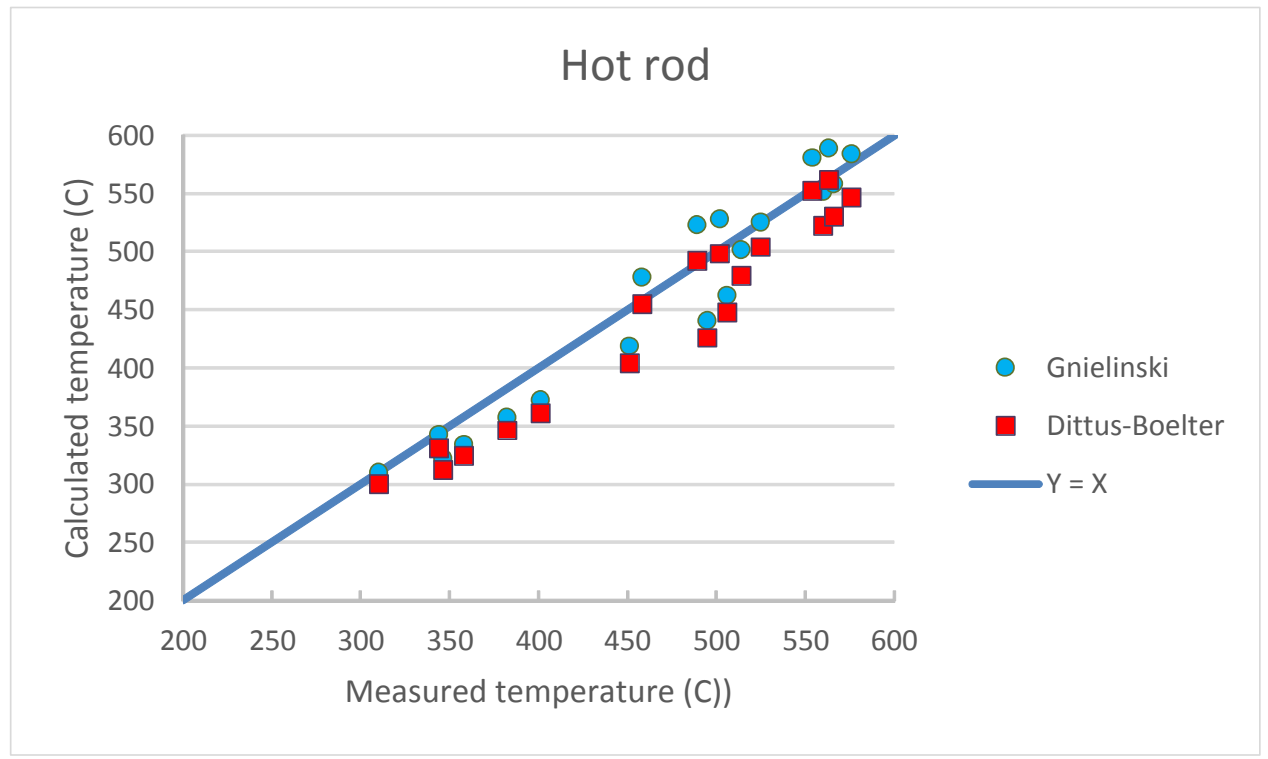

Figure 19. The effect of heat-transfer correlation on temperatures in the hot heater rod.

\subsection{Transient Simulations}

\subsubsection{Base Case}

The RELAP5-3D model of HE-FUS3 was also used to simulate the first LOFA described in the posttest analysis report (Meloni and Polidori 2009). The transient was initiated by a reduction in the compressor speed. Electronic data were not available, so data were obtained by digitizing results from graphs contained in the post-test analysis report. Each symbol on the subsequent figures corresponds to a point read from the graph, and the data were judged to be approximately linear between symbols. The uncertainty introduced by the digitization is expected to be about $2 \%$ of full scale.

The transient was simulated by restarting from the steady conditions of Step 4, which are shown in Table 4. As mentioned previously, insufficient data were available to characterize the performance of the 
new compressor used in these tests. Therefore, the old model of the compressor was used, but the same control system used during the steady-state calculations was used to vary the compressor speed to match the desired flow rate. Two flow measurements were available, one located downstream of the expansion tank (fic212x) and one located downstream of the hot side of the economizer (fic 228x). The two measurements agree closely, as shown in Figure 20. The flow rate from fic $212 \mathrm{x}$ was input to the control system as that flow rate was used during the steady-state calculations. The figure illustrates how the test was performed. The flow rate was held constant at its initial value for about $450 \mathrm{~s}$. The flow was then quickly reduced by about $40 \%$ and held constant for about $2200 \mathrm{~s}$, after which the flow rate was quickly increased back to its initial value. The figure shows that the control system caused the calculated flow to closely follow the desired flow rate.

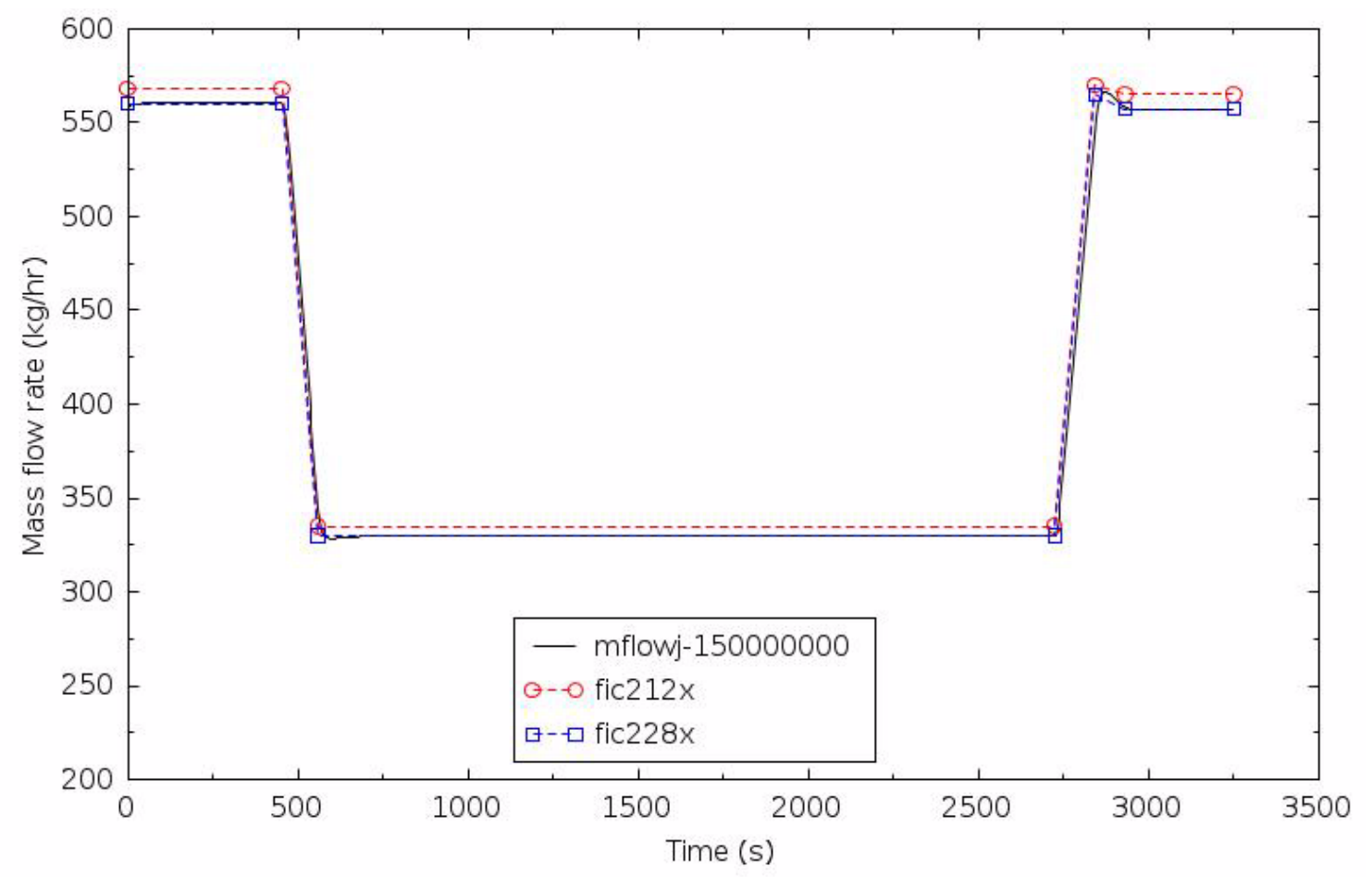

Figure 20. Loop flow rate during the LOFA.

The calculated and measured differential pressures across the compressor and the test section are shown in Figure 21. The lines without symbols denote the calculations, while the lines with symbols denote the measurements. The trends of the differential pressures are similar to those of the mass flow rates shown in the previous figure. The calculated results are generally in reasonable agreement with the measurements. One exception is that the calculated differential pressure across the test section increases consistently with the increase in the mass-flow rate at about $2700 \mathrm{~s}$, whereas there is a noticeable delay in the response of the measurement. 


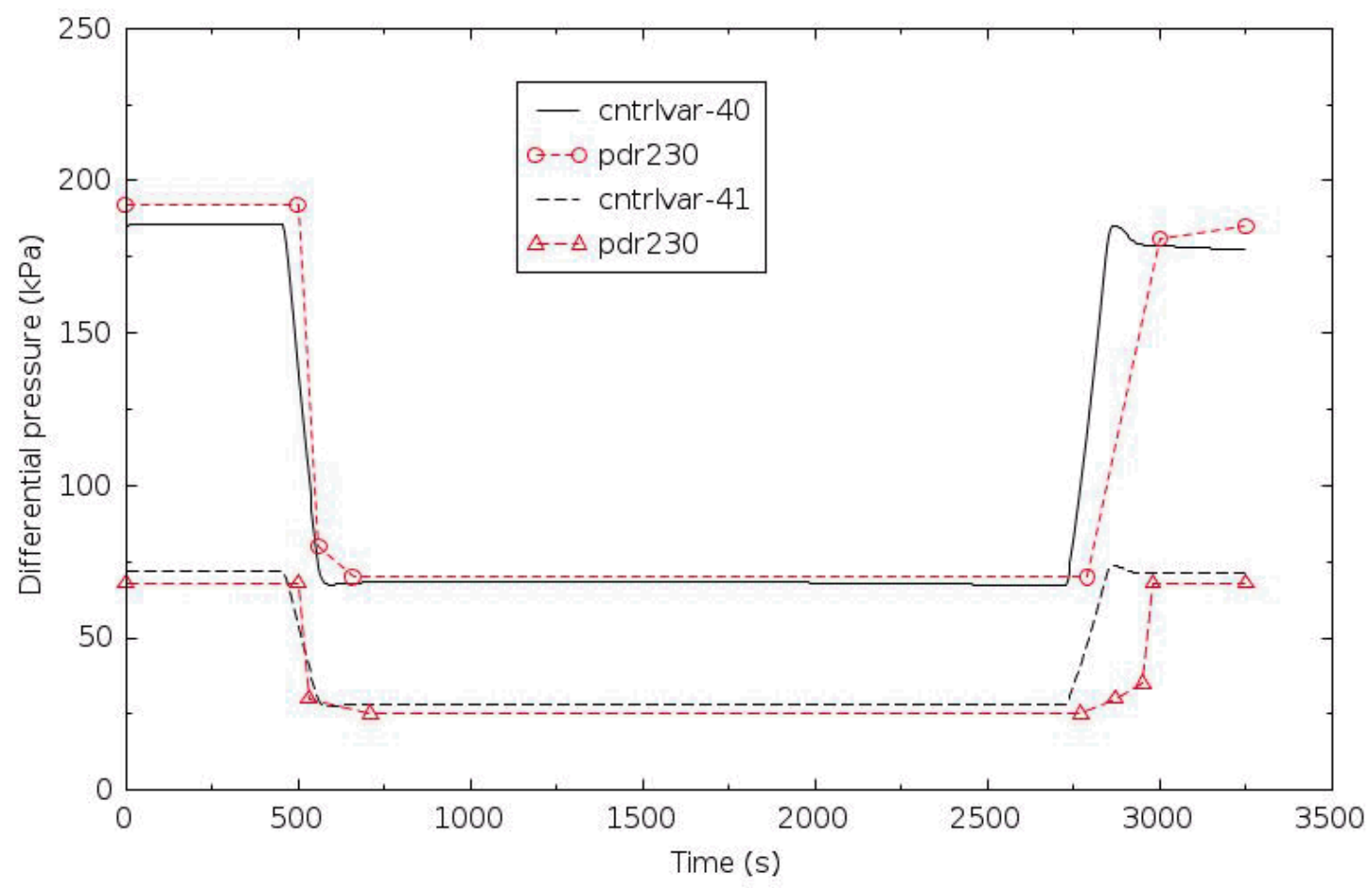

Figure 21. Differential pressures during the LOFA.

The calculated and measured flow areas of the hot-bypass valve are shown in Figure 22. The hotbypass valve is controlled to maintain the temperature downstream of the mixer. The calculated valve position is smoother than the measured position, but overall the trends are similar.

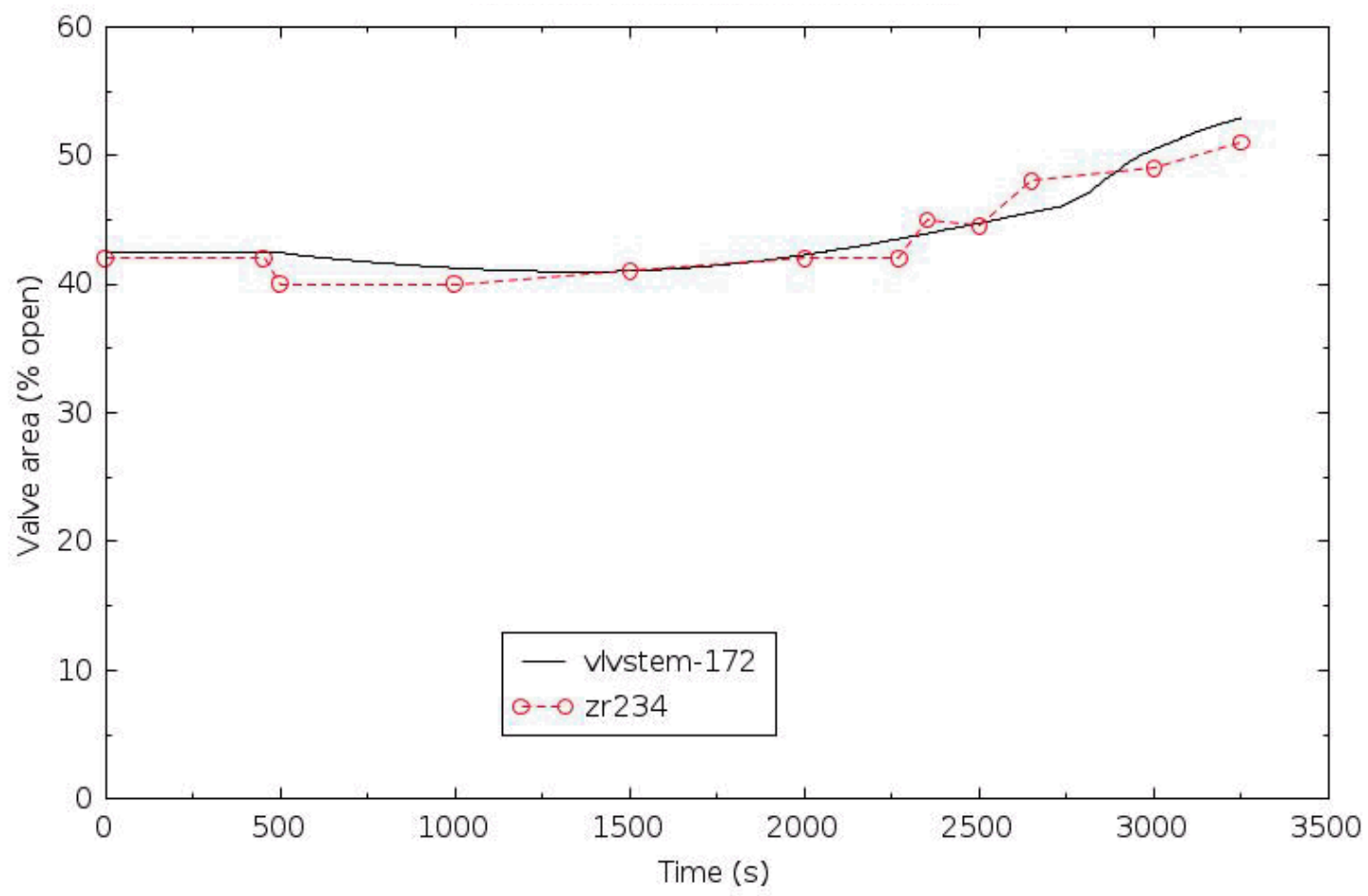

Figure 22. Hot-bypass valve area during the LOFA. 
Calculated and measured fluid temperatures on the cold and hot sides of the economizer are shown in Figure 23 and Figure 24, respectively. The calculated temperatures corresponding to TR215 and TR218, which are located at the inlet of the cold side of the economizer and the outlet of the hot side of the economizer, are in excellent agreement with the measurements. The agreement is not as good for TR216 and TR217, which are located at the outlet of the cold side and the inlet of the hot side of the economizer. The calculated temperatures respond more quickly than the measurements following the flow decrease near $500 \mathrm{~s}$ and the flow increase near $2700 \mathrm{~s}$. According to Meloni and Polidori (2009), these thermocouples are strongly influenced by the thermal capacity of the wall. That is, the measurements are affected by the wall temperature and do not accurately measure fluid temperature during transients. Thus, the differences between the calculated and measured results for TR216 and TR217 are significantly affected by inaccuracies in the measurement system.

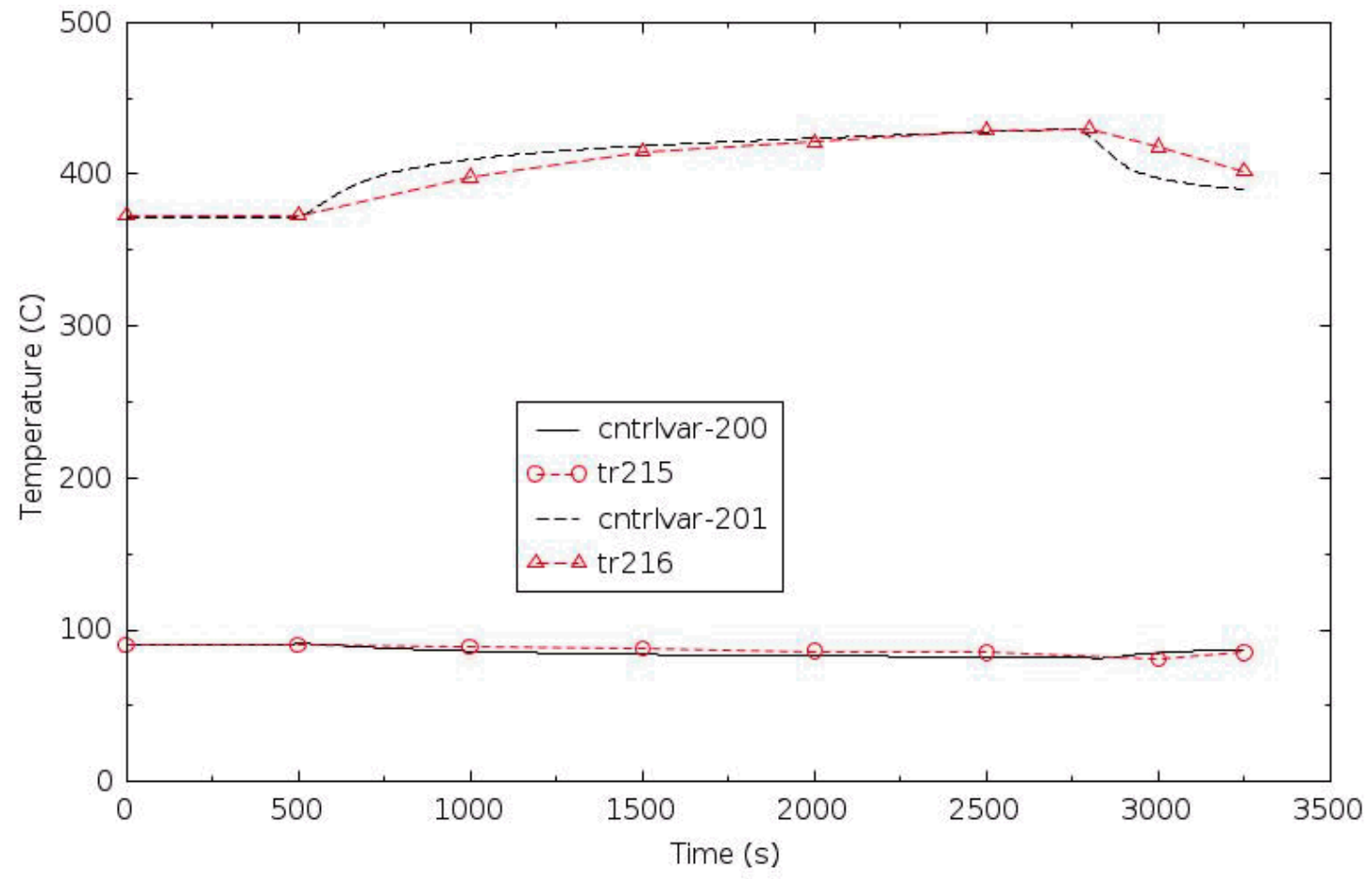

Figure 23. Economizer cold-side fluid temperatures during the LOFA. 


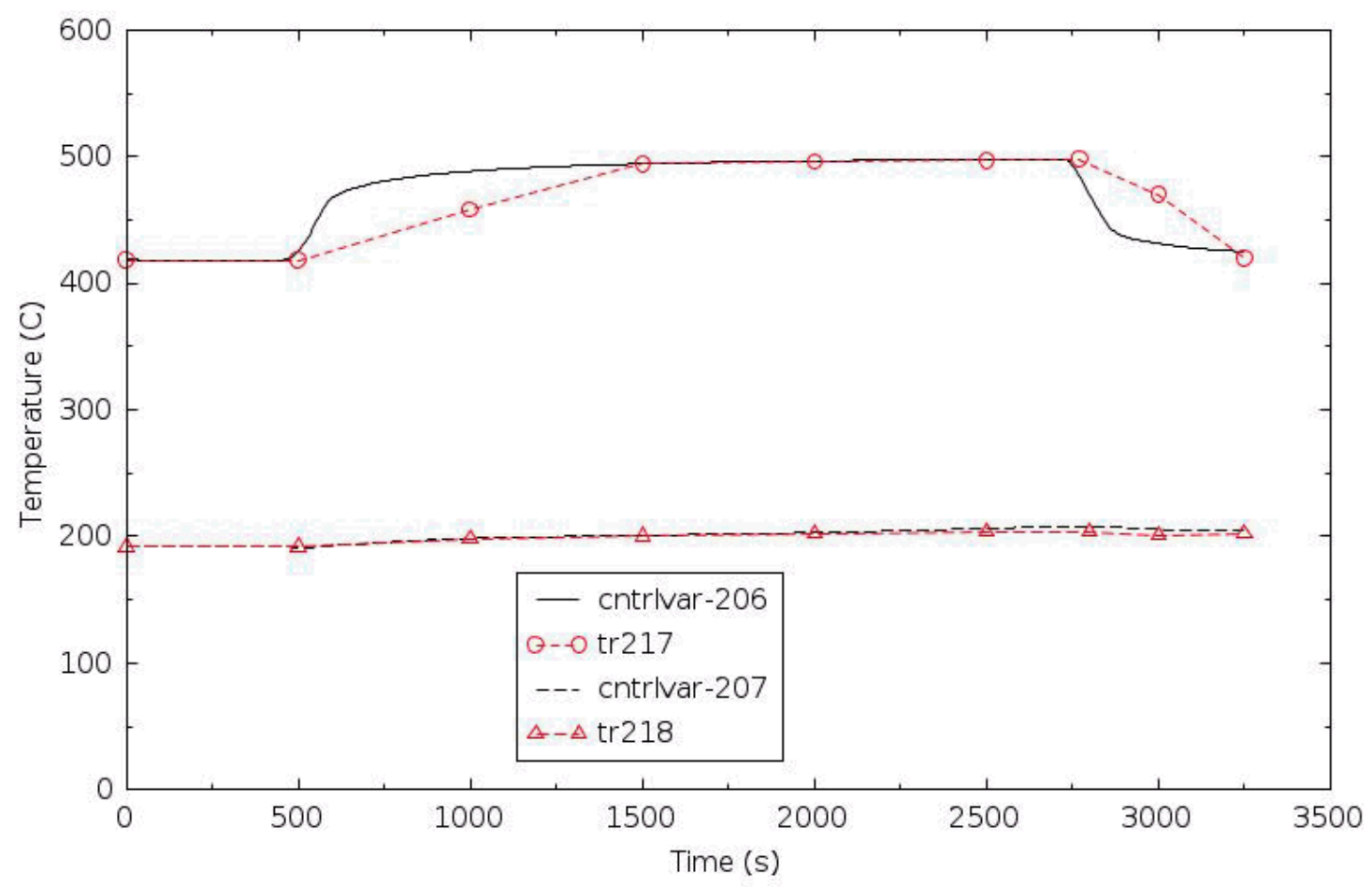

Figure 24. Economizer hot-side fluid temperatures during the LOFA.

Calculated and measured fluid temperatures at the inlet and outlet of the test section are shown in Figure 25. The temperature at the inlet, TE101, was nearly constant because the hot-bypass valve controlled the fluid temperatures at the mixer at $300^{\circ} \mathrm{C}$. The temperatures at the inlet to the test section were a few degrees lower than that because of heat loss. The temperature at the outlet, TE102, increased following the flow reduction near $500 \mathrm{~s}$, became nearly steady about $1000 \mathrm{~s}$, and then decreased following the flow increase near $2700 \mathrm{~s}$. The measured outlet temperature did not exhibit the slow response that was discussed for the previous figure. The calculated results were judged to be in reasonable agreement with the measurements. 


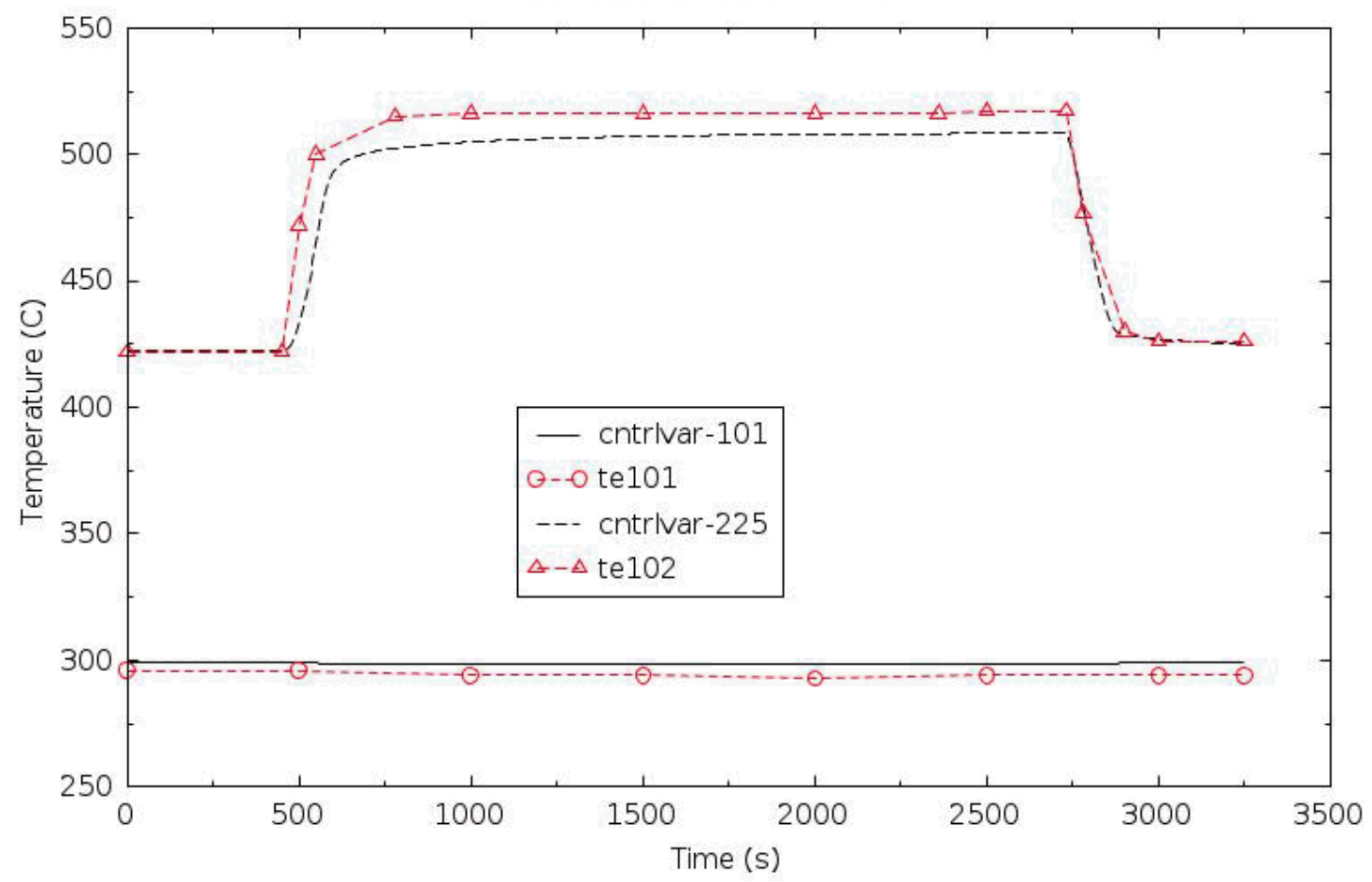

Figure 25. Test section fluid temperatures during the LOFA.

Figure 26 through Figure 29 show the response of the heater rods during the LOFA. Results are shown at $0.5 \mathrm{~m}$ increments ranging from $0.25 \mathrm{~m}$ to $1.75 \mathrm{~m}$ above the bottom of the heated length. Each figure shows measurements for four of the six average rods. Meloni and Polidori (2009) did not report the results from the other two rods because of an unphysical decrease in temperature with an increase in elevation. The base RELAP5 calculation, denoted by the solid line, was performed with a hot-rod peaking factor (PF) of 1.70, which is the average of the reported values of 1.4 and 2.0. Calculations were also performed with the bounding values of 1.4 and 2.0.

The calculated and measured heater-rod temperatures showed similar trends to those discussed previously for the fluid temperature at the outlet of the test section. Specifically, the temperatures increased following the flow reduction near $500 \mathrm{~s}$, approached a quasi-steady state, and then decreased following the flow increase near $2700 \mathrm{~s}$. The quasi-steady calculated results were too low compared to the measured values at an elevation of $0.25 \mathrm{~m}$, were too high at $0.75 \mathrm{~m}$, and were too low again at $1.25 \mathrm{~m}$. The differences between the calculated and measured temperatures are qualitatively similar to those shown previously in Figure 10 for Step 4. However, the magnitude of the difference between the calculated and measured results at $1.75 \mathrm{~m}$ is much larger for the LOFA than obtained previously for Step 4. Figure 29 shows that the quasi-steady calculated temperature at $1.75 \mathrm{~m}$ is far below measured values. The measurements indicate a severe deterioration in the heat transfer at $1.75 \mathrm{~m}$ compared to the lower elevations. The calculated heat-transfer coefficient at $1.75 \mathrm{~m}$ would have to be reduced by more than $40 \%$ in order to match the average of the measurements at $2000 \mathrm{~s}$. In contrast, the average calculated heat-transfer coefficient was only about $5 \%$ too high compared to the measurements between 0.25 and $1.25 \mathrm{~m}$.

Figure 26 through Figure 29 also indicate that the amount of scatter in the measurements at $1.75 \mathrm{~m}$ is much larger than the scatter at lower elevations. For example, the variation between the maximum and minimum measurements at $2000 \mathrm{~s}$ is less than $30^{\circ} \mathrm{C}$ at $1.25 \mathrm{~m}$ and below versus more than $90^{\circ} \mathrm{C}$ at $1.75 \mathrm{~m}$. 
McEligot and Jackson (2004) investigated the conditions at which turbulent, convective heat transfer might deteriorate in gas reactors due to the effects of radial property variation, acceleration, and buoyancy. Based on their work, deterioration in the heat transfer at the quasi-steady conditions at $1.75 \mathrm{~m}$ in the LOFA would not be expected. Because a physical explanation for the observed deterioration in heat transfer could not be determined, the cause probably is due to problems in the facility itself, such as a nonuniform axial power distribution, unintended rod-to-rod variations in power, or lack of contact between some thermocouples and the surrounding materials.

The calculated quasi-steady average-rod temperatures were not very sensitive to the assumed peaking factor in the hot rod. For example, a decrease in the peaking factor from 1.7 to 1.4 caused the power in the average rod to increase by $4 \%$ and caused the calculated temperatures in the heater rod to increase by about $6^{\circ} \mathrm{C}$ at all elevations. However, the assumed peaking factor had a large effect on the calculated temperatures in the hot rod as shown in Figure 30 through Figure 32. A decrease in the peaking factor from 1.7 to 1.4 caused the power in the hot rod to decrease by $14 \%$ and the calculated rod temperatures to decrease by about $40^{\circ} \mathrm{C}$. The calculated temperatures of both the hot and average rods are generally improved if a peaking factor of 1.4 is used for the LOFA.

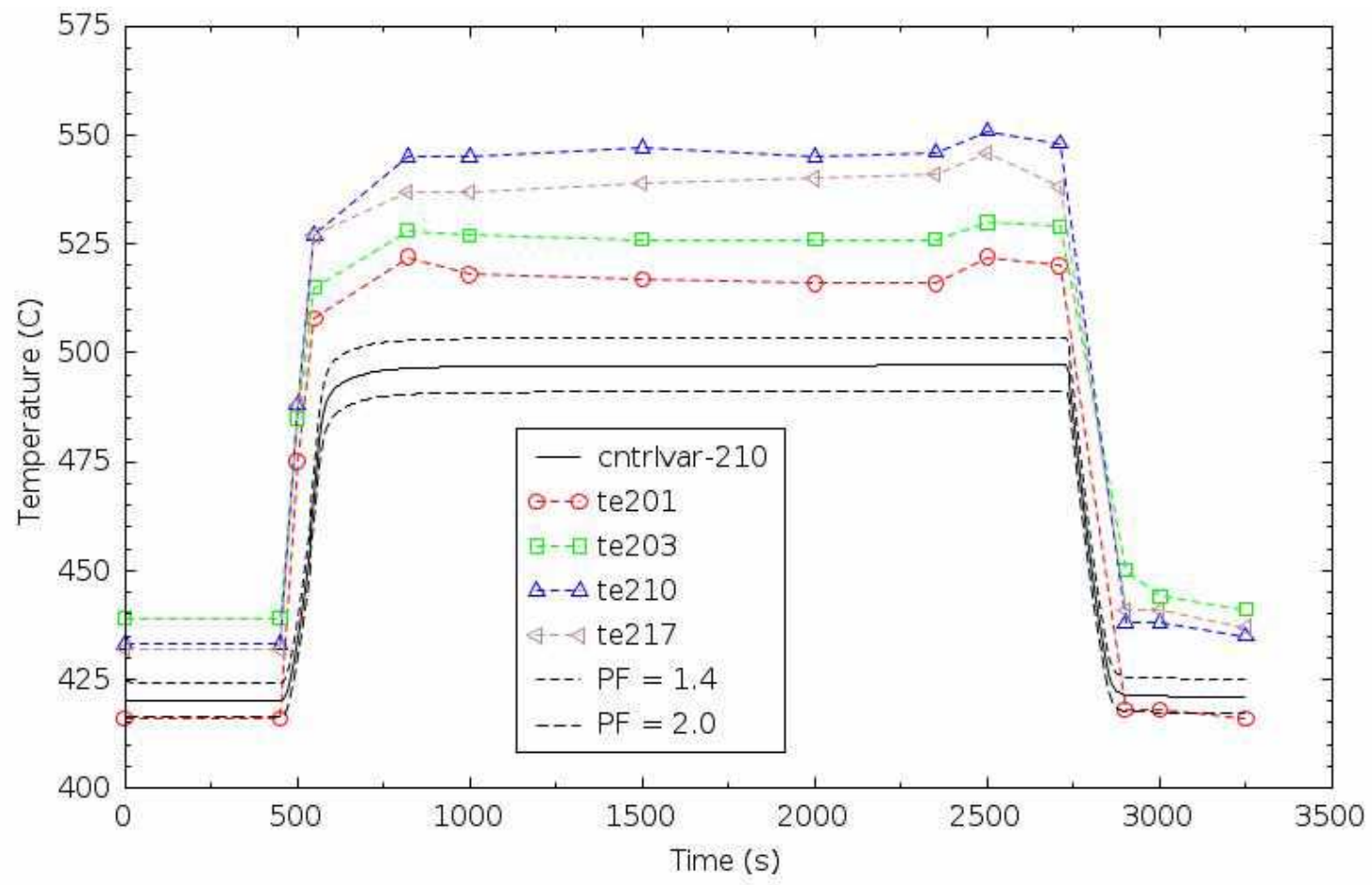

Figure 26. Average-rod temperatures at $0.25 \mathrm{~m}$ during the LOFA. 


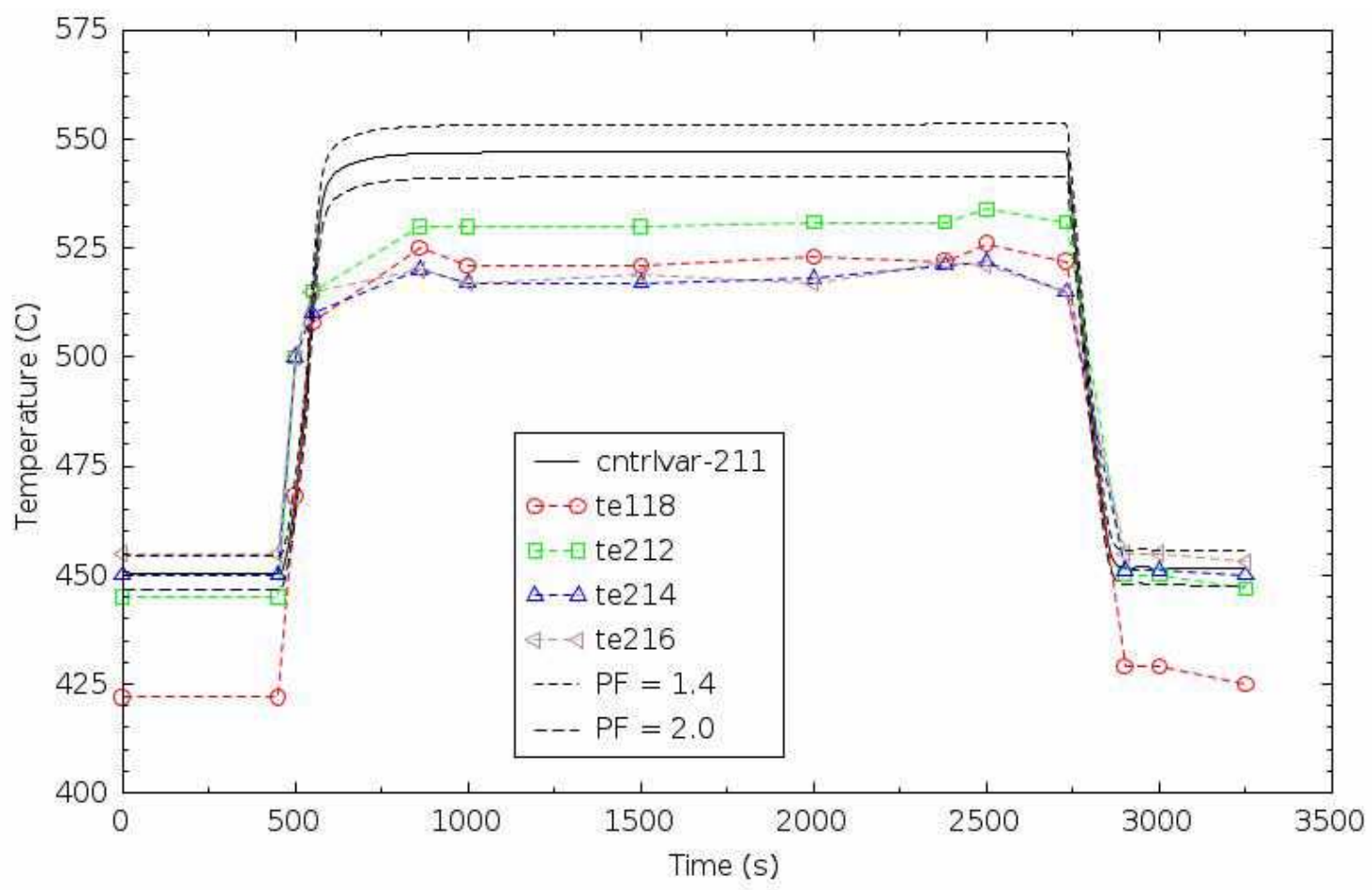

Figure 27. Average-rod temperatures at $0.75 \mathrm{~m}$ during the LOFA.

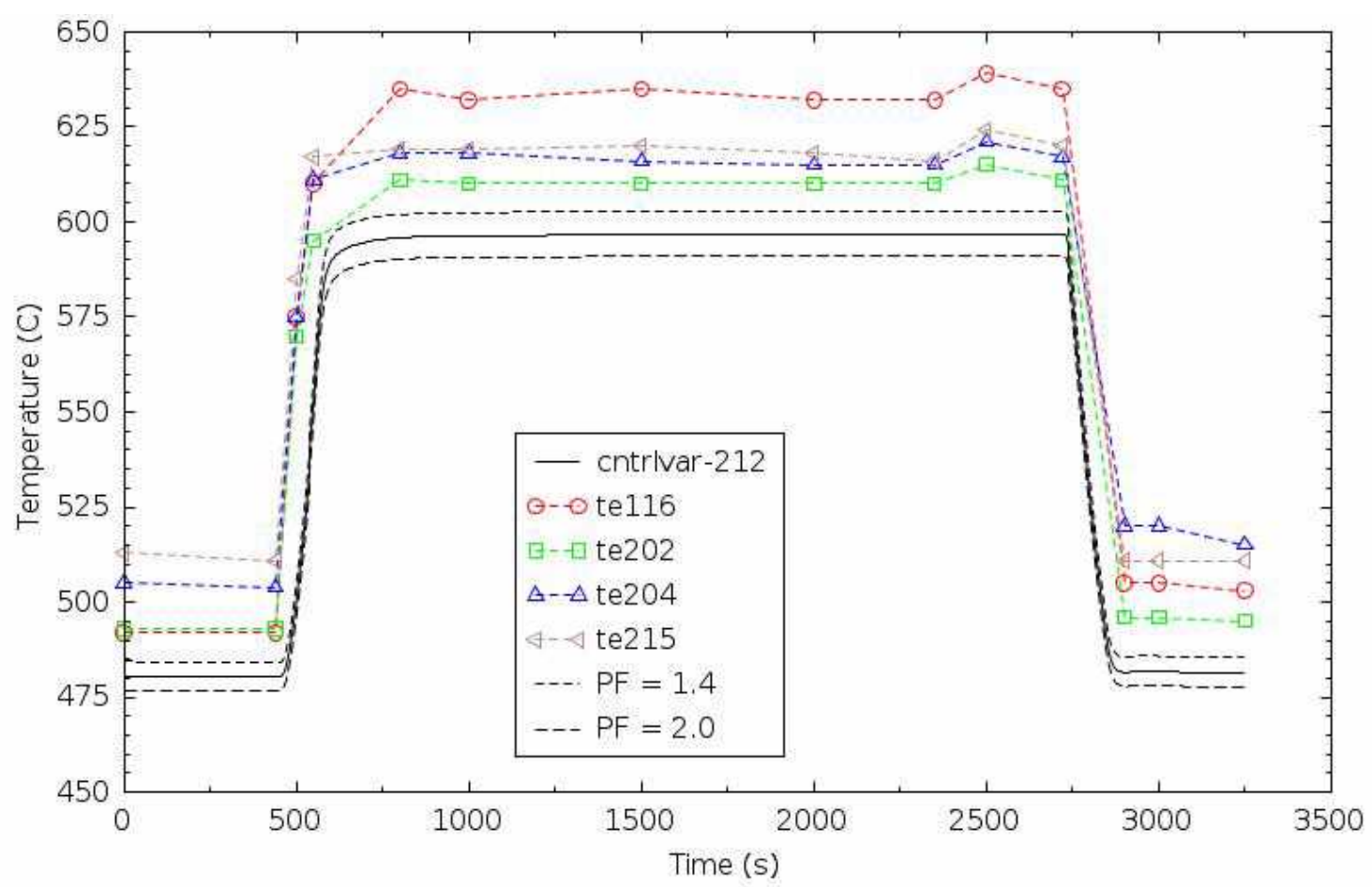

Figure 28. Average-rod temperatures at $1.25 \mathrm{~m}$ during the LOFA. 


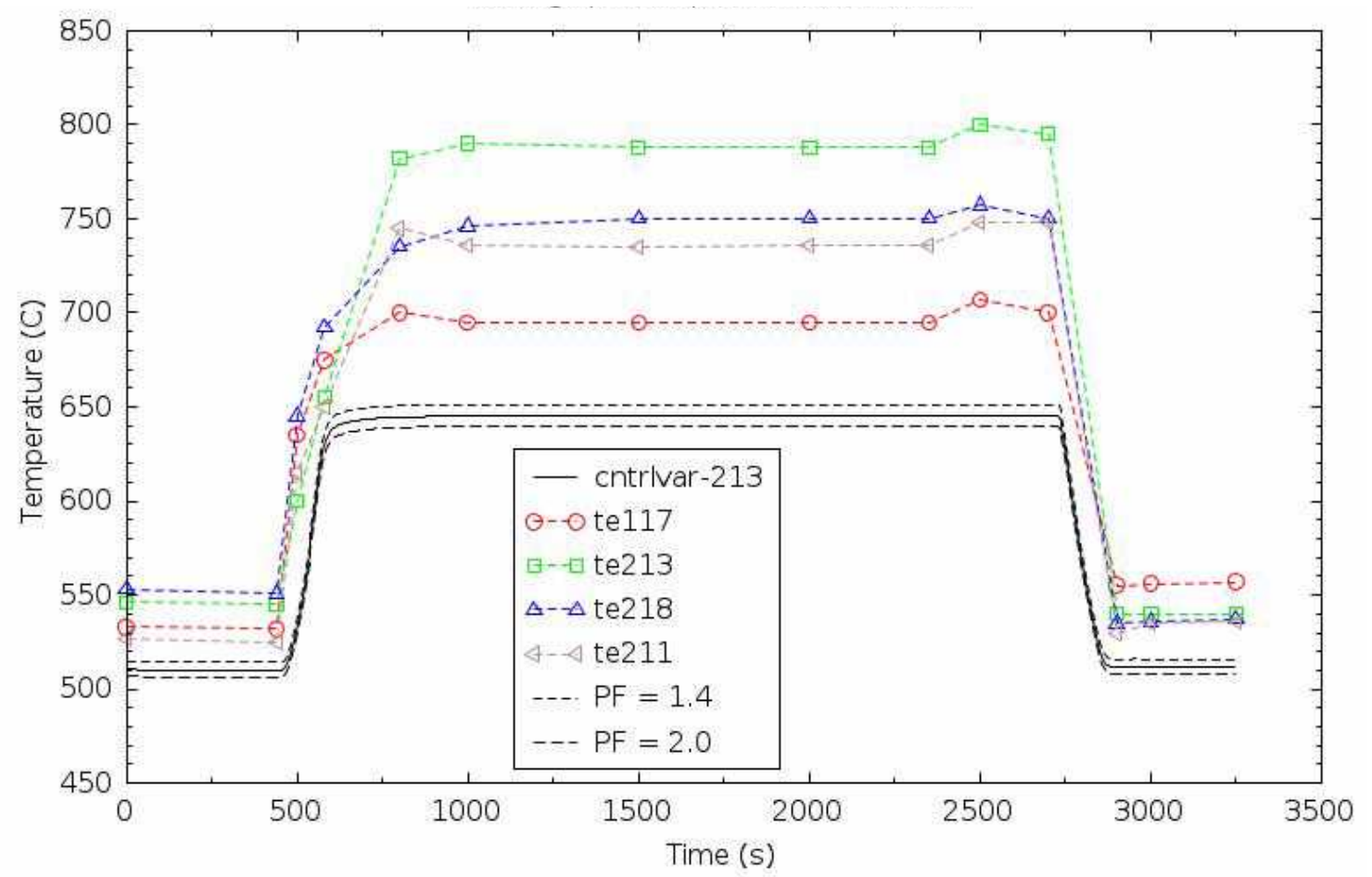

Figure 29. Average-rod temperatures at $1.75 \mathrm{~m}$ during the LOFA.

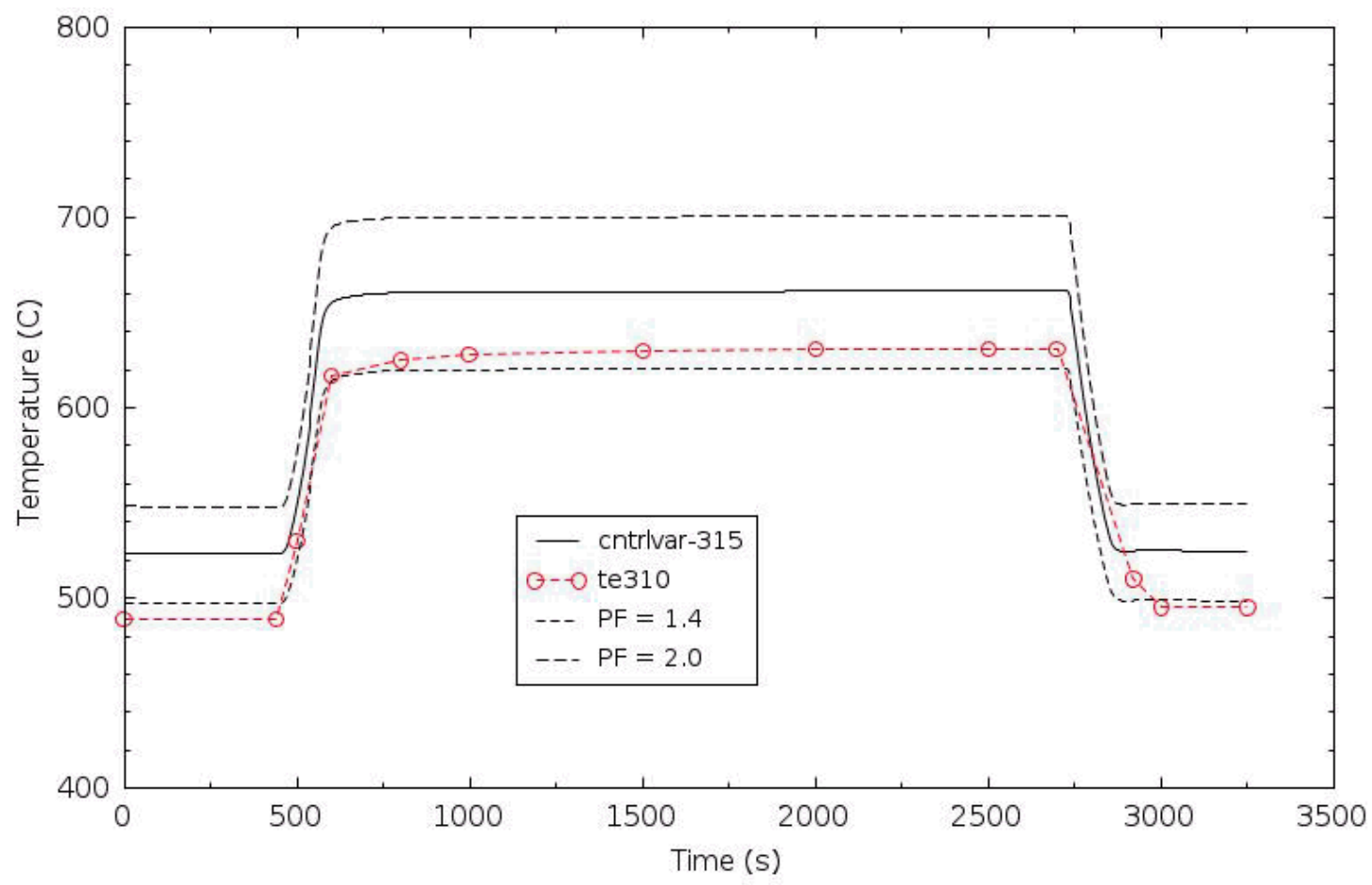

Figure 30. Hot-rod temperatures at $0.75 \mathrm{~m}$ during the LOFA. 


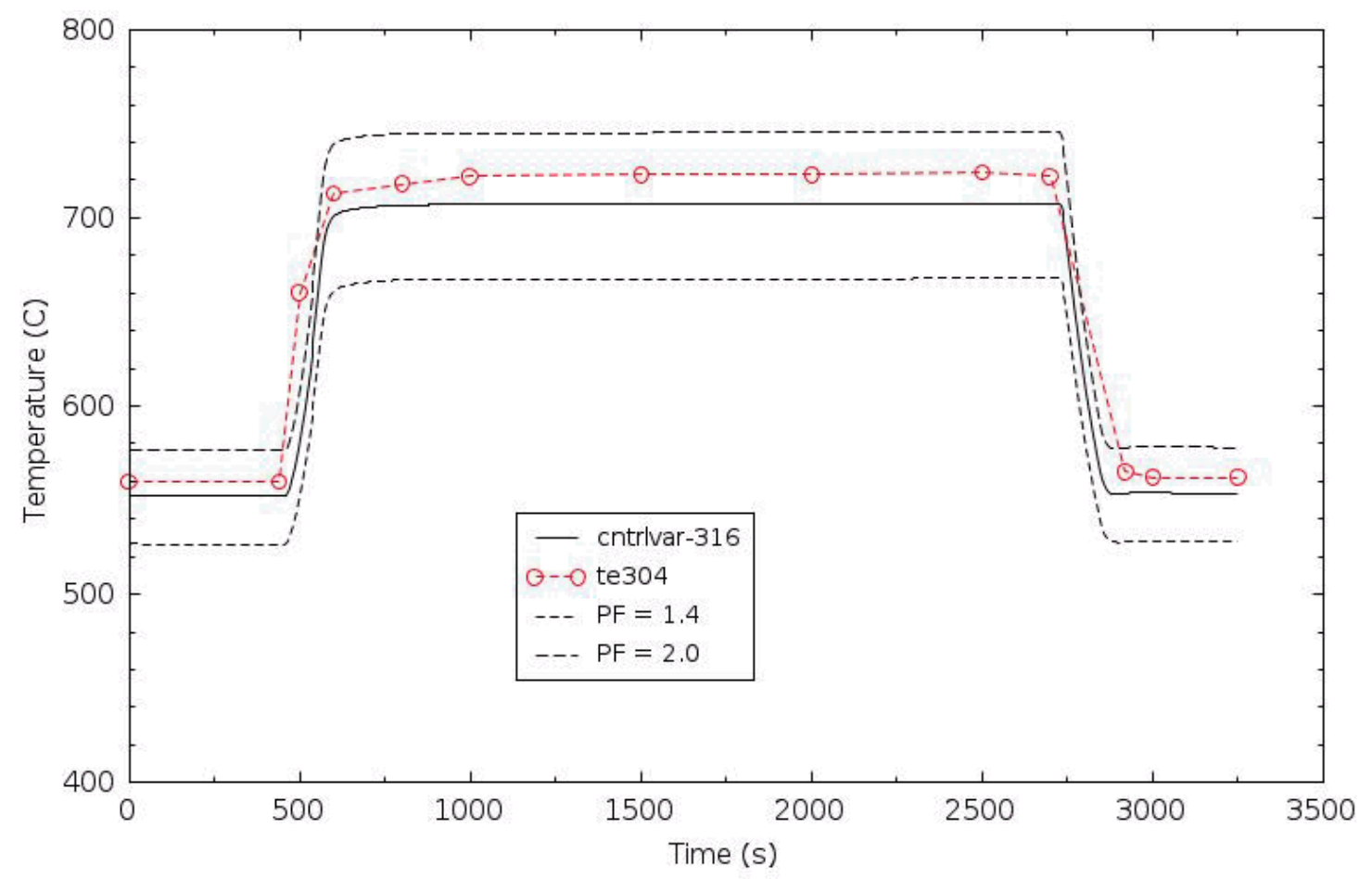

Figure 31 . Hot-rod temperatures at $1.25 \mathrm{~m}$ during the LOFA.

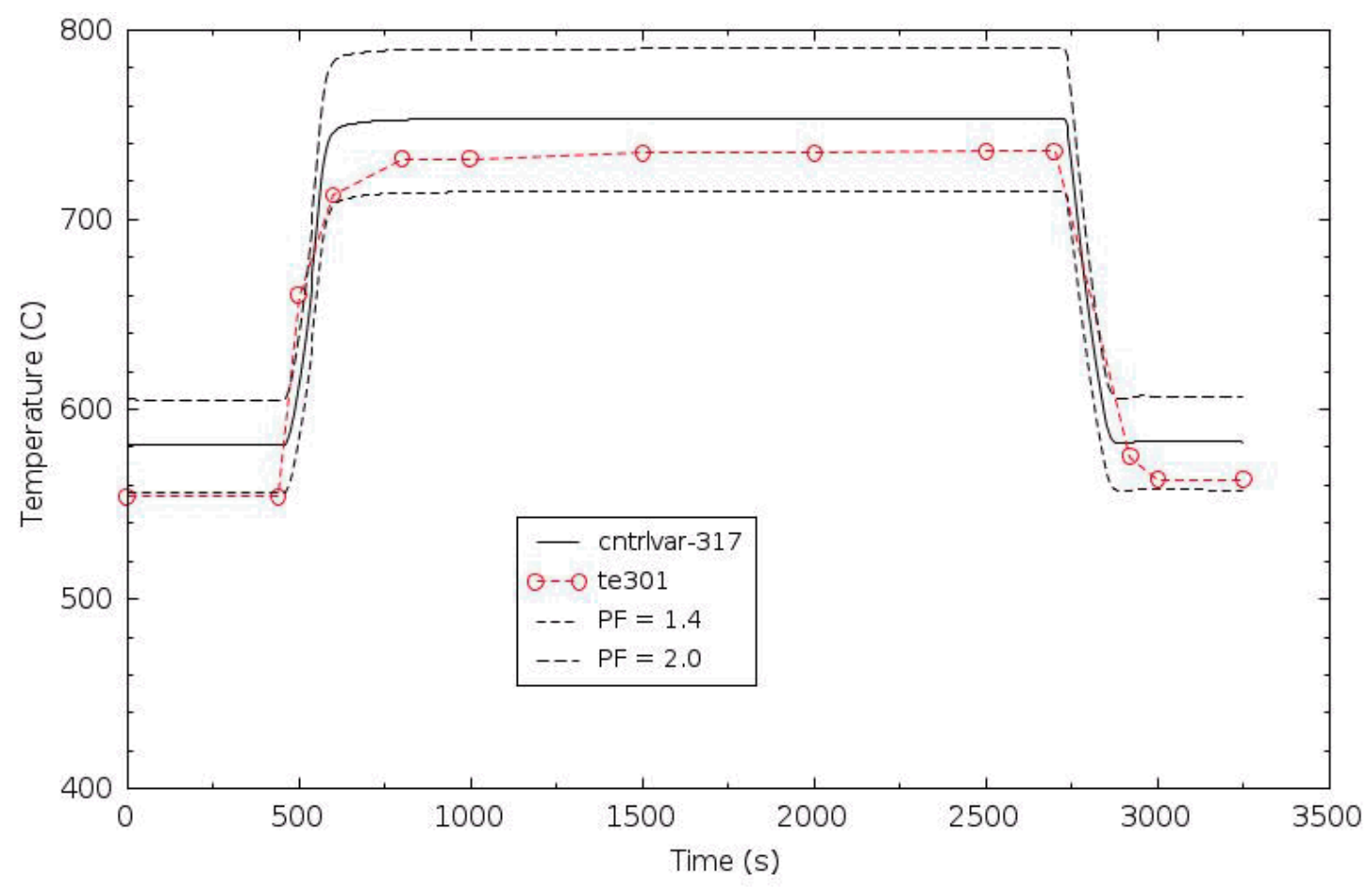

Figure 32. Hot-rod temperatures at $1.75 \mathrm{~m}$ during the LOFA.

The measured heater-rod temperatures exhibit anomalous and, probably unphysical, behavior at the $1.75 \mathrm{~m}$ elevation in the LOFA. For example, Figure 33 shows that the measured temperature in the hot 
rod, TE301, is lower at $2000 \mathrm{~s}$ than that of two of the average rods, TE213 and TE218, and is practically the same as that of another of the average rods, TE211. This is completely unexpected behavior if the power in the hot rod is really at least 1.4 times the power of one of the average rods. Furthermore, the temperature of the average rods show a small, about $10^{\circ} \mathrm{C}$, increase beginning at about $2350 \mathrm{~s}$. This increase occurs before the flow reduction, which occurs at about $2700 \mathrm{~s}$. There is some movement of the hot-bypass valve at about this time, as shown in Figure 22, but there is a negligible increase in the fluid temperature at the inlet to the test section, as shown in Figure 25. Figure 26 through Figure 28 show similar behavior for the average rods at lower elevations. There is no corresponding temperature increase in the hot rod at $2350 \mathrm{~s}$, which would be expected if either the flow or the inlet temperature changed. These results point to a problem in the average rods, perhaps due to electrical interference in the measured temperatures or due to an increase in the power applied to the rods. An increase in power is somewhat supported by a small increase in the measured outlet fluid temperature at this time (see Figure 25), but the magnitude of the increase, about $1{ }^{\circ} \mathrm{C}$, is much smaller than the increase in the measured rod temperatures. The power applied to the heater rods was assumed to be constant in the LOFA calculation.

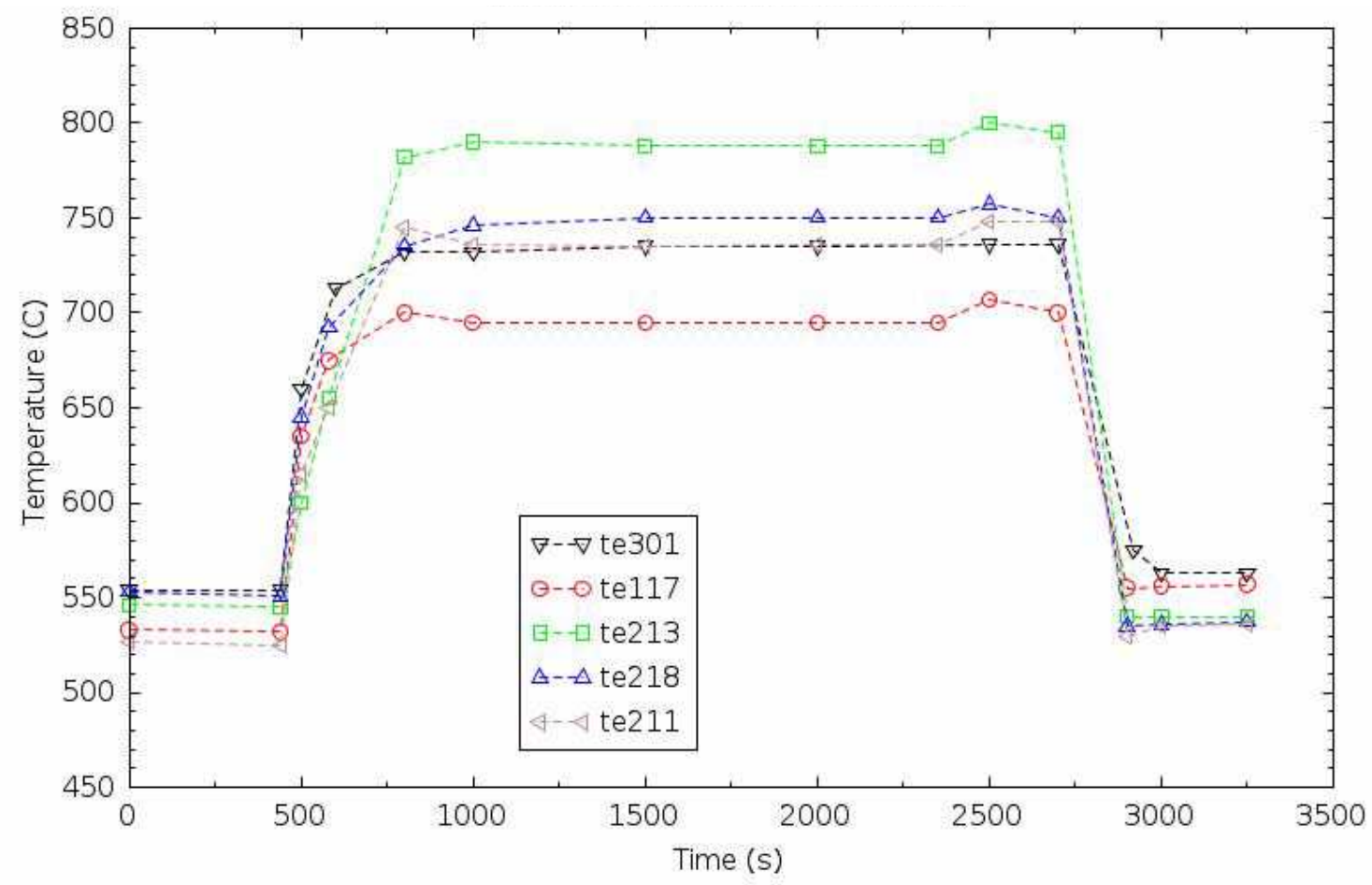

Figure 33. Measured rod temperatures at $1.75 \mathrm{~m}$ during the LOFA.

The axial temperature profile of the heater rods during the LOFA is shown in Figure 34. The results apply at $2000 \mathrm{~s}$, during the quasi-steady portion of the transient. The solid lines represent the calculated results, while the dashed lines represent measured values. The calculated results were obtained with the nominal peaking factor of 1.7. The measured results for the average rod are the average of the four individual measurements shown in Figure 26 through Figure 29. As discussed previously, the temperature of two of the average rods exceeded the temperature of the hot rod at $1.75 \mathrm{~m}$. This figure shows that the average temperature of the average rods also exceeds the temperature of the hot rod at $1.75 \mathrm{~m}$. 


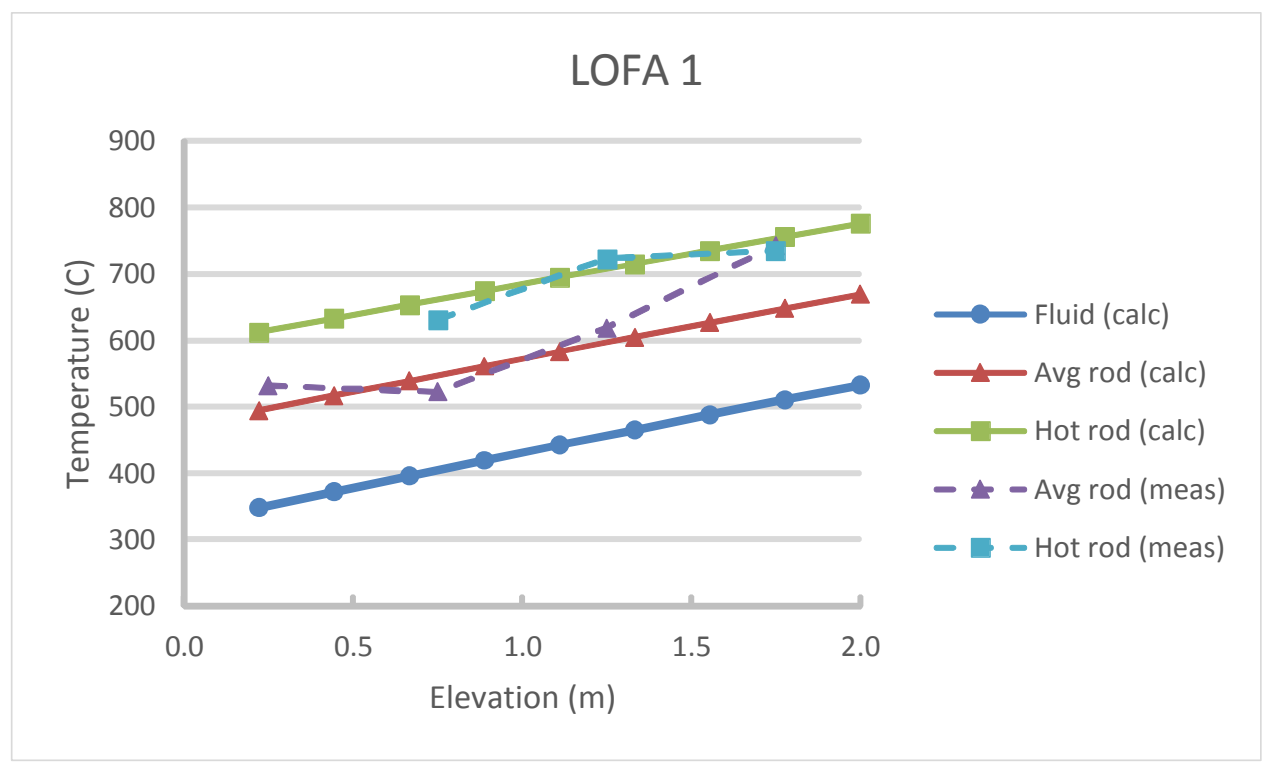

Figure 34. Quasi-steady axial temperature profile in the heater rods at $2000 \mathrm{~s}$ during the LOFA.

Figure 35 and Figure 36 are scatter plots that compare calculated and measured temperatures for the average and hot rods, respectively. The figures include the steady-state results from Steps 1 through 7, as shown previously, and the quasi-steady results from $2000 \mathrm{~s}$ for the LOFA. The figures show that the quasisteady LOFA results are consistent with those obtained previously except for the average rods at an elevation of $1.75 \mathrm{~m}$.

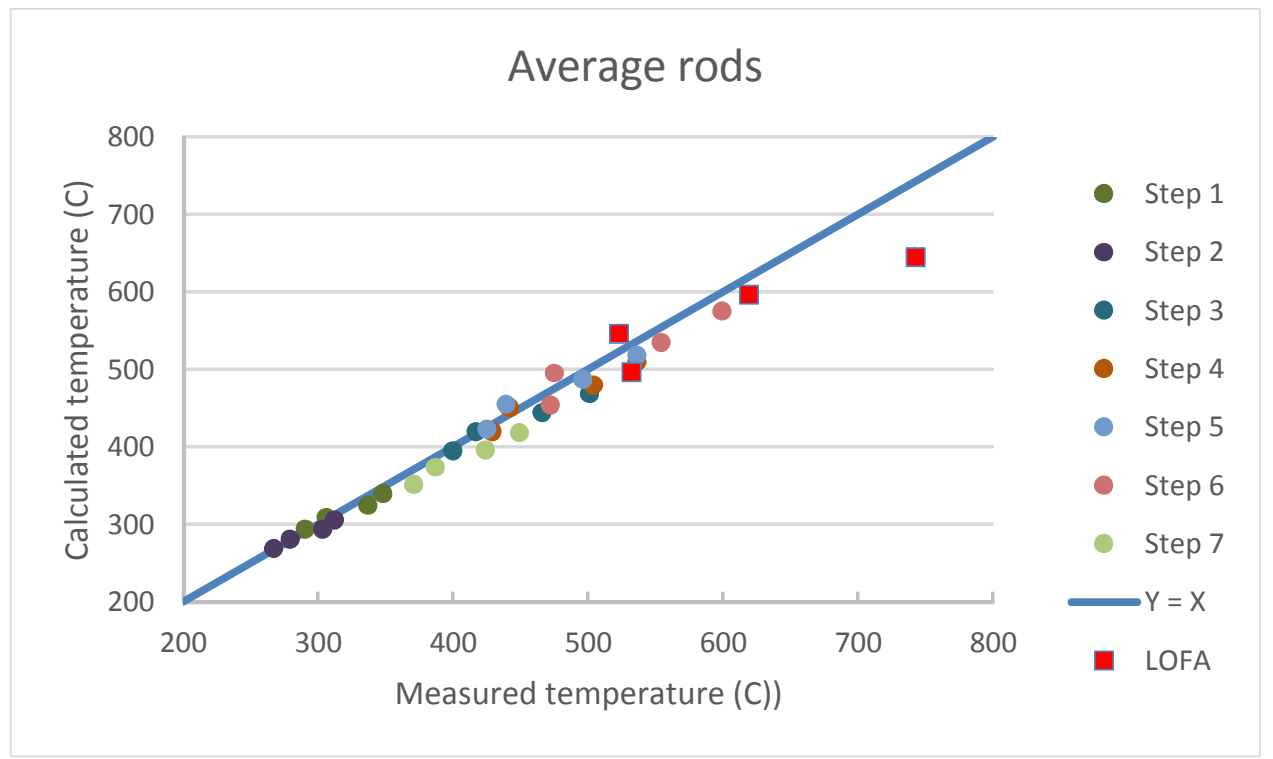

Figure 35. Temperatures in the average heater rods, including data from the LOFA. 


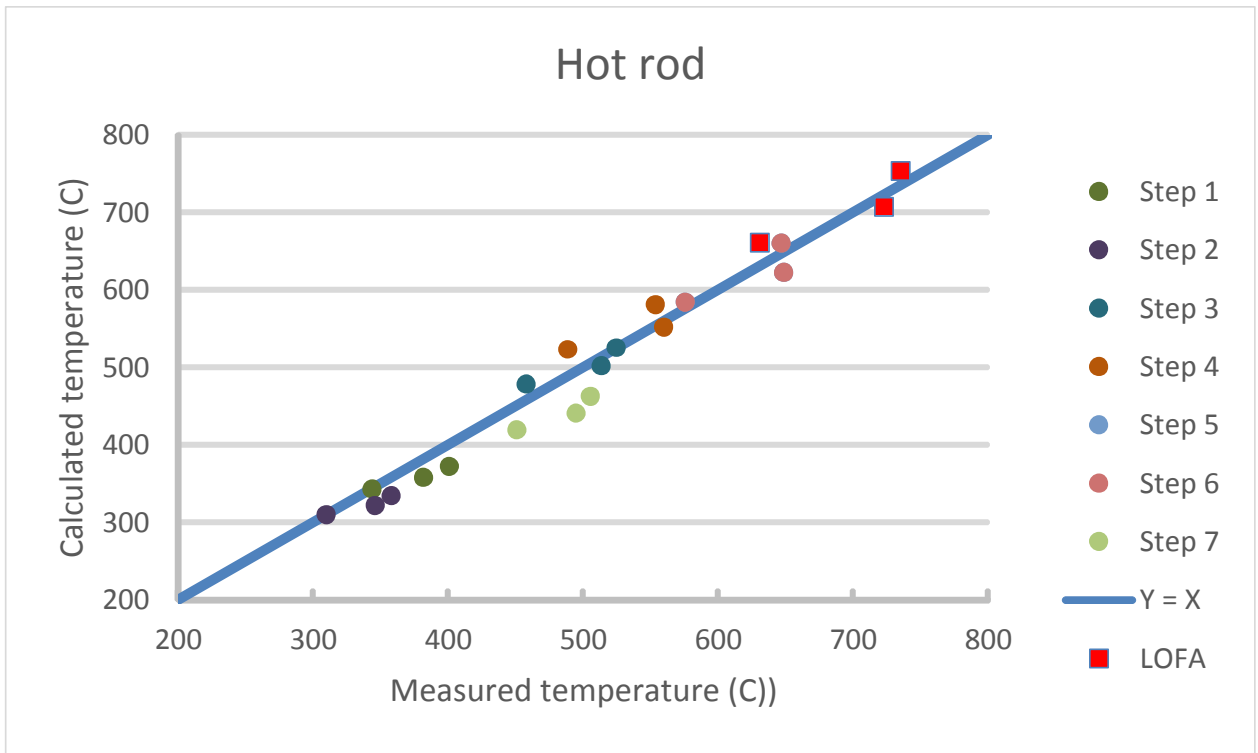

Figure 36. Temperatures in the hot heater rod, including data from the LOFA.

\subsubsection{Sensitivity Calculation}

The calculated fluid temperature in the lower plenum is higher than at the inlet to the test section because of heat transfer from the core simulator to the downcomer, which effectively preheats the gas entering the bottom of the core simulator. The major resistance to this heat transfer is across the stagnant helium gap. In the base calculation, the heat-transfer coefficients at the inside and outside surfaces of the stagnant helium gap are calculated from laminar convection correlations, which approximates the heat transfer due to conduction across the helium. The base model also accounts for radiation between the outer surface of the simulator wall and the inner surface of the downcomer wall. However, the model does not account for any natural circulation within the helium gap or any forced convection that would result from flow in the gap due to leakage. The base model represents the facility as designed, but the actual heat transfer across the gap could be higher than modeled. A sensitivity calculation was performed in which the heat transfer across the gap was enhanced by applying a multiplier of five to the calculated heat-transfer coefficients on the outer wall of the core simulator and the inner wall of the downcomer.

The heat transfer across the stagnant gap caused the fluid temperature in the lower plenum to be about $10^{\circ} \mathrm{C}$ higher than at the inlet to the test section at $250 \mathrm{~s}$ in the base calculation, as shown in Figure 37 . The enhanced heat transfer in the sensitivity calculation caused the temperature difference to increase to about $20^{\circ} \mathrm{C}$ at $250 \mathrm{~s}$ in the sensitivity calculation. The temperature differences between the test section and the lower plenum were even larger at $2000 \mathrm{~s}$, about $25^{\circ} \mathrm{C}$ in the base calculation and $50^{\circ} \mathrm{C}$ in the sensitivity calculation.

The higher temperature in the lower plenum in the sensitivity calculation resulted in higher heater-rod temperatures throughout the core simulator as shown in Figure 38 through Figure 44. This resulted in improved results for the average rod at $0.25 \mathrm{~m}$ and $1.25 \mathrm{~m}$, where the calculated temperature is now within the scatter of the data, and worse results at $0.75 \mathrm{~m}$. The calculated temperature of the average rod was improved somewhat at $1.75 \mathrm{~m}$, but the temperature in the sensitivity calculation was still far below the data. The effect of the enhanced heat transfer was also mixed for the hot rod, with better results at $1.25 \mathrm{~m}$ and worse results at 0.75 and $1.75 \mathrm{~m}$. The comparisons between calculated and measured results for the hot rod are not too meaningful because the correct value of the peaking factor was not available for use in this analysis. 


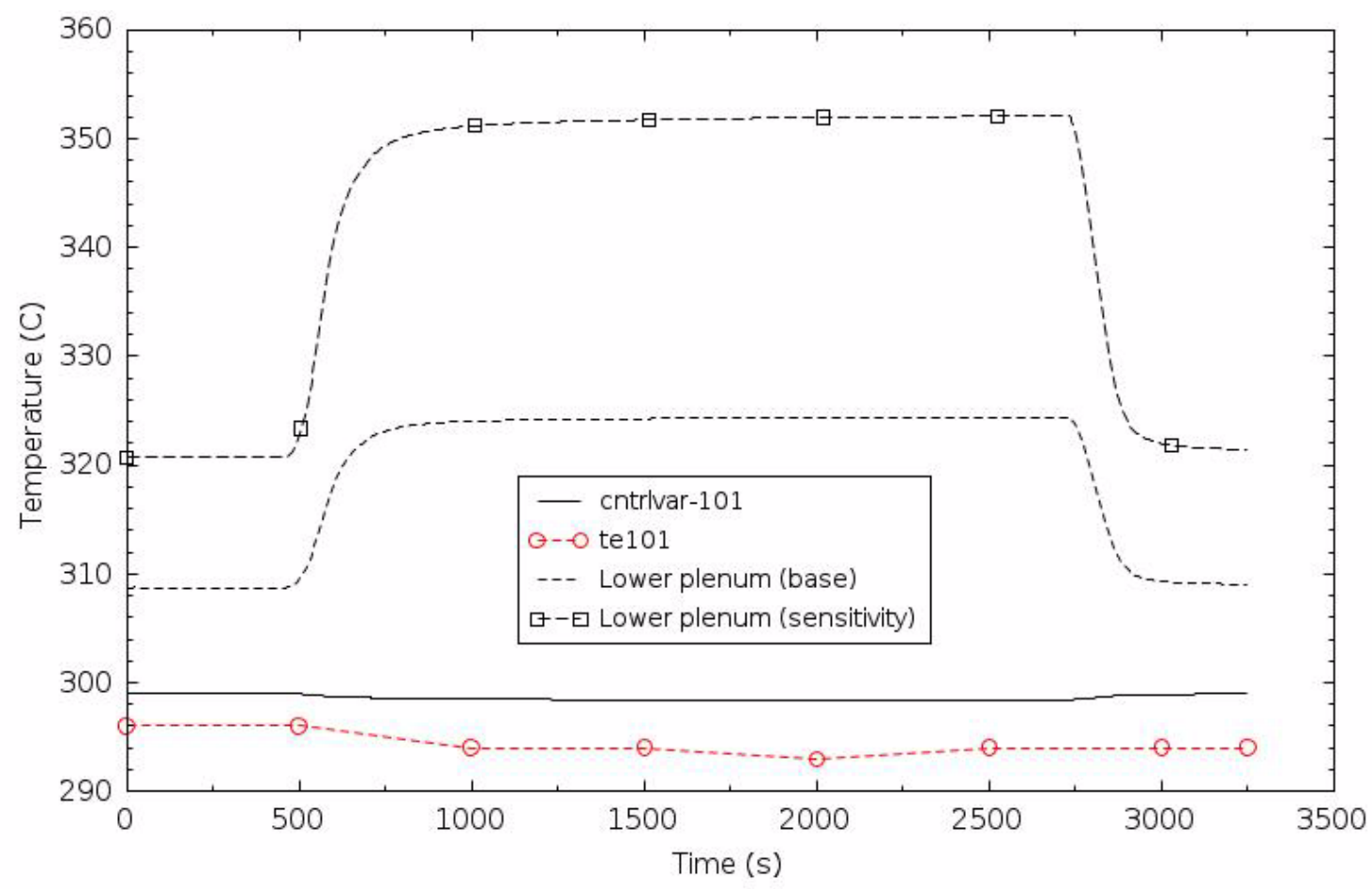

Figure 37. Test section inlet and lower-plenum temperatures during the LOFA.

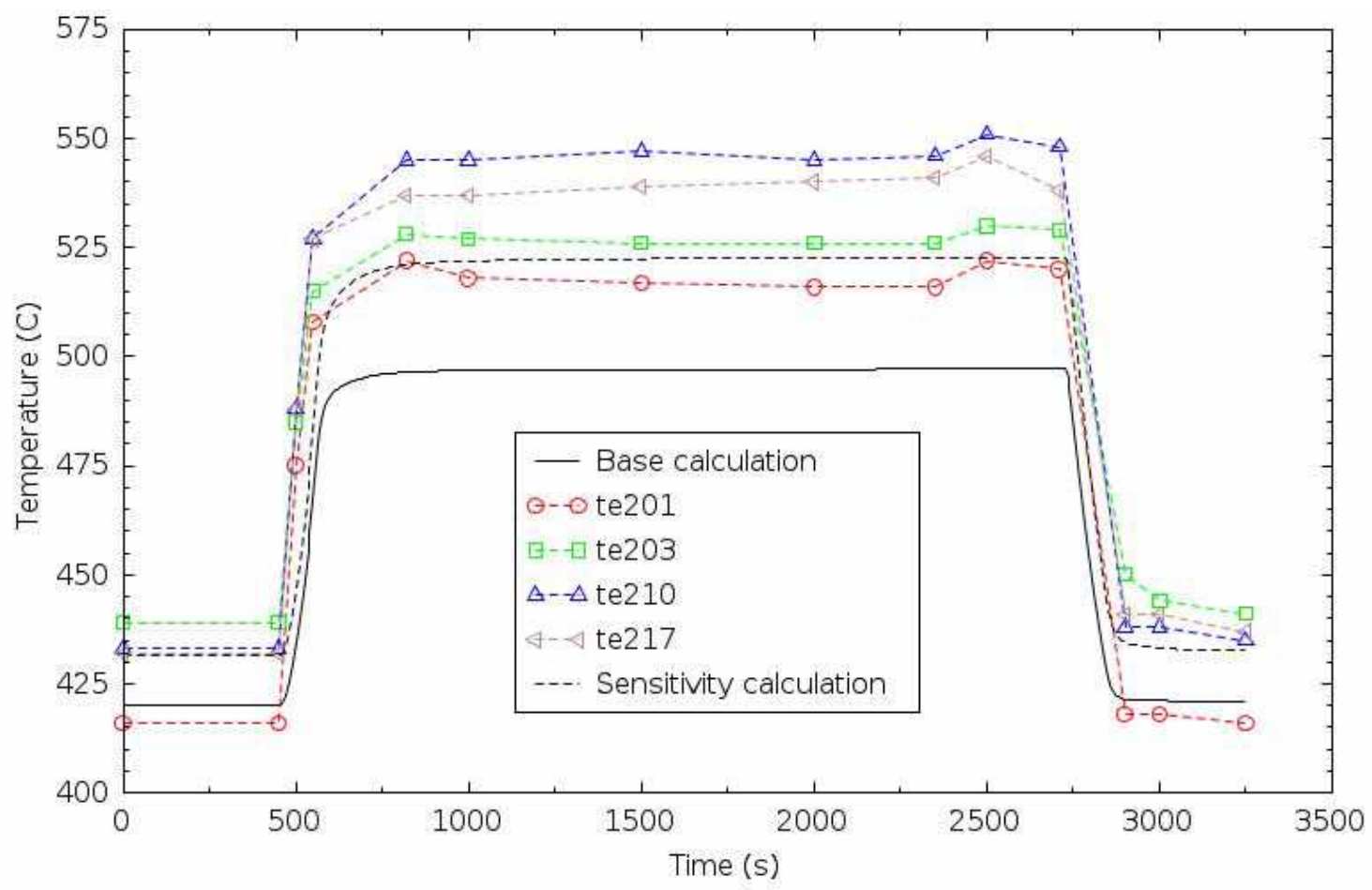

Figure 38. The effect of preheating on average-rod temperature at $0.25 \mathrm{~m}$ in the LOFA. 


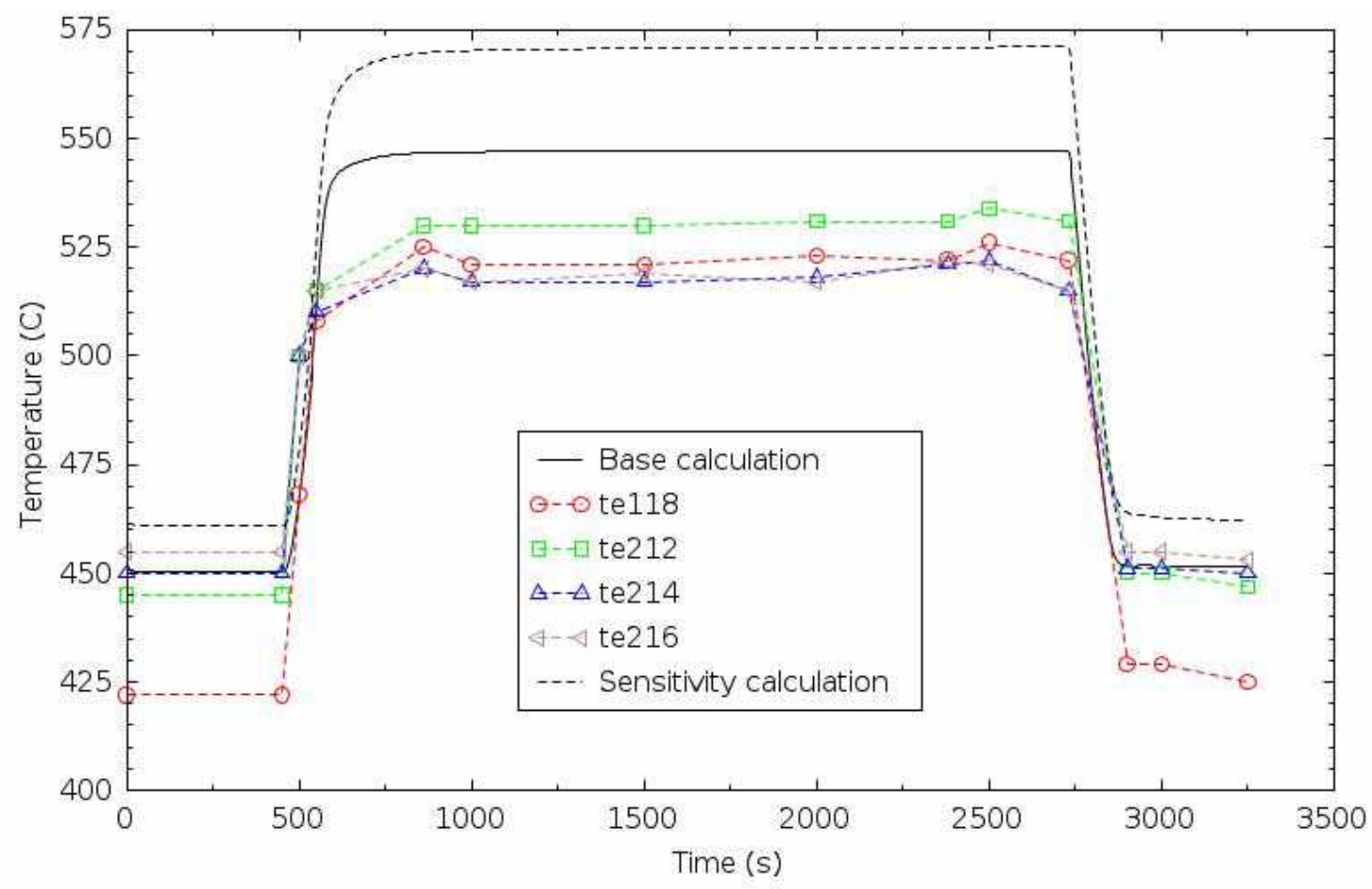

Figure 39. The effect of preheating on average-rod temperature at $0.75 \mathrm{~m}$ in the LOFA.

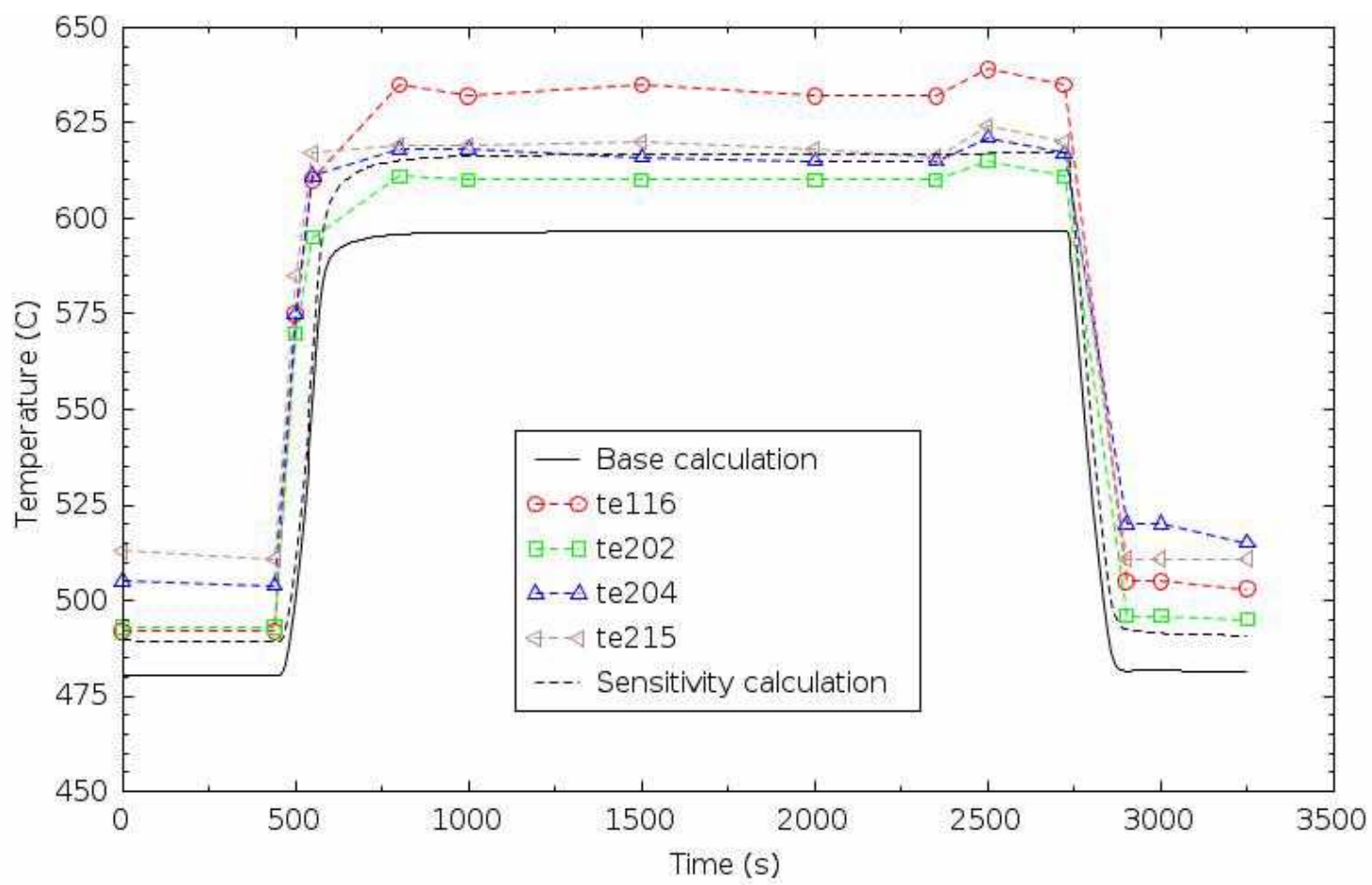

Figure 40. The effect of preheating on average-rod temperature at $1.25 \mathrm{~m}$ in the LOFA. 


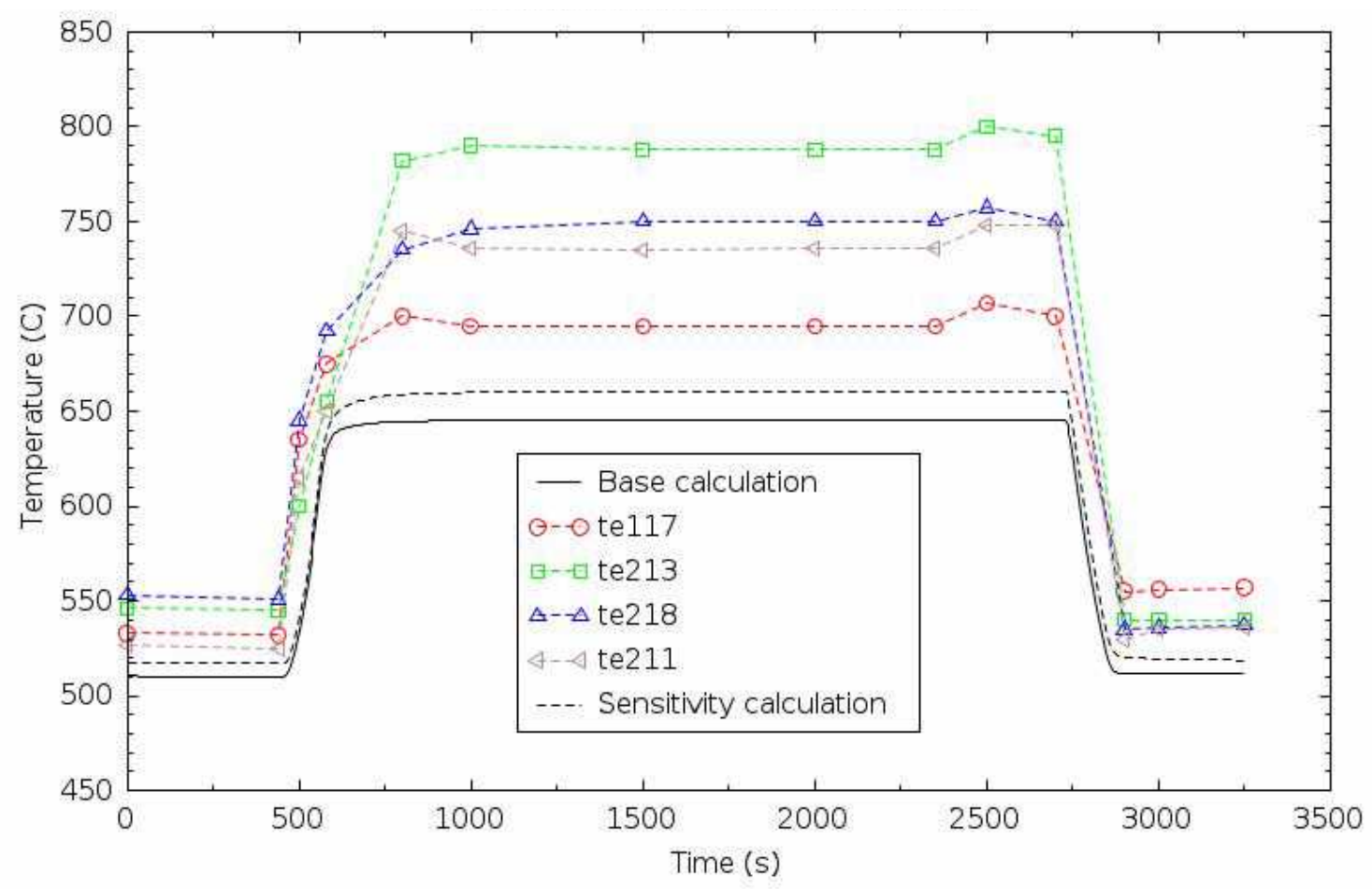

Figure 41. The effect of preheating on average-rod temperature at $1.75 \mathrm{~m}$ in the LOFA.

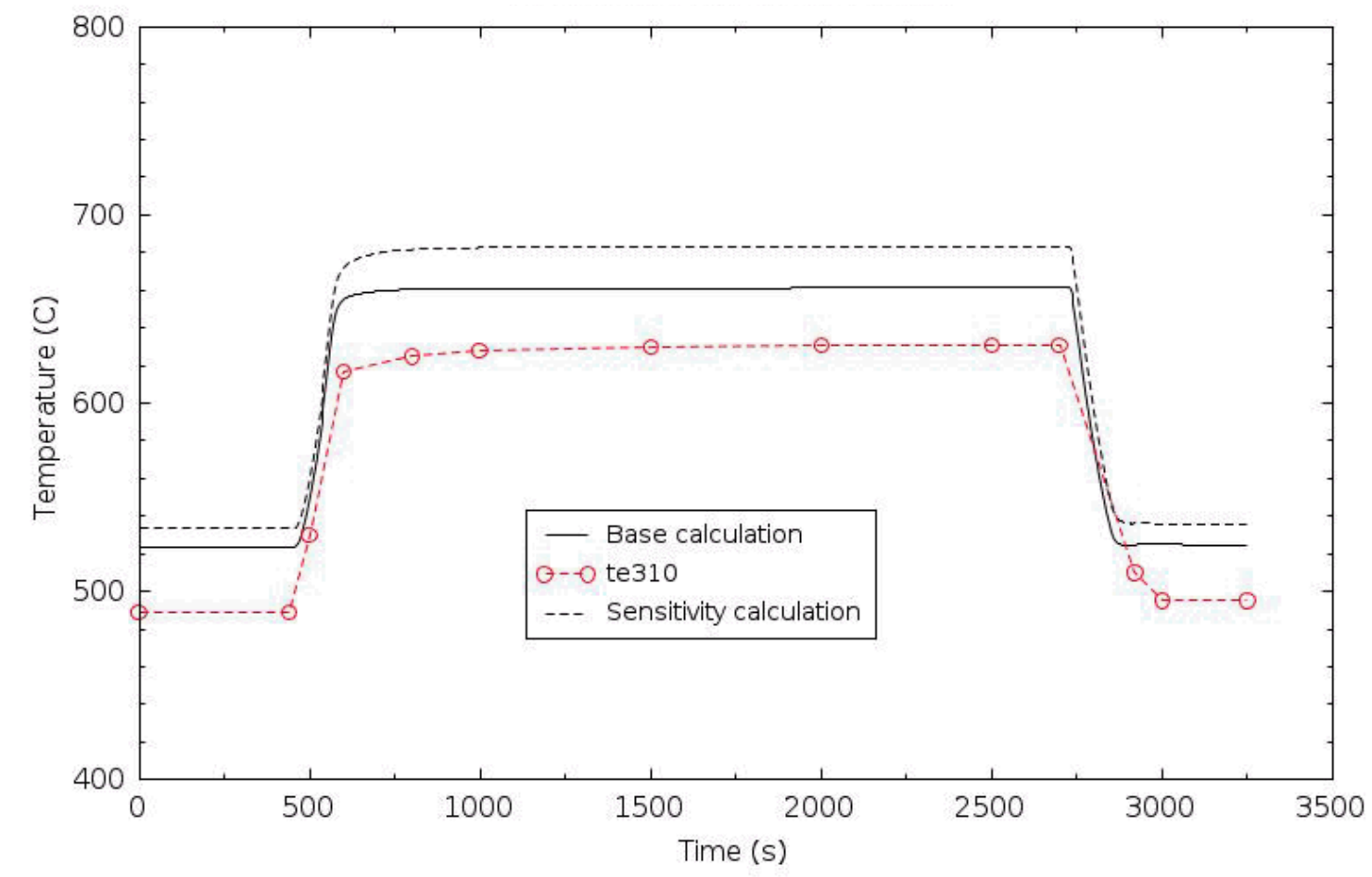

Figure 42. The effect of preheating on hot-rod temperature at $0.75 \mathrm{~m}$ in the LOFA. 


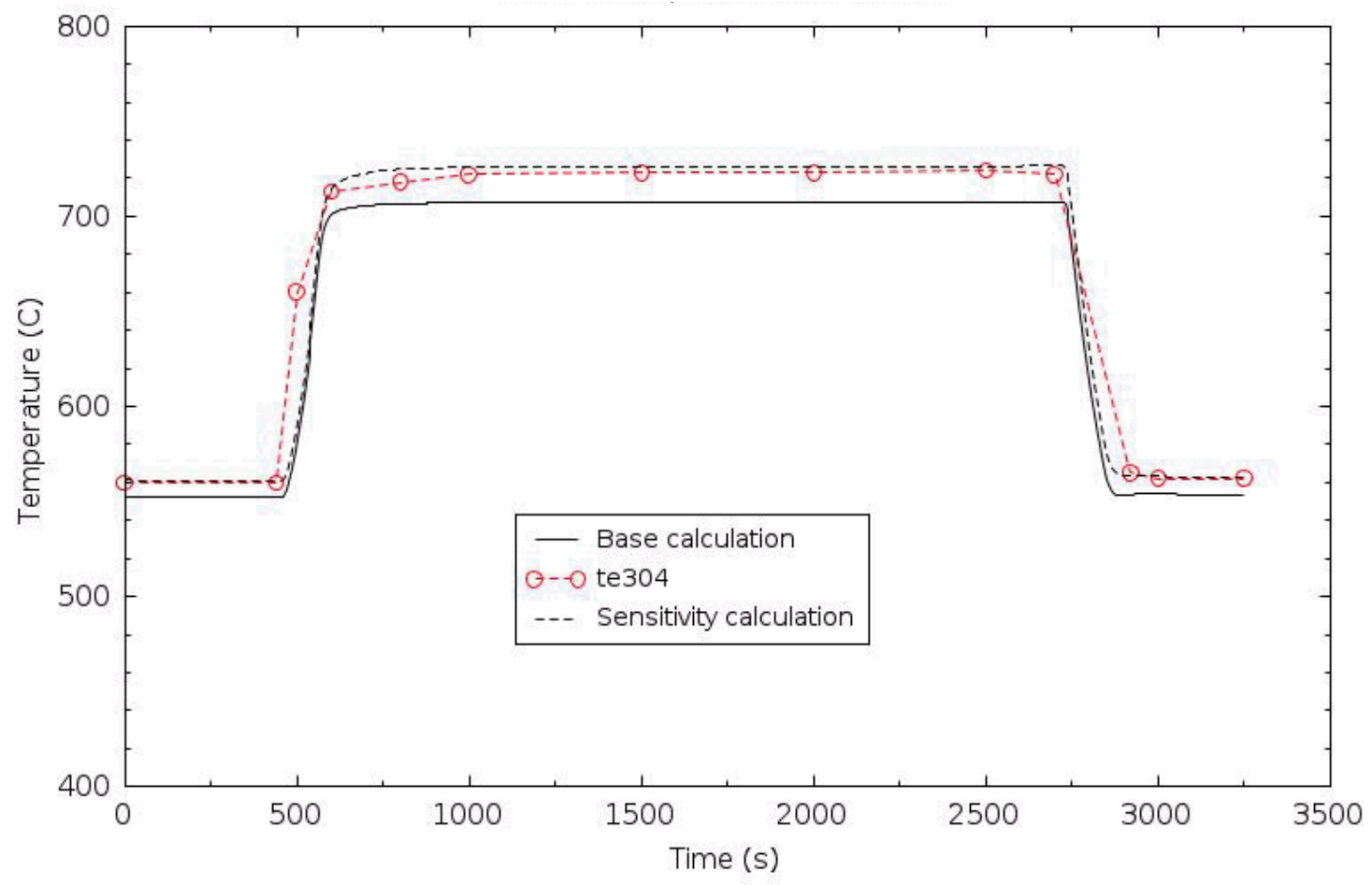

Figure 43. The effect of preheating on hot-rod temperature at $1.25 \mathrm{~m}$ in the LOFA.

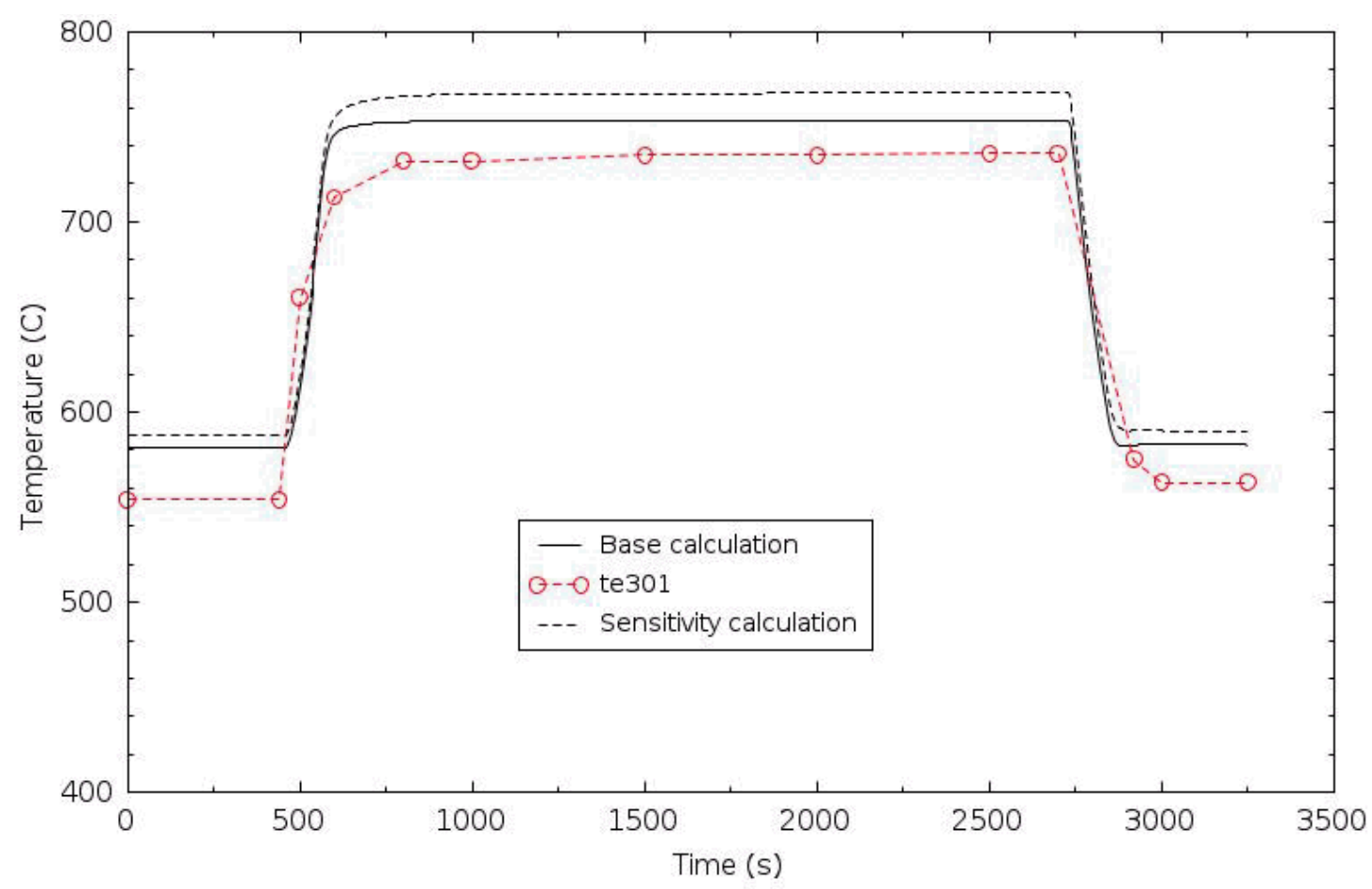

Figure 44. The effect of preheating on hot-rod temperature at $1.75 \mathrm{~m}$ in the LOFA.

The heater-rod temperature measurements in the HE-FUS3 facility are not suitable for a rigorous validation of heat-transfer correlations or the development of a new heat-transfer correlation because of the lack of a fluid temperature measurement in the lower plenum and the unphysical behavior of some of 
the measurements as discussed previously.

\section{SUMMARY AND DISCUSSION}

RELAP5-3D was validated using data from the HE-FUS3 facility, which is a helium-cooled, electrically heated experimental facility. The facility contains a compressor, expansion tank, economizer heat exchanger, core simulator with a seven-pin bundle of simulated fuel rods, valves, and associated piping. The code was validated primarily using measurements of fluid temperature, heater rod temperature, and differential pressure. Other measurements, such as mass flow rate, pressure, and power, were used as boundary conditions.

A RELAP5-3D input model of the HE-FUS3 facility was created. The input model was based on a model described by Meloni and Nitti (2010). The model was changed substantially to take advantage of advanced features of RELAP5-3D, incorporate typical modeling practices used at the INL, and adjust various input parameters to match the steady-state data. The model of the economizer was adjusted to match its measured performance. This adjustment was required because the economizer contains diaphragms that promote cross flow on the shell side of the heat exchanger that are not accounted for in the correlations used by the code. Form loss coefficients at the simulated grids in the test section were increased to match the measured differential pressure across the test section. The thermal conductivity of the insulation was adjusted to match measured fluid temperature differences across components. The model was not adjusted to any particular step; instead, the adjustments were made so that the errors between the calculated and measured values were close to zero when averaged over all seven steps.

The input model and the code were then validated using data from seven steady-state steps and one LOFA. Estimates of measurement uncertainty were generally not available. Therefore, typical assessment judgments of excellent, reasonable, minimal, and insufficient (INL 2018) could not be formally made. However, informal judgments concerning the performance of the code and input model were made and are summarized below.

The steady-state calculations of differential-pressure measurements across the compressor and test section were judged to be in reasonable agreement with the measurements. Overall, the calculated and measured fluid temperatures were judged to be in reasonable agreement. The average deviation between calculated and measured fluid temperatures was less than $1{ }^{\circ} \mathrm{C}$. The scatter in the deviations was significant, with a maximum standard deviation of $7.8^{\circ} \mathrm{C}$. The loop temperatures varied over a wide range, from 43 to $470^{\circ} \mathrm{C}$, during the steady-state steps. The poorest performance occurred for Step 7, but a large fraction of the deviation occurred in the vicinity of the compressor, which isn't represented mechanistically in the model because of a lack of information.

The overall agreement between the calculated and measured heater-rod temperatures was reasonably good in the steady-state steps. On average, the calculated temperatures were $9.6^{\circ} \mathrm{C}$ too low for the average rods and $6.1^{\circ} \mathrm{C}$ too low for the hot rod. The agreement for individual steps were substantially worse, particularly for the hot rod. However, the worst deviations were probably caused by differences between the assumed and actual power-peaking factors of the hot rod. Meloni and Polidori (2009) reported that the power-peaking factor varied from 1.4 to 2.0 during the tests, so an average value of 1.7 was used for this analysis.

The base calculation described previously applied the Gnielinski heat-transfer correlation to the heater rods. A sensitivity calculation was performed in which forced convection heat transfer was calculated with the code's default heat-transfer correlation, Dittus-Boelter. The calculated temperatures were consistently higher, and in better agreement with the measurements, with the Gnielinski correlation. On average, the use of the Dittus-Boelter correlation reduced the calculated temperatures by $10.1{ }^{\circ} \mathrm{C}$ for the average rods and by $21.5^{\circ} \mathrm{C}$ for the hot rod. The Gnielinski correlation is recommended for similar applications in the future. 
RELAP5-3D and the HE-FUS3 input model were also validated using data from an experimental simulation of a LOFA. The calculated and measured differential pressures were judged to generally be in reasonable agreement. Calculated and measured fluid temperatures were also judged to be in reasonable agreement. Some relatively large differences were observed near the economizer during the transient, but they were attributed to the thermocouples being influenced by the thermal capacity of the wall and not accurately measuring fluid temperature. Calculated and measured temperatures in the average rod were judged to be in reasonable agreement for elevations at and below $1.25 \mathrm{~m}$. The quasi-steady LOFA results were consistent with those obtained previously during the steady-state steps except for the average rods at an elevation of $1.75 \mathrm{~m}$. The measurements indicate a severe deterioration in the heat transfer at $1.75 \mathrm{~m}$ compared to the lower elevations. The calculated heat-transfer coefficient at $1.75 \mathrm{~m}$ would have to be reduced by more than $40 \%$ in order to match the average of the quasi-steady measurements. A physical explanation for the observed deterioration in heat transfer could not be determined. Therefore, the indicated deterioration was probably due to problems in the facility itself, such as a non-uniform axial power distribution, unintended rod-to-rod variations in power, or lack of contact between some thermocouples and the surrounding materials. A similar deterioration in the heat transfer in the hot rod at $1.75 \mathrm{~m}$ was not observed, but the deterioration may have been masked by the use of too large of a hot-rod peaking factor in the calculations.

The fluid temperature in the lower plenum is higher than at the inlet to the test section because of heating from the core simulator to the downcomer, which effectively preheats the gas entering the bottom of the core simulator. The heat transfer across the stagnant gap caused the fluid temperature in the lower plenum to be between 10 and $25^{\circ} \mathrm{C}$ higher than at the inlet to the test section during the LOFA in the base calculation. A sensitivity calculation was performed in which the heat transfer across the stagnant gap was approximately doubled. The preheating of the fluid entering the lower plenum had a significant effect on the temperatures of the heater rods. The higher temperature in the lower plenum in the sensitivity calculation resulted in higher heater-rod temperatures throughout the core simulator. The resulted in improved results for the average rod at $0.25 \mathrm{~m}$ and $1.25 \mathrm{~m}$, and worse results at $0.75 \mathrm{~m}$. The calculated temperature of the average rod was improved somewhat at $1.75 \mathrm{~m}$, but the temperature in the sensitivity calculation was still far below the data. The usefulness of the measured heater-rod temperatures would have been improved significantly with a fluid temperature measurement in the lower plenum.

RELAP5-3D and the HE-FUS3 input model demonstrated a broad capability to represent steady-state and LOFA phenomena associated with gas reactors. However, the experiments used in the validation are not ideal for several reasons. First, the source of data used for the validation is not from a test data report, but rather from a post-test analysis report that does not contain all of the measured data. In particular, the post-test analysis report does not contain the measured powers to the average and hot heater rods or the peaking factor derived from those measurements, the measured fluid temperatures between the mixer and the test section inlet, or estimates of measurement uncertainties. Second, the transient data were not available electronically, which required the data to be digitized from graphs in the post-test report, resulting in a loss of accuracy and a loss of some fine detail. Third, the facility lacked some key instrumentation, including a fluid temperature measurement in the lower plenum and differential pressures across important components such as flow-control valves and the filter. Fourth, the heater-rod temperature measurements are not suitable for a rigorous validation of heat-transfer correlations because of the lack of a fluid-temperature measurement in the lower plenum as discussed previously and various anomalous behaviors, including a lack of linearity with elevation, instances where the measured temperature decreases with elevation for a given rod, and instances where the measured temperature of an average rod exceeds the temperature of the hot rod at the same elevation.

There are probably additional reports that describe the HE-FUS3 facility and data better than the reports that were available to INL during this code validation. For example, Peers (2013) refers to a detailed description of the HE-FUS3 facility and the experimental data used for a code benchmarking exercise. Improved results would be expected if more detailed reports and data were made available to 
INL. It might be worth repeating the RELAP5-3D validation calculations if more data becomes available in the future.

\section{REFERENCES}

Gnielinski, V., "New Equations for Heat and Mass Transfer in Turbulent Pipe and Channel Flow," International Chemical Engineering 16.2, April 1976, pp. 359-368.

Incropera, Frank P. and David P. DeWitt, Fundamentals of Heat and Mass Transfer, Third Edition, John Wiley \& Sons, New York, 1990.

INL, 2018, RELAP5-3D Code Manual, Volumes I-V, INL/MIS-15-36723, Rev. 4.4, June 2018.

McEligot, Donald M. and J. Derek Jackson, "Deterioration Criteria for Convective Heat Transfer in Gas Flow through Non-Circular Ducts," Nuclear Engineering and Design 232, 2004, pp. 327-333.

Meloni, Paride 2009, HE-FUS3 Experimental Campaign for the Assessment of Thermal-Hydraulic Codes: Pre-Test Analysis and Test Specifications, ENEA Report RSE/2009/89.

Meloni, Paride and Massilmiliano Polidori, 2009, HE-FUS3 Experimental Campaign for the Assessment of Thermal-Hydraulic Codes: Post-Test Analysis, ENEA Report RSE/2009/89.

Meloni, P. and F. S. Nitti, 2010, Pre-Test Analysis for an Experimental Campaign in the Upgraded HEFUS3 Loop, ENEA Report RdS/2010/112.

Peers, K., FP7 GoFastR Project Publishable Final Report, GoFastR-DEL-5.2, February 2013. 